\title{
Los micromamíferos (Eulipotyphla, Chiroptera, Rodentia y Lagomorpha) del yacimiento del Pleistoceno Superior de la cueva de El Castillo (Cantabria, España).
}

\section{The small mammals (Eulipotyphla, Chiroptera, Rodentia and Lagomorpha) from the Late Pleistocene site of the cave of El Castillo (Cantabria, Spain).}

\author{
C. Sesé ${ }^{1}$ \\ ${ }^{1}$ Museo Nacional de Ciencias Naturales (C.S.I.C.). Dpto. de Paleobiología. C/ José Gutiérrez Abascal 2, 28006 - Madrid. \\ España. Email: c.sese@mncn.csic.es. ORCID ID: https://orcid.org/0000-0002-6833-1901
}

A la memoria de Victoria Cabrera Valdés

\begin{abstract}
RESUMEN
El material de micromamíferos del yacimiento del Pleistoceno Superior de la cueva de El Castillo, objeto de estudio detallado en este trabajo, proviene de los niveles auriñacienses 18b y 18c (datados en 40.000-45.000 BP), nivel 19, y niveles musterienses 20b, 20c, 20d, 20e (datados en 41.000-49.000 BP), 21a y 21b. La asociación de micromamíferos es la siguiente: Erinaceus europaeus, Crocidura russula, Sorex coronatus, Sorex minutus, Neomys fodiens, Talpa europaea, Galemys pyrenaicus, cf. Miniopterus schreibersii, Chiroptera indet., Pliomys lenki, Microtus arvalis - Microtus agrestis, Microtus lusitanicus, Microtus oeconomus, Chionomys nivalis, Arvicola terrestris, Apodemus sylvaticus - Apodemus flavicollis y Lepus sp. La mayoría de estas especies están presentes en la fauna actual de Cantabria, excepto Pliomys lenki que se extinguió en el último tercio del Pleistoceno Superior, y Microtus oeconomus, que persistió en la península ibérica durante el Holoceno bien avanzado hasta su desaparición en tiempos históricos, y que actualmente está en regiones euroasiáticas más septentrionales. Hay una gran continuidad de la gran mayoría de los taxones en todos los niveles. La fauna en su conjunto parece indicar un medio predominantemente abierto, por lo general de praderas húmedas ( $\mathrm{y}$ en mucha menor medida praderas secas) con una buena cobertura vegetal a nivel del suelo, en el que habría también algunas zonas arboladas o boscosas, y algún curso de agua. Los indicadores termófilos son escasos y poco abundantes, lo que podría indicar que el clima podría ser algo menos templado que en otros periodos del Pleistoceno Superior y quizás también que actualmente en la zona.
\end{abstract}

Palabras clave: Micromamíferos; Pleistoceno Superior; Región Cantábrica; Tafonomía; Paleoecología; Paleoclimatología.

Recibido el 20 de julio de 2017 / Aceptado el 20 de noviembre de 2017 / Publicado online el 8 de enero de 2018

Citation / Cómo citar este artículo: Sesé, C. (2017). Los micromamíferos (Eulipotyphla, Chiroptera, Rodentia y Lagomorpha) del yacimiento del Pleistoceno Superior de la cueva de El Castillo (Cantabria). Estudios Geológicos 73(2): e072. http://dx.doi.org/10.3989/ egeol.41589.471.

Copyright: ( 2017 CSIC. This is an open-access article distributed under the terms of the Creative Commons Attribution-Non Commercial (by-nc) Spain 3.0 License. 


\begin{abstract}
The micromammals remains from the Late Pleistocene site of the cave of El Castillo studied here in detail, came from the Aurignacian levels 18b and 18c (dated in 40.000-45.000 BP), level 19, and the Musterian levels 20b, 20c, 20d, 20e (dated in 41.000-49.000 BP), 21a and 21b. The micromammal association is the following: Erinaceus europaeus, Crocidura russula, Sorex coronatus, Sorex minutus, Neomys fodiens, Talpa europaea, Galemys pyrenaicus, cf. Miniopterus schreibersii, Chiroptera indet., Pliomys lenki, Microtus arvalis - Microtus agrestis, Microtus lusitanicus, Microtus oeconomus, Chionomys nivalis, Arvicola terrestris, Apodemus sylvaticus Apodemus flavicollis and Lepus sp. Most of these species are in the present fauna of Cantabria, except Pliomys lenki that got extinct in the last third of the Upper Pleistocene, and Microtus oeconomus that disappeared from the Iberian Peninsula during the Holocene, in historical times, and is nowadays present in northern Euroasiatic regions. There is a great continuity of most of the taxa in all the levels. The faunal association seems to indicate a mainly open environment, in general with wet meadows (and few dry meadows), with good vegetation cover in the soil, with perhaps also some tree-covered areas, and some watercourses. The thermophiles indicators are very scarce, which could indicate that the climate could be a lesser temperate than other Upper Pleistocene periods and the present-day climate in the area.
\end{abstract}

Keywords: Micromammals; Late Pleistocene; Cantabrian Region; Taphonomy; Paleoecology; Paleoclimatology.

\section{Introducción}

La cueva de El Castillo está situada en el municipio de Puente Viesgo (Cantabria), en el monte del mismo nombre. Fue descubierta por H. Alcalde del Rio en 1903, quien realizó las primeras excavaciones en niveles Magdalenienses. Posteriormente $\mathrm{H}$. Breuil y H. Obermaier junto con H. Alcalde del Río realizaron nuevas excavaciones que se sucedieron entre 1910 y 1914, descubriendo una larga secuencia estratigráfica desde la Edad del Bronce hasta el Paleolítico Inferior que dividieron en 26 unidades. Desde entonces fue reconocida como uno de los yacimientos más importantes y con una de las secuencias más largas conocidas en Europa, que sirvió en gran parte para que $\mathrm{H}$. Breuil realizara un primer esquema de las subdivisiones del Paleolítico Superior (Bernaldo de Quirós et al., 2014). La cueva de El Castillo es importante en toda Europa desde entonces por su amplio registro de ocupaciones humanas del Paleolítico medio y superior, con una numerosa industria lítica y también algunos restos de industria ósea y arte mueble que, aunque escasos, son muy significativos (Bernaldo de Quirós et al., 2014). Asimismo presenta uno de los conjuntos de arte rupestre paleolíticos más significativos de Europa al ser un compendio de temas, técnicas y estilos, y por su gran antigüedad ya que las fechas obtenidas están entre 12.096 y 23.460 años cal. BP las más recientes, y entre $34.250 \pm 170$ años y 41.400 \pm 570 años las más antiguas (Pike et al., 2012).

Desde 1980 las excavaciones fueron retomadas por Victoria Cabrera Valdés y Federico Bernaldo de
Quirós hacia la entrada de la cueva: los niveles más recientes del Paleolítico Superior (unidades 16 y 18) y las unidades musterienses subyacentes (Wood et al., 2016, en prensa). El material de micromamíferos objeto de este trabajo proviene de estas últimas excavaciones, de las campañas realizadas entre 1994 y 2004 en las unidades 18, 19, 20 y 21, a su vez subdivididas en niveles: 18 dividido en 18 a (estéril) $18 \mathrm{~b}$ y $18 \mathrm{c}$; 20 en $20 \mathrm{a}, \mathrm{b}, \mathrm{c}, \mathrm{d}$ y e, y 21 en $21 \mathrm{a}$ y 21b (Bernaldo de Quirós et al., 2014; Wood et al., 2016, en prensa). Con respecto al material de micromamíferos del mencionado nivel 19, considerado arqueológicamente estéril por Bernaldo de Quirós et al. (2014), véase la Adenda al final del manuscrito.

Con anterioridad al presente estudio, y con material proveniente de un muestreo realizado en los niveles del 13 al 22 de El Castillo, se realizó una Tesis de Licenciatura, no publicada, (Sánchez, 1983) sobre los micromamíferos, en la que la asociación faunística determinada es la siguiente: Arvicola terrestris, Microtus agrestis, Microtus cf. arvalis, Microtus oeconomus, Pitymys pyrenaicus (= Microtus gerbei), Pitymys lusitanicus (= Microtus lusitanicus), Microtus nivalis (= Chionomys nivalis) Pliomys lenki, Apodemus sp., Talpa europaea, Talpa caeca, Galemys pyrenaicus, Sorex coronatus, Sorex minutus, Neomys fodiens y Neomys anomalus.

Por otra parte, la revisión de los restos de macromamíferos de la unidad 10 del Solutrense y de las unidades 12 y 14 del Gravetiense, procedentes de las excavaciones realizadas por $\mathrm{H}$. Obermaier a principios del siglo pasado, fueron realizadas respectivamente por Bernaldo de Quirós et al. (2015 y 2012). 
Sanchiz \& Lobo (2016) realizaron el estudio de la herpetofauna de los niveles auriñacienses $16,17 \mathrm{~b}$, $17 \mathrm{c}, 18 \mathrm{~b}, 18 \mathrm{c}$ y 19 sup.

Las dataciones obtenidas para diferentes niveles de El Castillo son las siguientes: la unidad Auriñaciense 18 por ${ }^{14} \mathrm{C}$ tiene unas dataciones por exceso de $46 \mathrm{ky}$ cal BP según Liberda et al. (2010), entre $40.000 \mathrm{y}$ 45.000 BP según Bernaldo de Quirós et al., (2014) y más reciente que $42 \mathrm{ky}$ cal BP según Wood et al. (2016, en prensa); la unidad Musteriense 20 (20c, 20d y 20e) ha sido datada por ESR (Electron Spin Resonance; Resonancia de Espín Electrónico) sobre esmalte de dientes de macromamíferos en $42.7 \pm$ $3.5 \pm 6.4 \mathrm{ka}$, que incluye las incertidumbres aleatorias y sistemáticas respectivamente (Liberda et al., 2010) y también por ${ }^{14} \mathrm{C}$, dataciones que en conjunto según Bernaldo de Quirós et al. (2014) se escalonan entre 41.000-49.000 BP. Las unidades Musterienses 21 y 22 fueron datadas por ESR en $70 \pm 8 \mathrm{ka}$ (Rink et al., 1997; Liberda et al., 2010), sin embargo recientemente, según Bernaldo de Quirós et al. (2014) la unidad 22 tiene una datación por ESR de $59.100 \mathrm{BP}$, por lo que el nivel 21 no podría ser tan antiguo como lo indicado anteriormente. Finalmente la Unidad 23 presenta una costra estalagmítica que sella las Unidades basales $(24,25$ y 26$)$ con dos dataciones en 89.000 y 92.000 BP (Rink et al., 1996 y 1997; Bernaldo de Quirós et al., 2014).

\section{Metodología}

El sedimento procedente de las excavaciones realizadas en el yacimiento a partir de 1980 ha sido cribado con varios tamices, el más fino de luz de malla de $0,2 \mathrm{~mm}$ (com. pers. de J. M. Maíllo).

Para realizar la determinación taxonómica de los distintos taxones de micromamíferos se han tenido en cuenta las siguientes piezas: en los arvicolinos, $\operatorname{los} \mathrm{M}_{1}$ que son los que permiten determinaciones taxonómicas precisas; en los múridos todo el material dentario; en los lagomorfos el $\mathrm{P}_{3}$; en los erinaceomorfos y soricomorfos se han estudiado mandíbulas, maxilares superiores y dentición, y en el caso del topo además de los restos mandibulares, maxilares y dentición, algunos huesos del esqueleto postcraneal como falanges, radios y húmeros. Los Soricidae es el único grupo en el que el cóndilo articular es importante como carácter con valor diagnóstico para la determinación taxonómica, razón por la cual en el apartado de material se da la relación de las mandíbulas que lo conservan. En el texto se dice mandíbula y maxilar superior, derecho o izquierdo, y no hemimandíbula y hemimaxilar superior derechos o izquierdos para simplificar.

Las medidas se han realizado con una lupa Nikon Measuroscope 10 5x que lleva incorporado un micrómetro de $0,025 \mathrm{~mm}$ de precisión y se expresan en milímetros (mm). En los insectívoros, según Pemán (1983) la altura coronoidea es la altura de la mandíbula tomada desde la escotadura preangular hasta el borde superior de la apófisis coronoidea.

Las abreviaturas utilizadas son las siguientes: Incisivo/Incisivos (I/Is), Canino/Caninos (C/Cs), Premolar/Premolares (P/Ps), Molar/Molares (M/Ms); estas letras con un número en subíndice o superíndice indican diente de la mandíbula o del maxilar superior respectivamente; alveolo/alveolos (alv./alvs.); mandíbula (man.); maxilar superior (max. sup.); rama ascendente (r.a.); cóndilo articular (c.a.); parte anterior de la mandíbula, que en roedores es la parte del diastema entre el incisivo y el primer molar (p.a.); derecho (der.); izquierdo (izq.); fragmento (fr.); indeterminado (indet.); Número Mínimo de Individuos (NMI); Castillo (CST); Museo Nacional de Ciencias Naturales (MNCN).

Para comparar la abundancia relativa de los taxones por niveles se ha utilizado el NMI teniendo en cuenta la pieza identificable más abundante entre derechas e izquierdas. En el apartado del material de cada taxón se da, para cada nivel, el número total de piezas que permiten su identificación, así como el NMI obtenido. El NMI se ha calculado en casi todos los grupos sobre el material dentario, en los arvicolinos sobre el $\mathrm{M}_{1}$, en el resto de los grupos sobre la pieza dentaria, mandibular o maxilar más abundante, finalmente en el topo se ha obtenido con respecto a la pieza craneal y postcraneal más abundante que en todos los niveles es el húmero.

Los dientes de micromamíferos y mandíbulas de soricomorfos se han dibujado utilizando un microscopio Nikon SMZ-10 40x que tiene una cámara clara acoplada. Los dibujos fueron retocados utilizando el programa Corel Drawn.

Todos los micromamíferos del yacimiento que tienen representantes actuales en la península ibérica se 
han comparado directamente con material actual de las colecciones de vertebrados del MNCN.

Para la nomenclatura de los dientes de roedores se ha seguido la de López Martínez (1980), para los diferentes dientes de los Eulipotyphla (I, C, P, M) la de Hillson (2005), para la mandíbula de los Eulipotyphla la de Reumer (1984), para la sistemática la de Wilson \& Reeder (2005).

El material objeto del presente estudio se ha devuelto a los directores de las excavaciones de El Castillo que finalmente lo depositarán en el Museo de Prehistoria y Arqueología de Cantabria (Santander).

\section{Paleontología sistemática}

Orden Eulipotyphla WADDELL, OKADA \& HASEGAWA, 1999 Familia Erinaceidae G. FISCHER, 1814
Erinaceus europaeus LINNAEUS, 1758

(Fig. 1: a)

Material por niveles:

\begin{tabular}{|c|c|c|}
\hline NIVEL & MATERIAL & NMI \\
\hline $20 \mathrm{e}$ & $1 \mathrm{M}^{1}$ der.; $2 \mathrm{P}$ sup. rango indet. & 1 \\
\hline $21 a$ & $\begin{array}{l}1 \mathrm{C}_{1} \text { der.; } 1 \mathrm{C}_{1} \text { izq.; } 1 \text { fr. de } \mathrm{P} \text { inf. der.; } \\
1 \text { fr. } \mathrm{M}_{1-2} \text { der.; } 1 \text { fr. } \mathrm{M}_{1-2} \text { izq.; } 1 \text { fr. } \mathrm{M}_{2} \\
\text { izq.; } 1 \mathrm{M}_{3} \text { der.; } 1 \mathrm{I} \text { inf.; } 1 \mathrm{P}^{4} \text { izq.; } 1 \mathrm{P} \\
\text { sup.; } 1 \mathrm{C}^{1} ; 2 \mathrm{Ps} \text { sup.; } 1 \text { fr. } \mathrm{M}^{1} \text { der.; } 1 \\
\text { fr. } \mathrm{M}^{1} \text { izq.; } 1 \text { fr. } \mathrm{M}^{1-2} \text { izq.; }\end{array}$ & 1 \\
\hline $21 b$ & $1 \mathrm{P}^{3}$ der.; 1 fr. $\mathrm{M}^{1}$ der. & 1 \\
\hline TOTAL & & 3 \\
\hline
\end{tabular}

\section{Comentarios:}

El material, aunque fragmentario, en una comparación directa con material actual de Erinaceus europaeus de las colecciones del MNCN, presenta la morfología y la talla características de esta

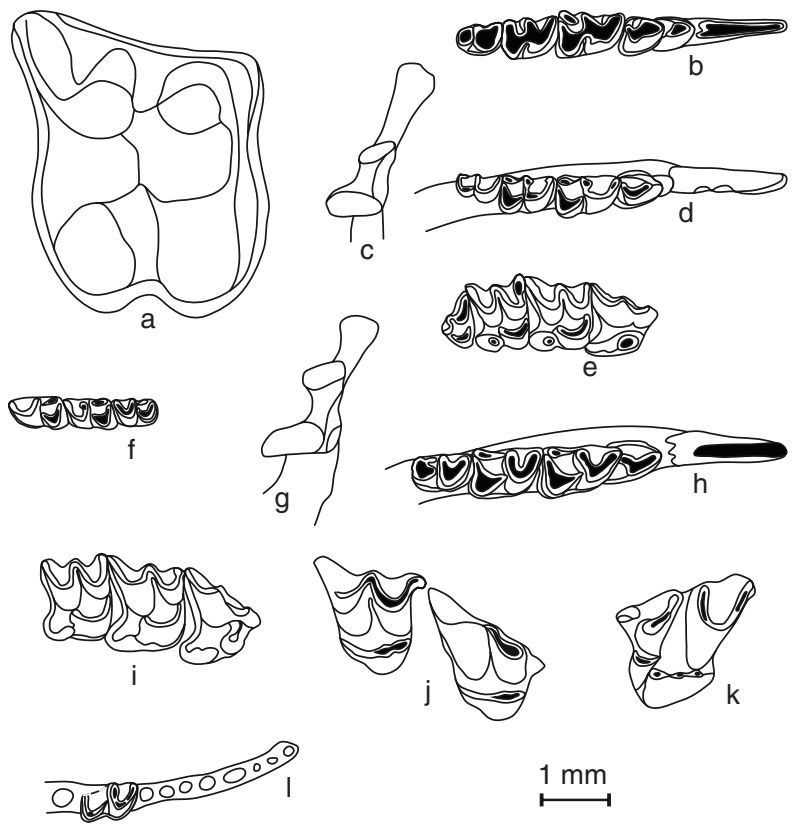

Fig. 1.-Dibujos de material dentario del yacimiento de la cueva de El Castillo: Erinaceomorpha: Erinaceus europaeus: a): $\mathrm{M}^{1}$ der. (CST99; Nivel 20e; N 17.6; Caja 141); Crocidura russula: b): Mandíbula der. con $\mathrm{I}_{1}-\mathrm{P}_{3}-\mathrm{P}_{4}-\mathrm{M}_{1}-\mathrm{M}_{2}-\mathrm{M}_{3}(\mathrm{CST}$ 95; Nivel 20b; $\mathrm{N} 17.4$; Caja 29); Sorex coronatus: Mandíbula der. (CST95; Nivel 20b; N 17.9; Caja 43): c): Cóndilo articular; d): Serie dentaria inferior $\left.I_{1}-P_{4}-M_{1}-M_{2}-M_{3} ; e\right)$ : Maxilar sup. der. con serie dentaria superior $\mathrm{P}^{4}-\mathrm{M}^{1}-\mathrm{M}^{2}-\mathrm{M}^{3}$ (CST01; Nivel 21b; $\mathrm{N}$ 17.5; Caja 276); Sorex minutus: f): Mandíbula izq. con $\mathrm{M}_{1}-\mathrm{M}_{2}-\mathrm{M}_{3}$ (CST98; Nivel 18b; K 15.4; Caja 165); Neomys fodiens: g): Cóndilo articular de Mandíbula der. (CST96; Nivel 20d; $\mathrm{N}$ 18.5; Caja 117); h): Mandíbula der. con $\mathrm{I}_{1}-\mathrm{P}_{4}-\mathrm{M}_{1}-\mathrm{M}_{2}-\mathrm{M}_{3}$ (CST99; Nivel 21a; $\mathrm{N} 16.2$; Caja 245); i): Maxilar sup. der. con: $\mathrm{P}^{4}-\mathrm{M}^{1}-\mathrm{M}^{2}$ (CST00; Nivel 21a; N. 16.1; Caja 246); Talpa europaea: j): Maxilar sup. der. con $\mathrm{M}^{1}-\mathrm{M}^{2}$ (CST01; Nivel 21b; N 17.1; Caja 334); Galemys pyrenaicus: k): $\mathrm{M}^{1}$ izq. (CST99; Nivel 21a; N 18.6; Caja 252); cf. Miniopterus schreibersii: I): Mandíbula der. con fr. de $\mathrm{M}_{1}$ y los alveolos de los dientes antemolares (CST00; Nivel 21a; M 17.6; Caja 255). 
especie: $\mathrm{M}_{1}$ y $\mathrm{M}_{2}$ con trigónido y talónido bien desarrollados; el $\mathrm{M}_{3}$ está constituido solo por el trigónido; el $\mathrm{P}^{4}$ tiene el metacono relativamente más grande que el de los molares superiores; molares superiores masivos, sin estilos; el $\mathrm{M}^{1}$ es trapezoidal, con las cuatros cúspides principales bien desarrolladas y un metacónulo central desarrollado (Chaline et al., 1974).

El erizo está escasamente representado por un NMI de un individuo en los niveles 20e, 21a y $21 \mathrm{~b}$, aunque con varias piezas dentarias en cada uno de ellos.

La especie se cita en numerosos yacimientos del Pleistoceno Superior y Holoceno de la península ibérica (Sesé, 1994 y 2005; Arribas, 2004; LópezGarcía, 2008; Garcia-Ibaibarriaga, 2005). Su registro más antiguo es en los yacimientos del Pleistoceno Inferior de Atapuerca de la Sima del Elefante, citado como cf. E. europaeus por Cuenca-Bescós \& García (2007) y en el nivel TD4 de Gran Dolina, citado como E. cf. europaeus por Gil (1986).

E. europaeus actualmente tiene una amplia distribución en la península ibérica y en Eurasia hasta el este de los Urales. Ocupa una gran variedad de hábitats, tanto boscosos como bordes de bosque $\mathrm{y}$ espacios abiertos pero con cobertura vegetal herbácea o arbustiva (Mitchell-Jones et al., 1999; Palomo \& Gisbert, 2002).

Familia Soricidae G. FISCHER, 1814 Subfamilia Crocidurinae MILNE-EDWARDS, 1872

Crocidura russula (HERMANN, 1780)

(Fig. 1: b)

\section{Material por niveles:}

- Nivel 18b: 1 fr. man. der. con $\mathrm{I}_{1}$, fr. $\mathrm{M}_{1}$ alvs. de Ps y Ms, r.a. y c.a.; 1 fr. man. der. con alvs. de Ms, r.a. y c.a.; NMI: 2

- Nivel 20b: 1 fr. man. der. con $\mathrm{I}_{1}-\mathrm{P}_{3}-\mathrm{P}_{4}-\mathrm{M}_{1}$ $\mathrm{M}_{2}-\mathrm{M}_{3} ; 1$ fr. man. izq. con $\mathrm{I}_{1}-\mathrm{M}_{1}$ y alvs. de Ps y Ms; NMI: 1

- Nivel 20c: 1 fr. man. der. con $\mathrm{M}_{2}$, alv. tercer $M$, r.a. y c.a.; 1 fr. man. izq. con fr. $\mathrm{M}_{1}-\mathrm{M}_{2}-\mathrm{M}_{3} ; 1 \mathrm{fr}$. man. izq. con fr. $\mathrm{I}_{1}-\mathrm{P}_{3}-\mathrm{P}_{4}$, alvs. de Ms, r.a. y c.a.; NMI: 2

- Nivel 20d: 1 fr. man. der. con fr. $\mathrm{M}_{1}$ alvs. del resto de Ms, r.a. y c.a.; 1 fr. man. izq. con $\mathrm{M}_{1}-\mathrm{M}_{2}$, r.a. y c.a.; $1 \mathrm{I}_{1}$ izq.; NMI: 1
Nivel 21a: 1 fr. man. der. con $\mathrm{M}_{2}-\mathrm{M}_{3} ; 1$ fr. man. der. con $\mathrm{M}_{2}$, r.a. y c.a.; 1 fr. man. izq. con $\mathrm{I}_{1}-\mathrm{P}_{3}$ $\mathrm{P}_{4}-\mathrm{M}_{1}-\mathrm{M}_{2} ; \mathrm{NMI}: 2$

NMI por niveles:

\begin{tabular}{lcccccc}
\hline NIVEL & $18 \mathrm{~b}$ & $20 \mathrm{~b}$ & $20 \mathrm{c}$ & $20 \mathrm{~d}$ & $21 \mathrm{a}$ & TOTAL \\
\hline NMI & 2 & 1 & 2 & 1 & 2 & 8 \\
\hline
\end{tabular}

\section{Comentarios:}

El material presenta las características propias del género Crocidura: dientes blancos sin ninguna pigmentación, incisivo con la cara oclusal lisa sin lóbulos, $\mathrm{M}_{3}$ con talónido muy reducido, $\mathrm{y}$ facetas del cóndilo articular fusionadas e integradas en una superficie articular continua. En una comparación con C. russula, C. suaveolens (PALLAS, 1811) y C. leucodon (HERMANN, 1780), el material de El Castillo presenta las características de la primera especie según distintos autores (Chaline et al., 1974; Saint Girons et al., 1979; Poitevin et al., 1986; Castells \& Mayo, 1993; Reumer, 1996; Palomo \& Gisbert, 2002): en el $\mathrm{M}_{2}$ casi todos los ejemplares tienen una ligera constricción del cíngulo bucal que no existe en C. suaveolens; el $\mathrm{P}_{4}$ es un diente tetraédrico en el que no hay cresta posterior lateral; el $\mathrm{M}_{3}$ presenta el talónido notablemente reducido a una cúspide simple y cortante; el incisivo inferior es de forma simple, puntiagudo, recurvado hacia adelante; el cóndilo articular de la mandíbula presenta una inclinación bastante pronunciada y una constricción lateral notable. La longitud de $\mathrm{M}_{1}-\mathrm{M}_{3}$ de 3,81 mm del ejemplar de $\mathrm{El}$ Castillo que conserva la serie dentaria, le asemeja también a C. russula, ya que según Saint Girons et al. (1979) en esta especie es inferior a $4,30 \mathrm{~mm}$, mientras que en C. leucodon es superior a dicho valor; asimismo es muy próxima a los valores mínimos (aproximadamente de $4 \mathrm{~mm}$ ) de la amplitud de variación que dan Chaline et al. (1974) para este parámetro en $C$. russula. En la mandíbula, la altura coronoidea de 4,58 $\mathrm{mm}$ del ejemplar de El Castillo en el que se ha podido medir, le aproxima a C. russula, especie en la que según Saint Girons et al. (1979) dicho valor es superior a $4,2 \mathrm{~mm}$, mientras que en C. suaveolens es inferior a 4,2 $\mathrm{mm}$. Por todo este conjunto de caracteres el material se atribuye a la especie $C$. russula. 
C. russula se distribuye actualmente desde la región costera del norte de África hasta el suroeste de Europa y algunas islas mediterráneas (Mitchell-Jones et al., 1999). En la península ibérica tiene actualmente una amplia distribución excepto en zonas de gran altitud (Palomo \& Gisbert, 2002). Su registro más antiguo es en el yacimiento del Pleistoceno Inferior de la Sima del Elefante, determinado como cf. C. russula (Cuenca-Bescós \& García, 2007). La especie se cita en algunos yacimientos del sur y norte de la península ibérica desde el Pleistoceno Medio y sobre todo del Pleistoceno Superior y Holoceno (Sesé, 1994 y 2005; Arribas, 2004; López-García, 2008; GarciaIbaibarriaga, 2015). Rofes \& Cuenca-Bescós (2010) sitúan la inmigración y expansión de esta especie en la península ibérica y en general en Europa durante el Pleistoceno Medio. Es una especie con requerimientos mediterráneos que suele vivir en medios abiertos y márgenes de bosques con bastante vegetación a nivel del suelo (Palomo \& Gisbert, 2002).

En general los crocidurinos están adaptados a condiciones más áridas que los soricinos (RzebikKowalska, 1995). Dada su distribución geográfica actual, el género Crocidura no habita por encima de $\operatorname{los} 53^{\circ}$ de latitud, al parecer evitando las bajas temperaturas (Rzebik-Kowalska, 1995), por lo que según esta autora (o.c.) es un buen indicador de climas templados.

\section{Subfamilia Soricinae G. FISCHER, 1814 Sorex coronatus MILLET, 1828}

(Fig. 1: c-e)

\section{Material craneal y dentario por niveles:}

- Nivel 18b: 49 fr. man. der. con dientes (21 de ellas con r.a. y c.a. ); 21 fr. man. der. sin dientes con r.a. y c.a.; 46 fr. man. izq. con dientes ( 29 de ellas con r.a. y c.a.); 26 fr. man. izq. sin dientes con r.a. y c.a.; 3 fr. max. sup. der. con dientes; 6 fr. max. sup. izq. con dientes; 9 dientes aislados; NMI: 72

- Nivel 18c: 8 fr. man. der. con dientes (4 de ellas con r.a. y c.a.); 8 fr. man. izq. con dientes ( 3 de ellas con r.a. y c.a.); 3 fr. man. izq. sin dientes, con r.a. y c.a.; NMI: 11

- Nivel 20b: 30 fr. man. der. con dientes (21 de ellas con r.a. y c.a.); 16 fr. man. der. sin dientes, con r.a. y c.a.; 22 fr. man. izq. con dientes (13 de ellas con r.a. y c.a.); 17 fr. man. izq. sin dientes, con r.a. y c.a.; 2 fr. max. sup. der. con dientes; 7 dientes aislados; NMI: 46

- Nivel 20c: 15 fr. man. der. con dientes (9 de ellas con r.a. y c.a.); 5 fr. man. der. sin dientes, con r.a. y c.a.; 7 fr. man. izq. con dientes ( 1 de ellas con r.a. y c.a.); 5 fr. man. izq. sin dientes, con r.a. y c.a.; 5 fr. max. sup. izq. con dientes; 3 dientes aislados; NMI: 20

- Nivel 20d: 23 fr. man. der. con dientes (14 de ellas con r.a. y c.a.); 7 fr. man. der. sin dientes, con r.a. y c.a.; 16 fr. man. izq. con dientes, r.a. y c.a.; 11 fr. man. izq. sin dientes, con r.a. y c.a.; 1 fr. de cráneo del que se conserva toda la bóveda y el maxilar con gran parte de la serie dentaria der. con $\mathrm{I}^{1}-\mathrm{I}^{2} \mathrm{e}$ izq.: $\mathrm{I}^{2}-\mathrm{I}^{3}-\mathrm{C}-\mathrm{P}^{2}$ y los alvs. del resto de los dientes; 2 fr. max. sup. der. con dientes; 1 fr. max. sup. izq. con dientes; 3 dientes aislados; NMI: 30

- Nivel 20e: 6 fr. man. der. con dientes, r.a. y c.a.; 2 fr. man. der. sin dientes, con r.a. y c.a.; 2 fr. man. izq. con dientes, r.a. y c.a.; 2 fr. man. izq. con dientes (1 de ellas con r.a. y c.a.); 1 fr. man. izq. sin dientes, con r.a. y c.a.; NMI: 8

- Nivel 21a: 86 fr. man. der. con dientes (47 de ellas con r.a. y c.a.); 52 fr. man. der. sin dientes, con r.a. y c.a.; 75 fr. man. izq. con dientes (40 de ellas con r.a. y c.a.); 23 fr. man. izq. sin dientes, con r.a. y c.a.; 1 fr. de cráneo en el que se conserva la parte anterior de la bóveda craneal, max. izq. con $\mathrm{I}^{1}-\mathrm{I}^{2}-\mathrm{I}^{3}-\mathrm{C}-\mathrm{P}^{2}-\mathrm{P}^{3}$ y alv. cuarto $\mathrm{P}, \mathrm{y}$ max. der. con $\mathrm{I}^{1}$ y alvs. de $\mathrm{C}$ y Ps; 7 fr. max. sup. der. con dientes; 9 fr. max. sup. izq.; 30 dientes aislados; NMI: 138

- Nivel 21b: 32 fr. man. der. con dientes (13 de ellas con r.a. y c.a.); 15 fr. man. der. sin dientes, con r.a. y c.a.; 27 fr. man. izq. con dientes (11 de ellas con r.a. y c.a.); 22 fr. man. izq. sin dientes, con r.a. y c.a.; NMI: 49

NMI por niveles:

\begin{tabular}{lccccccccc}
\hline NIVEL & $18 \mathrm{~b}$ & $18 \mathrm{c}$ & $20 \mathrm{~b}$ & $20 \mathrm{c}$ & $20 \mathrm{~d}$ & $20 \mathrm{e}$ & $21 \mathrm{a}$ & $\mathrm{c}$ & TOTAL \\
\hline NMI & 72 & 11 & 46 & 20 & 30 & 8 & 138 & 49 & 374 \\
\hline
\end{tabular}

\section{Comentarios:}

Los dientes presentan la pigmentación en rojo de la parte superior de las cúspides y crestas que las reúnen, característica del género Sorex. 
Aunque la distinción de Sorex coronatus y Sorex araneus LINNAEUS, 1758 no es fácil (Reumer, 1996), y en muchas publicaciones se da de forma conjunta su denominación generalmente como Sorex grupo coronatus-araneus, al disponer de mucho material en el yacimiento de El Casillo, con numerosas mandíbulas y series dentarias completas, y al comparar con material actual del MNCN de ambas especies, se ha podido determinar como $S$. coronatus porque presenta el siguiente conjunto de caracteres que le aproximan a esta especie: la mandíbula es más robusta que la de $S$. araneus que sin embargo es frágil; el proceso coronoide está inclinado hacia adelante mientras que en $S$. araneus es verticalmente recto; el foramen mandibular es generalmente simple y se sitúa bajo la mitad posterior de la fosa temporal en una depresión bien marcada, mientras que en $S$. araneus el foramen mandibular es con frecuencia doble, se sitúa en una depresión poco marcada y se extiende hasta la mitad del borde inferior de la fosa temporal; el foramen mental está más adelantando situándose bajo el trigónido del $\mathrm{M}_{1}$ casi donde comienza la base del $\mathrm{P}_{4}$, mientras que en $S$. araneus se sitúa bajo la mitad del $\mathrm{M}_{1}$; la apófisis articular está más desarrollada que en $S$. araneus y dirigida hacia atrás; la fosa temporal interna presenta el contorno inferior ovoide, mientras que en $S$. araneus la fosa temporal presenta el contorno bastante triangular, con el margen inferior recto; la escotadura superior es mayor de $90^{\circ}$ de arco, mientras que en $S$. araneus es de aproximadamente $90^{\circ}$; el incisivo inferior está ligeramente dirigido hacia arriba, mientras que en $S$. araneus se prolonga siguiendo el eje de la rama horizontal mandibular; el $\mathrm{M}_{3}$ presenta una reducción muy notable del talónido, mientras que en $S$. araneus el $\mathrm{M}_{3}$ no muestra una reducción apreciable del talónido (Reumer \& Hordijk, 1999; Castells \& Mayo, 1993; Palomo \& Gisbert, 2002; López-García, 2008).

$S$. coronatus se distribuye actualmente en el tercio norte peninsular, desde Galicia hasta el noroeste del Pirineo de Cataluña y norte del Sistema Ibérico mientras que $S$. araneus tiene una distribución limitada a algunas zonas de Cataluña: parte del Pirineo, Prepirineo y zona húmeda oriental del Montseny (Palomo \& Gisbert, 2002). En el resto de Europa $S$. coronatus se distribuye ampliamente desde los Pirineos hasta el norte de Alemania y oeste de Austria, mientras que $S$. araneus está en zonas aisladas del centro y sur de Italia, Pirineos y Macizo central de Francia, y está muy extendida en el Reino Unido, en el resto de Europa central y oriental, en toda Escandinavia, y por el este hasta el Lago Baikal en Siberia (Mitchell-Jones et al., 1999, Palomo \& Gisbert, 2002). S. araneus estuvo muy ampliamente distribuida durante el Pleistoceno Medio y Pleistoceno Superior, sufriendo una considerable reducción durante la última glaciación en este último periodo, mientras S. coronatus, endémica de Europa, se expandía a sus expensas, en el Pleistoceno Superior, bien desde el suroeste de Francia (Palomo \& Gisbert, 2002), o desde alguna zona del Golfo de Vizcaya y más probablemente de la Cornisa Cantábrica (Arribas, 2004).

En efecto, $S$. araneus, o formas afines (Sorex. gr. araneus, Sorex sp.), se citan en la península ibérica desde el Pleistoceno Medio, pero sobre todo en el Pleistoceno Superior y Holoceno hasta la actualidad con una distribución más amplia que en la actualidad en yacimientos tanto del sur como del centro y norte peninsular (Sesé, 1994 y 2005; Arribas, 2004; Sesé, 2009 y 2014; Arsuaga et al., 2010).

Se cita $S$. gr. coronatus-araneus o bien $S$. araneuscoronatus (denominaciones que implícitamente indican la dificultad de distinguir morfológicamente ambas especies) en muchos yacimientos del Pleistoceno Superior y Holoceno como Gorham (Gibraltar) (López-García et al., 2011b), El Portalón (Atapuerca, Burgos) (López-García et al., 2010), Unidad Faunística 7 de Atapuerca (Burgos) (Cuenca-Bescós et al., 2010a), El Mirón (Cantabria) (Cuenca-Bescós et al., 2008), Laminak II (Vizcaya) (Pemán, 1994), Askondo (Vizcaya) (Garcia-Ibaibarriaga et al., 2015a), Arlanpe (Vizcaya) (Garcia-Ibaibarriaga et al., 2013a), Arenaza I (Vizcaya) (Ordiales et al., 2015), Lezetxiki II (Guipúzcoa) (GarciaIbaibarriaga et al., 2015b), Aizkoltxo (Guipúzcoa) (Murelaga et al., 2008), Kiputz (Guipúzcoa) (Garcia-Ibaibarriaga et al., 2013b), Aratzu VII (Guipúzcoa) (Suárez-Bilbao et al., 2016), Peña Larga (Álava) (Rofes et al., 2013), La Arbreda (Gerona) (López-García et al., 2015), Cova del Gegant y Abric Romani (Barcelona) (López-García, 2008; LópezGarcía \& Cuenca-Bescós, 2010).

Hay sin embargo pocas citas de $S$. coronatus en el Pleistoceno y Holoceno, entre otras en los yacimientos de El Mirador (Atapuerca, Burgos) (López-García 
et al., 2007), de Cueva del Conde (Asturias) (LópezGarcía et al., 2011a), El Juyo (Cantabria) (Pokines, 1998), Antoliñako Koba (Vizcaya) (Rofes et al., 2015) y Teixoneres (Barcelona) (López-García et al., 2012).

Es posible que algunas de las citas del Pleistoceno y Holoceno que en el norte peninsular se atribuyen a $S$. araneus, $S$. coronatus-araneus o $S$. araneuscoronatus, Sorex gr. araneus-articus o a Sorex sp. puedan corresponder a $S$. coronatus o quizás a algún antepasado común con $S$. araneus y $S$. granarius MILLER, 1910 (una especie endémica de la península ibérica que vive actualmente en el Sistema Central y norte del Tajo hasta Galicia, según Palomo \& Gisbert, 2002), con morfologías todavía afines a estas especies, tal como sugiere Arribas (2004). Palomo \& Gisbert (2002) señalan las distintas hipótesis sobre la relación filogenéticas de estas especies: una de ellas sería que los cariotipos de $S$. araneus y $S$. coronatus habrían derivado del de $S$. granarius, y la otra, que estudios de ADN mitocondrial parecen indicar por el contrario que $S$. coronatus sería la especie más primitiva del grupo europeo de $S$. araneus.

$S$. coronatus requiere suelos húmedos con una buena cobertura vegetal sobre el suelo, tanto en bosques como en praderas (Mitchell-Jones et al., 1999; Palomo \& Gisbert, 2002).

\section{Sorex minutus LINNAEUS, 1766}

(Fig. 1: f)

Material por niveles:

- Nivel 18b: 3 fr. man. der. con dientes; 2 fr. man. izq. con dientes; NMI: 3

- Nivel 20d: 1 fr. man. der. con $\mathrm{M}_{1}-\mathrm{M}_{2} ; 1$ fr. man. izq. con $\mathrm{M}_{1}$; $\mathrm{NMI}=1$

- Nivel 21a: 2 fr. man. der. con dientes; 1 fr. man. izq. con dientes; NMI: 2

- $\quad$ Nivel 21b: 3 fr. man. der. con dientes; NMI = 3

NMI por niveles:

\begin{tabular}{lccccc}
\hline NIVEL & $18 b$ & $20 d$ & $21 a$ & $21 b$ & TOTAL \\
\hline $\mathrm{NMI}$ & 3 & 1 & 2 & 3 & 9 \\
\hline
\end{tabular}

\section{Comentarios:}

Los dientes presentan la pigmentación en rojo característica del género Sorex de la parte superior de las cúspides y crestas que las reúnen. Su pequeña talla le distingue claramente de $S$. coronatus presente en El Castillo, y en general de otras especies del género Sorex. La talla del único ejemplar que conserva la serie dentaria $\mathrm{M}_{1}-\mathrm{M}_{3}\left(\mathrm{~L} \mathrm{M}_{1}-\mathrm{M}_{3}=3,27 \mathrm{~mm}\right)$ está dentro de la variación de la de las poblaciones de S. minutus de diversos yacimientos Plio-Pleistocenos europeos según Reumer (1984), y de las poblaciones actuales de la especie según Gosàlbez et al. (1980). Asimismo, en la mandíbula, la altura coronoidea, que según Chaline et al. (1974) distingue a S. minutus de otras especies, es del orden de 3,25 $\mathrm{mm}$, altura que en la mandíbula de El Castillo que conserva esta parte es incluso menor: 3,16 mm. Morfológicamente, las mandíbulas de El Castillo presentan las siguientes características propias de S. minutus según Reumer (1984): la parte anterior del proceso coronoide es cóncava, estando el apéndice superior, que es estrecho y puntiagudo, doblado ligeramente hacia adelante; no hay espícula coronoide; la fosa temporal externa está desarrollada como un surco longitudinal, paralelo al borde posterior del proceso coronoide, y presenta una cresta central en su parte superior; la fosa temporal interna es alta y triangular; la faceta superior del cóndilo articular es cilíndrica y la faceta inferior se ensancha en su parte central; el foramen mandibular es grande y está situado bajo la esquina posterior de la fosa temporal interna; el foramen mentoniano está situado bajo el trigónido del $\mathrm{M}_{1 .}$. Chaline et al. (1974) señalan que en el cóndilo articular las facetas están muy separadas, algo que se observa en el material de El Castillo.

La especie se conoce en Europa desde el Plioceno (MN 14), hasta la actualidad (Rzebik Kowalska, 2007). Es la única especie actual del genero Sorex que tiene su origen durante el Terciario. Reumer \& Hordijk (1999) señalan que, aunque hay hallazgos en numerosos yacimientos pliocenos y cuaternarios de Europa, se registra generalmente en porcentajes muy bajos. Es lo que ocurre en el yacimiento de El Castillo, que frente al 6,88\% de representación de $S$. coronatus, presente en todos los niveles, $S$. minutus, presente en 4 de los 8 niveles, solo se registra en un $0,17 \%$.

En la península ibérica esta especie se encuentra actualmente en el tercio norte peninsular, desde el norte de Portugal y Galicia hasta la parte húmeda de Cataluña (Montseny) y Sierra de Prades (Tarragona), extremo norte del Sistema Ibérico y Sistema Central 
(Palomo \& Gisbert, 2002). La especie se registra en la península ibérica desde el Plioceno en algunos yacimientos de Teruel, Castellón y Granada (Hoek Ostende \& Furió, 2005). Durante el Pleistoceno tuvo una distribución mucho más amplia que en la actualidad, ya que, además de citarse en muchos yacimientos de las zonas antes mencionadas del norte y centro (Sesé, 1994 y 2005; Arribas, 2004; López García, 2008; García Ibaibarriaga, 2015), se registra en varios yacimientos del Levante (Guillem Calatayud, 2000; Agusti et al., 2011) y del sur peninsular, en la cuenca de Guadix-Baza, Granada (Agusti et al., 2010) y en Gibraltar (López-García et al., 2011b). Es decir que durante el Plioceno y Pleistoceno en la península ibérica ocupó regiones de la mitad sur de las que ahora está ausente, no solo esta especie, sino en general el género Sorex.

S. minutus vive en bosques y praderas con una densa cobertura vegetal a nivel del suelo. El factor limitante de su presencia es la humedad por lo que suele habitar en zonas con una precipitación anual media superior a los 600 mm (Palomo \& Gisbert, 2002).

La retracción en la distribución geográfica hacia zonas septentrionales de la península ibérica que ha sufrido el género Sorex en general desde el Pleistoceno Superior y Holoceno hasta la actualidad, junto con la de otros taxones ligados en general a climas húmedos y buen desarrollo de la cobertura vegetal, se ha relacionado con la aridificación del clima que ha tenido lugar en la península ibérica desde el Pleistoceno Superior y Holoceno especialmente en la mitad meridional (Sesé, 1994).

\section{Neomys fodiens (PENNANT, 1771)}

(Fig. 1: g-i)

\section{Material por niveles:}

- Nivel 18b: 2 fr. man. der. con dientes; 1 fr. man. izq. sin dientes, con r.a. y c.a.; 1 fr. max. sup. der. con $\mathrm{P}^{4}-\mathrm{M}^{1}-\mathrm{M}^{2}$; NMI: 2

- Nivel 20b: 1 fr. man. der. con $\mathrm{P}_{4}-\mathrm{M}_{1}-\mathrm{M}_{2} ; 1$ fr. man. der. con r.a. y c.a.; 1 fr. man. izq. con $\mathrm{P}_{4^{-}}$ $\mathrm{M}_{1}-\mathrm{M}_{2}-\mathrm{M}_{3} ; 1$ fr. man. izq. con r.a. y c.a.; NMI: 2

- Nivel 20c: 1 fr. man. der con $\mathrm{I}_{1}-\mathrm{P}_{3}-\mathrm{P}_{4}-\mathrm{M}_{1}$, alvs. del resto de Ms, r.a. y c.a.; NMI: 1

- Nivel 20d: 1 fr. man. der. con $\mathrm{M}_{2}$, alv. tercer M, ra. y c.a.; 1 fr. man. izq. con alvs. de Ms, r.a. y c.a.; NMI: 1
- $\quad$ Nivel 20e: 1 fr. man. der. con $\mathrm{P}_{4}-\mathrm{M}_{1}$; $\mathrm{NMI}=1$

- Nivel 21a: 11 fr. mand. der. con dientes (5 de ellas con r.a. y c.a.); 2 fr. man. der. sin dientes, con alvs. de Ps/Ms, r.a. y c.a.; 12 fr. mand izq. con dientes (3 de ellas con r.a. y c.a.); 1 fr. mand. izq. sin dientes, con alvs. de Ps/Ms, r.a. y c.a.; 1 fr. max. sup. der. con dientes; 1 fr. max. sup. izq. con dientes; NMI: 13

- Nivel 21b: 2 fr. man. der. con alvs. de Ps/Ms, r.a. y c.a; 2 fr. man. izq. con dientes, r.a. y c.a; 2 fr. man. izq. con dientes ( 1 de ellas con r.a. y c.a); NMI: 2

NMI por niveles:

\begin{tabular}{lcccccccc}
\hline NIVEL & $18 \mathrm{~b}$ & $20 \mathrm{~b}$ & $20 \mathrm{c}$ & $20 \mathrm{~d}$ & $20 \mathrm{e}$ & $21 \mathrm{a}$ & $21 \mathrm{~b}$ & TOTAL \\
\hline $\mathrm{NMI}$ & 2 & 2 & 1 & 1 & 1 & 13 & 2 & 22 \\
\hline
\end{tabular}

Medidas:

Medidas en $\mathrm{mm}$ de la altura la altura coronoidea de la mandíbula: $\mathrm{N}=9$ : 4,60; 4,67; 4,76; 4,78; 4,81; 4,$88 ; 4,91 ; 4,97 ; 5,10$.

\section{Comentarios:}

El material presenta las características propias del género Neomys: cúspides dentarias pigmentadas en rojo, incisivo inferior sin cúspides y cóndilo articular de la mandíbula con las dos facetas articulares notablemente separadas por un área interarticular estrecha y alargada, la faceta superior relativamente corta y la inferior alargada lingualmente. Las dos especies que actualmente habitan en la península ibérica y en general en Europa, Neomys fodiens y Neomys anomalus CABRERA, 1907, difieren por el tamaño, algo más grande la primera que la segunda especie. Sin embargo, la mayoría de las medidas craneales y mandibulares se solapan en ambas especies (Pemán, 1983), excepto las medidas de la altura coronoidea de la mandíbula que las separan claramente y es un carácter discriminatorio para diferenciarlas que es utilizado por muchos autores (Saint Girons, 1972; Chaline et al., 1974; Pemán, 1983; Palomo \& Gisbert, 2002), aunque según unos u otros autores dichos límites varían. Así, la altura coronoidea según Saint Girons (1972) (en: Pemán, 1983; p. 119) en $N$. fodiens varía entre $4,3 \mathrm{~mm}$ y $5,3 \mathrm{~mm}$, y en $N$. anomalus entre $3,8 \mathrm{~mm}$ y 4,6 mm; según Chaline 
et al. (1974) en $N$. fodiens varía entre 4,4 y 5,3 mm y en $N$. anomalus entre 3,9 y 4,4 mm; según Pemán (1983) en $N$. fodiens es superior a $5,1 \mathrm{~mm}$ y en $N$. anomalus inferior a $4,7 \mathrm{~mm}$; y según Palomo \& Gisbert (2002) en $N$. fodiens es superior a 4,7 y en $N$. anomalus inferior a $4,8 \mathrm{~mm}$. La variación de las medidas de la altura coronoidea en $\operatorname{los} 9$ ejemplares de El Castillo en los que se ha podido medir, que está comprendida entre $4,6 \mathrm{~mm}$ y 5,1 $\mathrm{mm}$, con un valor medio de $4,83 \mathrm{~mm}$, encaja en los valores de $N$. fodiens y le diferencia claramente de N. anomalus. Aunque Sánchez (1983) cita dos especies en El Castillo, $N$. anomalus y $N$. fodiens, en el presente trabajo, con el material disponible y por los criterios morfobiométricos anteriormente expuestos, solo se ha identificado esta última especie.

En Europa el registro de $N$. fodiens comienza en el Pleistoceno Medio, aunque con escasos hallazgos, y empieza a ser frecuente en yacimientos del Pleistoceno Superior y Holoceno (Reumer, 1996; Krystufek et al., 2000; Rzebik-Kowalska, 2009). En la península ibérica se cita desde el Pleistoceno Superior en varios yacimientos del norte peninsular (Sesé, 1994 y 2005; Arribas, 2004; López-García, 2008). Se distribuye actualmente desde el norte de la península ibérica hasta el Lago Baikal en Siberia (MitchellJones et al., 1999; Palomo \& Gisbert, 2002).

Es una especie con requerimientos eurosiberianos. Es la más acuática de las musarañas: suele vivir en zonas litorales y orillas de lagos y ríos de aguas oxigenadas, aunque también se encuentra alejada del agua pero en zonas húmedas de praderas, pantanos y bosques (Mitchell-Jones et al., 1999; Palomo \& Gisbert, 2002).

\section{Soricidae indet.}

Material por niveles:

- Nivel 18b: 9 fr. man. der. sin dientes; 21 fr. man. izq. sin dientes; NMI: 21

- Nivel 18c: 2 fr. man. der. sin dientes; 2 fr. man. izq. sin dientes; NMI: 2

- Nivel 20b: 2 fr. man. der. sin dientes; 4 fr. man. izq. sin dientes; NMI: 4

- Nivel 20c: 3 fr. man. der. sin dientes; 3 man. izq. sin dientes; NMI: 3

- Nivel 20d: 5 fr. man. der. sin dientes; 1 fr. man. izq. sin dientes.; NMI: 5

- Nivel 20e: 4 fr. man. der. sin dientes; 1 fr. man. izq. sin dientes; NMI: 4

- Nivel 21a: 40 man. der. sin dientes; 37 fr. man. izq. sin dientes; NMI: 40

- Nivel 21b: 17 fr. man. der. sin dientes; 10 fr. man. izq. sin dientes; NMI: 17

\section{NMI por niveles:}

\begin{tabular}{lccccccccc}
\hline NIVEL & $18 \mathrm{~b}$ & 18c & $20 \mathrm{~b}$ & $20 \mathrm{c}$ & $20 \mathrm{~d}$ & $20 \mathrm{e}$ & $21 \mathrm{a}$ & $21 \mathrm{~b}$ & TOTAL \\
\hline NMI & 21 & 2 & 4 & 3 & 5 & 4 & 40 & 17 & 96
\end{tabular}

\section{Comentarios:}

Se incluyen como sorícidos indeterminados aquellos restos mandibulares sin dientes y que no conservan el cóndilo articular completo que sería el que permitiría incluirlos bien en el género Sorex o en el género Crocidura, presentes en el yacimiento. Por la talla, la mayor parte del material parece similar a Sorex coronatus, que es por otra parte el sorícido más abundante en el yacimiento, sin por ello poder descartar completamente que algún ejemplar pueda pertenecer a Crocidura russula, aunque sí que son descartables la especie de menor talla Sorex minutus y la de mayor talla Neomys fodiens.

Este material permite constatar la abundancia de sorícidos de talla media en el yacimiento, además del material que ha podido ser identificado taxonómicamente a nivel de género y especie.

Familia Talpidae G. FISCHER, 1814

Subfamilia Talpinae G. FISCHER, 1814

Talpa europaea LINNAEUS, 1758

(Fig. 1: j)

\section{Material por niveles:}

Aunque muchas mandíbulas conservan parte o gran parte de la rama ascendente, solo raramente se conserva completa y más excepcionalmente se conserva el cóndilo articular completo. Del esqueleto postcraneal, aunque por su especial morfología se han hallado y reconocido numerosos restos de prácticamente todo tipo de piezas esqueléticas (vértebras, 
húmeros, fémures, cúbitos, radios, tibia-peroné, etc.), solo se han contabilizado los radios, últimas falanges y húmeros. Los radios y falanges presentan en general muy buena conservación y en su mayoría están completos, especialmente estas últimas. El NMI se ha calculado sobre el número de húmeros al ser las piezas más abundantes en todos los niveles.

- Nivel 18b: Material craneal: 6 fr. man. der. con dientes; 12 fr. man. der. sin dientes; 7 fr. man. izq. con dientes; 10 fr. man. izq. sin dientes; 2 fr. max. sup. der. con dientes; 2 fr. max. sup. izq. con dientes; 22 dientes aislados. Material postcraneal: Radios der.: 12; Radios izq.: 7; Últimas falanges: 32; Húmeros der.: 18; Húmeros izq.: 14; NMI: 18

- Nivel 18c: Material craneal: 2 fr. man. der. sin dientes; 2 fr. man. izq. con dientes; 4 dientes aislados. Material postcraneal: Radios der. : 2; Radios izq. 3; Últimas falanges: 3; Húmeros der. 3; Húmeros izq. 2; NMI: 3

- Nivel 20b: Material craneal: 10 fr. man der. con dientes; 11 fr. de man. der. sin dientes; 7 fr. man. izq. con dientes; 8 fr. man. izq. sin dientes; 2 fr. max. sup. der con dientes; 2 fr. max. sup. izq. con dientes; 11 dientes aislados; Material postcraneal: Últimas falanges: 1 ; Húmeros der.: 39; Húmeros izq.: 40; NMI: 40

- Nivel 20c: Material craneal: 25 fr. man. der. con dientes; 30 fr. man. der. sin dientes; 21 fr. man. izq. con dientes; 19 fr. man. izq. sin dientes; 3 fr. max. sup. der. con dientes; 30 dientes aislados. Material postcraneal: Radios der.: 1; Radios izq.: 3; Últimas falanges: 27; Húmeros der.: 99; Húmeros izq.: 101; NMI: 101

- $\quad$ - Nivel 20d: Material craneal: 25 fr. man. der. con dientes; $25 \mathrm{fr}$. man. der. sin dientes; $12 \mathrm{fr}$. man. izq. con dientes; 20 fr. man izq. sin dientes; 6 fr. max. sup. der. con dientes; 4 fr. max. sup. izq. con dientes; 50 dientes aislados. Material postcraneal: Radio der.: 6; Radio izq.: 4; Últimas falanges enteras: 36; Húmeros der.: 83; Húmeros izq.: 82; NMI: 83

- Nivel 20e: Material craneal: 24 fr. man. der. con dientes; 23 fr. man. der. sin dientes; 13 fr. man. izq. con dientes; 3 fr. man. izq. sin dientes; 1 fr. max. sup. der. con dientes; 3 fr. max. sup. izq. con dientes; 1 diente aislado. Material postcraneal:
Radio der.: 15; Radio izq.: 22; Últimas falanges: 6; Húmeros der.: 175; Húmeros izq.: 184; NMI: 184

- Nivel 21a: Material craneal: 104 fr. man. der. con dientes; 164 fr. man. der. sin dientes; 98 fr. man. izq. con dientes; 179 fr. man. izq. sin dientes; 3 fr. max. sup. der. e izq. sin dientes; 22 fr. max. der. con dientes; 22 fr. max. sup. izq. con dientes; 309 dientes aislados. Material postcraneal: Radio der.: 223; Radio izq.; 189; Últimas falanges: 266; Húmeros der.: 535; Húmeros izq.: 500; NMI: 535

- Nivel 21b: Material craneal: 21 fr. man. der. con dientes; 55 fr. man. der. sin dientes; 18 fr. man. izq. con dientes; 59 fr. man. izq.. sin dientes; 6 fr. max. der. con dientes; 11 fr. max. sup. izq. con dientes; 103 dientes aislados. Material postcraneal: Radio der.: 58; Radio izq.: 51; Últimas falanges: 100; Húmeros der.: 132; Húmeros izq.: 121; NMI: 132

NMI por niveles:

\begin{tabular}{lccccccccc}
\hline NIVEL & $18 b$ & $18 c$ & $20 b$ & $20 c$ & $20 d$ & $20 e$ & $21 a$ & $21 b$ & TOTAL \\
\hline NMI & 18 & 3 & 40 & 101 & 83 & 184 & 535 & 132 & 1096 \\
\hline
\end{tabular}

\section{Comentarios:}

El material craneal y postcraneal de El Castillo presenta la morfología característica del género Talpa. Por lo que respecta a las dos especies que habitan actualmente en la península ibérica, Talpa europaea y Talpa occidentalis CABRERA, 1907, aunque la primera tiene en general una talla ligeramente superior a la segunda, las dimensiones craneales y dentarias no sirven para separarlas porque se solapan ampliamente. Según Cleef-Roders \& Hoek Ostende (2001) hay un carácter en la dentición superior que permite diferenciarlas: en T. europaea el mesostilo (cúspide central labial) es simple, aunque en algunos ejemplares que no han sufrido desgaste pueden distinguirse dos cúspides, mientras que en $T$. occidentalis el mesostilo está dividido en dos cúspides muy cercanas la una de la otra, que pueden unirse con el desgaste del diente. Todos los molares superiores de El Castillo presentan el mesostilo como en $T$. europaea por lo que consideramos que se trata de esta especie. Cleef-Roders \& Hoek Ostende (2001) señalan que las diferencias métricas de los húmeros, obtenidas por Niethammer, 1990 en los húmeros de varias especies europeas del 
género Talpa (Niethammer, 1990 en: Cleef-Roders \& Hoek Ostende (2001, Table 3, p. 57), son mayores y más útiles que las de la dentición. En este sentido hay que señalar que es raro encontrar húmeros que estén completamente enteros y permitan medir la longitud total y la anchura de la epífisis, ya que sus extremos proximal y distal son frágiles, especialmente en individuos juveniles, razón por la que quizás algunos autores como López-García (2008) para diferenciar ambas especies, ante la ausencia o escasez de material dentario, optan por tener en consideración la anchura de la diáfisis que es la zona generalmente mejor conservada. La variación de la anchura de la diáfisis (según Niethammer, 1990 en: Cleef-Roders \& Hoek Ostende, 2001, Table 3, p. 57) en material actual de T. europaea de varios países europeos, entre ellos España, se sitúa entre $3,3 \mathrm{~mm}$ y $4,8 \mathrm{~mm}$, mientras que la de T. occidentalis de España varía entre $3 \mathrm{~mm}$ y $4,1 \mathrm{~mm}$; es decir, que se solapan, aunque la primera alcanza valores sensiblemente mayores. En una muestra de 35 ejemplares del nivel $20 \mathrm{E}$ de El Castillo que consideramos representativa de la variación que se observa en general en el yacimiento, la variación de la anchura de la diáfisis está entre $3,03 \mathrm{~mm}$ y 4,65 $\mathrm{mm}$ con una media de $3,68 \mathrm{~mm}$, lo que a nuestro juicio le aproxima más a la primera especie. Otros caracteres que según Cleef-Roders \& Hoek Ostende (2001) permiten diferenciar ambas especies por la dentición son: en T. europaea (como sucede en el material de El Castillo en una comparación directa con material actual de ambas), están más desarrollados el trigónido en $\mathrm{M}_{1}$, el hipocono en molares superiores, y los estílidos y estilos en general que en T. occidentalis. Por todo ello, pero fundamentalmente por la morfología del mesostilo de los molares superiores, identificamos la especie de El Castillo como T. europaea. Sánchez (1983) cita en El Castillo dos especies: T. europaea y T. caeca SAVI, 1822 (especie que actualmente no está en la península ibérica sino en otras regiones europeas mediterráneas), sin embargo, en el presente trabajo, con el material disponible y por los criterios morfobiométricos anteriormente mencionados, solo se ha identificado T. europaea.

Una abundancia tan extraordinaria de restos de topo en El Castillo es inusual en los yacimientos pleistocenos de la península ibérica. Así, el porcentaje de abundancia de este taxón entre los diferentes niveles varía entre el $4,32 \%$ y el $58,97 \%$, con un porcentaje total para el conjunto de niveles del $20,17 \%$. Únicamente en el yacimiento del Pleistoceno Superior de Cualventi (Cantabria), T. europaea no solo es extraordinariamente abundante, sino que es con diferencia el taxón más abundante de la asociación de micromamíferos en todos los niveles: el $30,7 \%$; un NMI de 503 del total de NMI de micromamíferos de 1640 en el conjunto de niveles del yacimiento (Sesé, 2016a y b). Aunque esta especie por sus hábitos hipogeos no suele ser presa frecuente de muchos predadores, parece ser un componente de la dieta de algunas aves y varios carnívoros (Palomo \& Gisbert, 2002). Hernández (2005) señala que en el noroeste de la península ibérica es habitual la predación de topos por el zorro rojo y que es frecuente también en general en la mitad norte peninsular, en zonas de montaña o premontaña en áreas con cubierta vegetal alta de praderas, la predación de topos por parte de otros carnívoros como el gato montés, la gineta y la garduña, coincidiendo en el norte peninsular el área de dispersión y mayor abundancia de los topos con la escasez de conejo, que suele ser la presa habitual del zorro rojo. Es interesante señalar también un caso de predación de topos en el yacimiento del Pleistoceno Inferior del nivel TE9 de la Sima del Elefante de Atapuerca, con evidencias de marcas de dientes en húmeros de T. europaea siendo el posible predador Beremendia fissidens, una especie de Eulipotyphla que se extinguió en el Pleistoceno Medio (Bennàsar et al., 2009). Aunque el topo figura también, como se ha dicho, en la composición de la dieta de muchas aves de presa (Andrews, 1990).

El registro más antiguo de T. europaea en la península ibérica es en el yacimiento del Pleistoceno Inferior de la Sima del Elefante, citado como cf. T. europaea por Cuenca-Bescós \& García (2007). T. europaea en la península ibérica se registra en numerosos yacimientos del Pleistoceno Superior y Holoceno (Sesé, 1994 y 2005; Arribas, 2004; López-García, 2008; García Ibaibarriaga, 2015). Actualmente vive en regiones templadas, desde el tercio norte peninsular hasta Siberia occidental, excepto Escandinavia y gran parte de las penínsulas mediterráneas. En la península ibérica se encuentra en los Pirineos, Prepirineos, y Región Cantábrica hasta el oriente de Asturias, norte del Sistema Ibérico, y montañas del País Vasco y Burgos. Debido a sus hábitos cavadores necesita suelos blandos y profundos fácilmente excavables; 
habita en praderas húmedas y bosques generalmente deciduos con suelos bien formados, desde el nivel del mar hasta los $2.000 \mathrm{~m}$ (Mitchell-Jones et al., 1999; Palomo \& Gisbert, 2002).

\section{Galemys pyrenaicus (GEOFFROY SAINT- HILAIRE, 1811)}

(Fig. 1: k)

Material por niveles:

- Nivel 18b: 1 fr. man. der. con alvs. de Ms y gran parte de la r.a.; $1 \mathrm{M}_{1}$ der.; $1 \mathrm{M}_{3}$ der.; $1 \mathrm{M}^{3}$ izq.; NMI: 1

- Nivel 21a: 1 fr. man. der. con alv. tercer M y gran parte de la r.a.; 1 fr. man. izq. con $\mathrm{I}_{1}-\mathrm{I}_{2}-\mathrm{P}_{3} \mathrm{y}$ alvs. del resto de Is, C y Ps; 1 fr. man. izq. con alvs. de Is, C y Ps, y parte anterior de la sínfisis mandibular; 1 fr. max. sup. izq. con $\mathrm{P}^{4}-\mathrm{M}^{1}-\mathrm{M}^{2} ; 1$ $\mathrm{M}_{2}$ izq.; $1 \mathrm{M}_{3}$ izq.; $2 \mathrm{M}^{1}$ izq.; NMI: 2

- Nivel 21b: $1 \mathrm{M}^{1}$ izq.; NMI: 1

NMI por niveles:

\begin{tabular}{lcccc}
\hline NIVEL & $18 b$ & $21 a$ & $21 b$ & TOTAL \\
\hline NMI & 1 & 2 & 1 & 4 \\
\hline
\end{tabular}

\section{Comentarios:}

El material, aunque escaso y fragmentario, presenta la talla y morfología características que se observan en el material actual de la especie de las colecciones del MNCN de Galemys pyrenaicus, que le diferencian claramente del género Talpa. La mayoría de los caracteres diagnóstico de G. pyrenaicus, según Rümke (1985), se refieren a medidas y morfología de incisivos, caninos y premolares inferiores y superiores, piezas de las que prácticamente no se dispone en El Castillo o no están en buen estado de conservación. En G. pyrenaicus los dientes anteriores a los molares no están completamente diferenciados en incisivos, caninos y premolares, según Chaline et al. (1974), como sucede en el fragmento mandibular de El Castillo que conserva algunos de estos dientes. La rama horizontal mandibular en $G$. pyrenaicus es curvilínea (López-García, 2008), como ocurre en el material de El Castillo. Con respecto al género Talpa, según nuestras propias observaciones, las diferencias son notables sobre todo en la dentición superior, con un mayor desarrollo de estilos y cúspides accesorias en G. pyrenaicus como ocurre en el material de El Castillo; así, en $\mathrm{M}^{1}$ y $\mathrm{M}^{2}$ hay dos mesostilos perfectamente diferenciados y separados entre sí.

G. pyrenaicus es una especie acuática, endémica de la península ibérica, cuya distribución está generalmente limitada a las cabeceras de los ríos de gran parte de la mitad norte peninsular desde la Región Cantábrica y los Pirineos hasta el Sistema Central y norte del Sistema ibérico, y de los Pirineos franceses. Suele vivir en cursos de aguas oxigenadas a bajas temperaturas $\mathrm{y}$ de flujo rápido $\mathrm{y}$ continuo durante todo el año, generalmente de arroyos de montaña, por lo que suele encontrase en climas oceánicos en lugar de mediterráneos, aunque también se encuentra en otro tipo de medios como lagos a gran altitud de los Pirineos franceses o cerca de la orilla del mar, a una altitud desde casi el nivel del mar en Portugal y la región Cantábrica, hasta los $2.500 \mathrm{~m}$ en los Pirineos (Mitchell-Jones et al., 1999; Palomo \& Gisbert, 2002).

En la península ibérica durante el Pleistoceno Inferior, Medio y Superior, G. pyrenaicus tuvo una distribución geografía más amplia que en la actualidad ya que se registra en algunos yacimientos de la región mediterránea del levante y sureste peninsular (Sesé, 1994; Arribas, 2004; López García, 2008). Su retracción actualmente hacia la mitad noroccidental de la península ha podido estar influida por la tendencia a la aridez del clima que se constata desde el Pleistoceno Superior especialmente en el sur peninsular (Sesé, 1994).

Orden Chiroptera BLUMENBACH, 1779

Suborden Microchiroptera DOBSON, 1875

Familia Vespertilionidae GRAY, 1821

cf. Miniopterus schreibersii (KUHL, 1817)

(Fig. 1:1)

Material por niveles y medidas:

- Nivel 21a: 1 fr. de man. der.: parte anterior con fr. de $\mathrm{M}_{1}$, y alvs. del segundo $\mathrm{M}$ y de todos los dientes unicuspidados anteriores. NMI: $1 ; \mathrm{M}_{1}$ : $\mathrm{L}=(1,32) ; \mathrm{A}=(0,78)$

\section{Comentarios:}

En el fragmento mandibular, la parte anterior sinfisaria está curvada ligeramente lingualmente y es más alta que el resto de la rama horizontal, lo que 
es característico de los quirópteros. $\mathrm{El}_{1}$, al que le falta el borde posterolingual, permite observar las siguientes características propias de Miniopterus schreibersii según Sevilla (1988): cíngulo grueso en el trigónido y fino en el talónido; entocréstida curva; paralófido cóncavo, sin escotadura. La talla es próxima a los valores mínimos de la de diversas poblaciones pleistocenas y actuales de la especie (Sevilla, 1988; López García, 2008). Sin embargo ante la escasez y fragmentariedad del material atribuimos este material a dicha especie con reservas.

M. schreibersii es una especie cavernícola que actualmente está ampliamente distribuía por toda la península ibérica y gran parte de las Islas Baleares (Palomo \& Gisbert, 2002). En la península ibérica se registra desde el Pleistoceno Medio (Sevilla, 1988; Sesé, 1994; Sesé \& Sevilla, 1996; Arribas, 2004; López García, 2008).

\section{Chiroptera indet.}

Material por niveles:

- Nivel 21a: 1 fr. de man. izq.: parte anterior con alvs. de todos los dientes unicuspidados anteriores y del primer M; NMI: 1

\section{Comentarios:}

Como en el caso anterior, en el fragmento mandibular la parte anterior sinfisaria está curvada ligeramente lingualmente y es más alta que el resto de la rama horizontal, lo que es característico de los quirópteros. Es muy notable al foramen mentoniano anterior. Es de mucha mayor talla, mayor robustez y de morfología diferente que el fragmento mandibular de El Castillo descrito anteriormente y atribuido a cf. Miniopterus schreibersii, por lo que sin duda de trata de un taxón distinto. Su talla solo es comparable a la de las especies de tamaño relativamente grande: Myotis myotis (BORKHAUSEN, 1797) y Eptesicus serotinus SCHREBER, 1774, con mayor semejanza morfológica por la primera. Pero puesto que no se conserva ningún diente, no se puede determinar taxonómicamente, aunque sí se puede afirmar que es un taxón distinto de Miniopterus schreibersii, determinado también en el nivel 21a de El Castillo, y que posiblemente se trate también de un vespertiliónido.
Orden Rodentia BOWDICH, 1821

Suborden Myomorpha BRANDT, 1855

Superfamilia Muroidea ILLIGER, 1811

Familia Cricetidae FISCHER, 1817

Subfamilia Arvicolinae GRAY, 1821

Pliomys lenki (HELLER, 1930)

(Fig. 2: a-c)

\section{Material por niveles:}

A continuación se da la relación del material craneal. En primer lugar el material dentario que está en mandíbulas y el número de dientes que no son $\mathrm{M}_{1}$, $\mathrm{y}$ en el cuadro final el número de $\mathrm{M}_{1}$ der. e izq. en el que se basa el NMI.

- Nivel 18b: 7 fr. man. der. y 2 fr. man. izq. con dientes. Otro rango de Ms aislados, no $\mathrm{M}_{1}$ : Ms: 91 fr. Ms: 18.

- Nivel 18c: 1 fr. man. izq. con $\mathrm{M}_{1}$. Otro rango de Ms aislados, no $\mathrm{M}_{1}$ : Ms: 15; fr. Ms: 2.

- Nivel 20b: 1 fr. man. der. y 1 fr. man. izq. con dientes. Otro rango de $\mathrm{Ms}$ aislados, no $\mathrm{M}_{1}$ : Ms: 35; fr. Ms: 3.

- Nivel 20c: Otro rango de Ms aislados, no $\mathrm{M}_{1}$ : Ms: 10; fr. Ms: 3.

- Nivel 20d: Otro rango de molares aislados, no $\mathrm{M}_{1}$ : Ms: 19; fr. Ms: 1 .

- Nivel 20e: 1 fr. man. izq. con $\mathrm{M}_{1}-\mathrm{M}_{2}$ y p.a. Otro rango de molares aislados, no $\mathrm{M}_{1}$ : Ms: 4 .

- Nivel 21a: 1 fr. man. der. y 4 fr. man. izq. con dientes. Otro rango de molares aislados, no $\mathrm{M}_{1}$ : M: 39; fr. M: 5.

- Nivel 21b: Otro rango de molares aislados, no $M_{1}: M=35$; fr. $M: 6$.

Número de $M_{1}$ y NMI por niveles:

\begin{tabular}{lcccc}
\hline NIVEL & $\mathrm{N}^{\circ} \mathrm{M}_{1}$ der. & $\mathrm{N}^{\circ} \mathrm{M}_{1}$ izq. & $\mathrm{N}^{\circ} \mathrm{M}_{1}$ Totales & $\mathrm{NMI}$ \\
\hline $18 \mathrm{~b}$ & 27 & 15 & 42 & 27 \\
$18 \mathrm{c}$ & --- & 3 & 3 & 3 \\
$20 \mathrm{~b}$ & 15 & 7 & 22 & 15 \\
$20 \mathrm{c}$ & 4 & --- & 4 & 4 \\
$20 \mathrm{~d}$ & 1 & 1 & 2 & 1 \\
$20 \mathrm{e}$ & 2 & 3 & 5 & 3 \\
$21 \mathrm{a}$ & 15 & 19 & 34 & 19 \\
$21 \mathrm{~b}$ & 6 & 5 & 11 & 6 \\
TOTAL & 70 & 53 & 123 & 78 \\
\hline
\end{tabular}



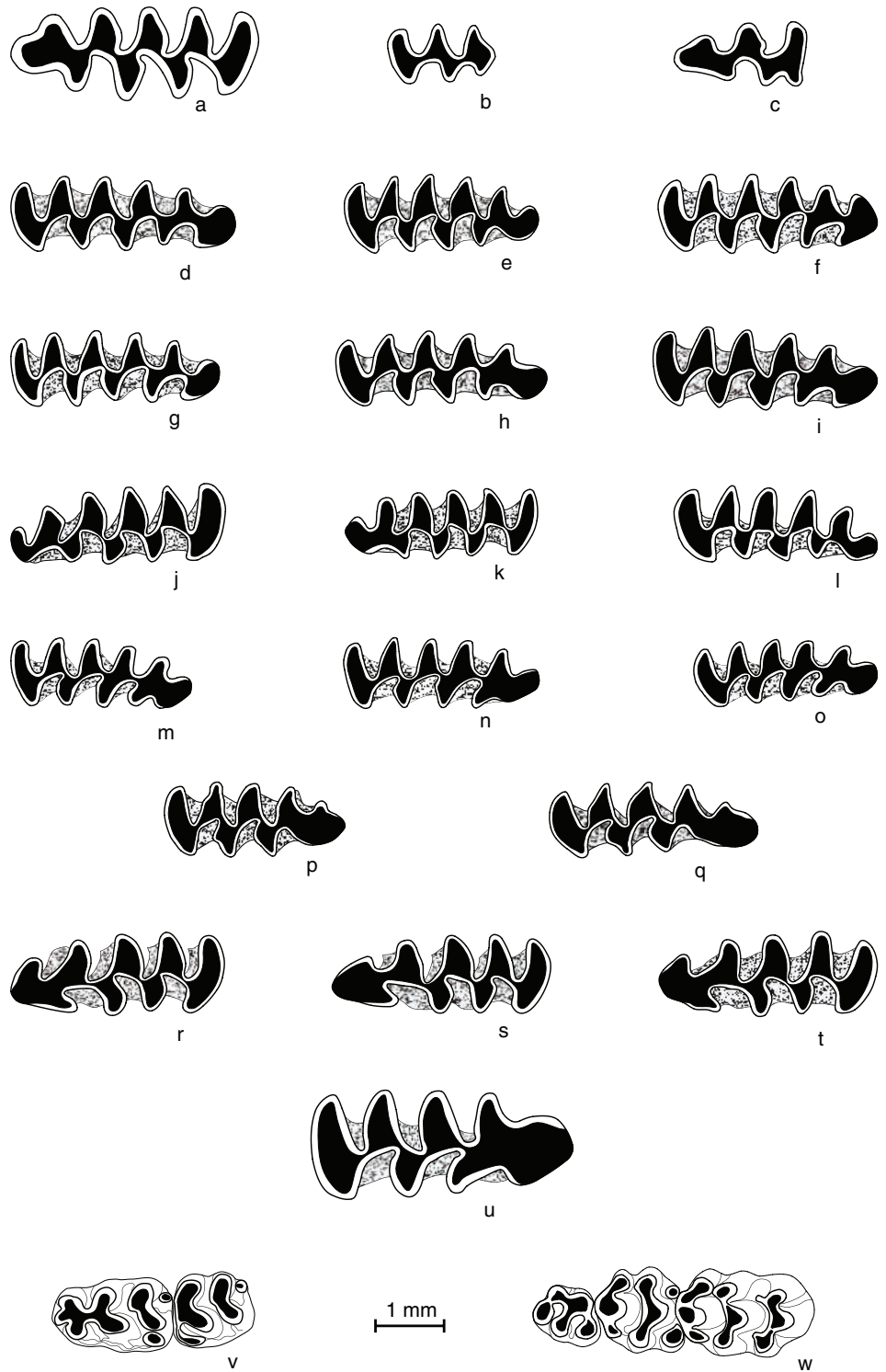

Fig. 2.-Dibujos de los dientes de roedores del yacimiento de la cueva de El Castillo: Pliomys lenki: a): $\mathrm{M}_{1}$ izq. (CST95; Nivel 20b; N 16.6; Caja 24: $2^{\circ}$ ); b): $\mathrm{M}_{3}$ der. (CST95; Nivel 20b; N 16.5; Caja 8); c): $\mathrm{M}^{3}$ izq. (CST96; Nivel 20c; N 16.1; Caja 2); Microtus arvalis - Microtus agrestis: d): $\mathrm{M}_{1}$ der. (CST95; Nivel 20b; N 18.4; Caja 30: 1a $^{\mathrm{a}}$ 10 $^{\circ}$ ); e): $\mathrm{M}_{1}$ der. (CST95; Nivel 20b; N 18.6; Caja 31: $\left.\left.3^{a}: 9^{\circ}\right) ; f\right): M_{1}$ der. (CST95; Nivel 20b; N 17.3; Caja 39: $\left.1^{a}: 3^{\circ}\right) ; g$ ): $M_{1}$ der. (CST95; Nivel 20b; $N$ 17.3; Caja 39: $\left.1^{a}\right) ; h$ ): $M_{1}$ der. (CST95; Nivel 20b; N 16.1; Caja 6: 19: 18º); i): $M_{1}$ der. (CST95; Nivel 20b; N 18.6; Caja 13: 19: 16º); j): $M_{1}$ izq. (CST95; Nivel 20b; N 17.7; Caja 27: $1^{\text {aa }} 13^{\circ}$ ); k): $M_{1}$ izq. (CST95; Nivel 20b; N 17.9; Caja 43: $3^{\mathrm{a}}$ : $2^{\circ}$ ); I): $\mathrm{M}_{1}$ der. (CST95; Nivel 20b; $N$ 16.5; Caja 8: $1^{\mathrm{a}}$ : $8^{\circ}$ ); Microtus lusitanicus: $\mathrm{m}$ ): $\mathrm{M}_{1}$ der. (CST95; Nivel 20b; $N$ 18.6; Caja 31: $3^{\mathrm{a}}$ : 22º); $\mathrm{n}$ ): $\mathrm{M}_{1}$ der. (CST95; Nivel 20d; $\mathrm{N} 18.4$; Caja 118: $2^{\mathrm{a}}$ :

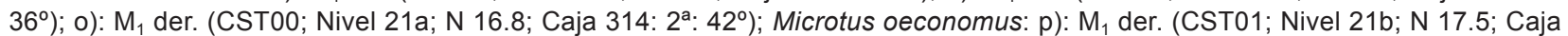
276: $2^{\mathrm{a}}$ : $5^{\circ}$ ); q): $\mathrm{M}_{1}$ der. (CST01; Nivel 21b; $N$ 17.1; Caja 334); Chionomys nivalis: $r$ ): $\mathrm{M}_{1}$ izq. (CST95; Nivel 20b; $N$ 18.6; Caja 13; $2^{\mathrm{a}}$ ); s): $\mathrm{M}_{1}$ izq. (CST95; Nivel 20b; $N$ 17.2; Caja 46: $2^{\mathrm{a}}$ ); t): $\mathrm{M}_{1}$ izq. (CST95; Nivel 20b; N 16.1; Caja 51); Arvicola terrestris: u): $\mathrm{M}_{1}$

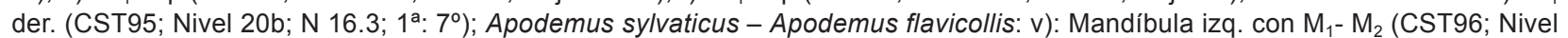
20c; $N$ 16.2: Caja 95); w) Maxilar sup. der. con $M^{1}-M^{2}-M^{3}$ (CST96; Nivel 20c; N 16.57; Caja 84). 


\section{Comentarios:}

Los molares tienen raíces, son hipsodontos y no tienen cemento en los ángulos entrantes. El esmalte está diferenciado: en los molares inferiores es algo más grueso en la parte anterior de los triángulos, y no se interrumpe en ningún ejemplar. El $\mathrm{M}_{1}$ presenta la morfología característica de Pliomys lenki: lóbulo posterior, cinco triángulos cerrados y triángulos T6 y T7 confluyentes en la cúspide anterior. La única variación morfológica se da en la parte anterior del complejo anterocónido: en algunos molares los triángulos T6 y T7 no están del todo diferenciados y comunican por una amplio cuello con la cúspide anterior de la que forman parte, y en otros casos estos triángulos están enfrentados y comunican por un cuello relativamente estrecho con la cúspide anterior que es redondeada. En los $\mathrm{M}_{1}$ de individuos juveniles, los ángulos BRA 4 y LRA 5 son más profundos y están más desarrollados que en los de dientes de adultos y seniles, por lo que la cúspide anterior está mejor delimitada y generalmente es de forma alargada oblicuamente al eje longitudinal del diente. Esta morfología es similar a la de las poblaciones de dicha especie de los yacimientos de Atapuerca según Gil (1986). En la población de P. lenki de Cueva del Agua, López Martínez \& Ruiz Bustos (1977) señalan la presencia de un sexto ángulo saliente en el borde lingual como para formar el triángulo T9, que está bien diferenciado en $P$. lenki relictus CHALINE (1975) (In: Bartolomei et al., 1975) del yacimiento de Nestier en Francia, y que sin embargo no aparece en ningún ejemplar de El Castillo.

$P$. lenki, desde sus primeros registros en el Pleistoceno Inferior, estuvo ampliamente distribuida por toda Europa durante el Pleistoceno Medio (Bartolomei et al., 1975; Kowalski, 2001; CuencaBescós et al., 2010b). Bartolomei et al. (1975) señalaron la emigración de esta especie hacia el suroeste hasta su desaparición del centro y este de Europa. En el Pleistoceno Superior solo se encuentra en zonas más meridionales europeas como el norte de Italia, el sur de Francia y sobre todo la España peninsular, regiones estas dos últimas en las que sobrevivió hasta el final de dicho periodo (Cuenca-Bescós et al., 2010b).

En la España peninsular $P$. lenki se registra desde la última parte del Pleistoceno Medio en yacimientos como los niveles superiores de Gran Dolina y
Complejo Tres Simas de Atapuerca (TZ 4, TN 4 y 6, TG 11, TD 10 y 11) (Gil, 1986; Sesé \& Gil, 1988; Gil \& Sesé, 1991) y en numerosos yacimientos de prácticamente todas las regiones peninsulares durante el Pleistoceno Superior, extinguiéndose en la última parte de dicho periodo (Sesé, 1994; Sesé y Sevilla, 1996; Arribas, 2004; Sesé, 2005; Cuenca-Bescós et al., 2010b). Hay cierta controversia respecto a cuando tuvo lugar la desaparición de P. lenki. Según Cuenca-Bescós et al. (2010b) su último registro habría tenido lugar en algunos niveles de yacimientos con cronologías relativamente recientes del final del Pleistoceno Superior, entre los 14.000 y 10.000 años $\mathrm{BP}$, aunque tal como estos autores indican y como ya señalamos en Sesé (2016b), hay claros indicios de que la retracción y casi desaparición de la especie parece que tuvo lugar en cronologías muy anteriores. Según Sesé (2016b), y en nuestra opinión, la mayoría de las citas de su registro en niveles de algunos yacimientos con cronologías tan recientes adolecen, en algunos casos, de falta de dataciones absolutas, $y$, en su mayoría, de estar basadas en determinaciones taxonómicas cuestionables ya que, o bien éstas no son contrastables al no estar documentado en el texto sobre el material en que se basan, o bien están realizadas sobre otras piezas dentarias que no son los primeros molares inferiores -que son las únicas que permiten identificar la especie con seguridad- y que podrían confundirse con Clethrionomys glareolus (SCHREBER, 1780), una especie en la que, como ocurre en $P$. lenki, los molares son también radiculados y el esmalte de cierto espesor.

En cuanto a las condiciones paleoclimáticas que podría indicar esta especie, de la que no existen representantes actuales, hay varias interpretaciones sobre las causas de su extinción. Algunos autores han señalado que la pervivencia de $P$. lenki en la península ibérica hasta el final del Pleistoceno Superior, mucho después de su extinción en Europa central y del este, podría ser debido a que en aquélla hubo unas condiciones de clima más templado que en regiones europeas más septentrionales durante dicho periodo en general, lo que, junto a que se encuentra generalmente asociada a faunas de dicho tipo de condiciones climáticas, avalaría la hipótesis de que sería un indicador de clima templado (Chaline, 1970; López Martínez \& Ruiz Bustos, 1977; Sesé, 1994 y 2005). Cuenca-Bescós et al. (2010b), sin embargo, 
argumentan que su extinción no se debió a causas estrictamente climáticas, puesto que vivieron en diferentes regiones y medios de toda Europa durante todo el Pleistoceno Medio, sino que, dada la retracción que sufrió la especie desde el final del Pleistoceno Medio, cuyo registro desde entonces suele ser en yacimientos kársticos, esta podría haber sido la causa de la fragmentación en la distribución de sus poblaciones, hasta llegar a estar cada vez más ligadas a este tipo de áreas rocosas y áridas, y finalmente entrar en competencia con especies inmigrantes (algunas con el mismo tipo hábitat como Chionomys nivalis) más ubicuas y con poblaciones más densas al final del Pleistoceno Superior. En nuestra opinión creemos que puede haber ocurrido una combinación de todos estos factores. La retracción inicial al final del Pleistoceno Medio de la distribución de P. lenki desde el norte y este al sur de Europa, pudo estar muy influida por los cambios en las condiciones climáticas y ambientales que eran propicias para la especie (Sesé, 1994 y 2005), que al comienzo del Pleistoceno Superior encontró refugio en zonas más meridionales, zonas que, al fragmentarse y reducirse sus poblaciones a lo largo de dicho periodo, se convirtieron en un callejón sin salida para la especie al final del mismo (Cuenca-Bescós et al., 2010b).

\section{Microtus arvalis (PALLAS, 1778) - Microtus agrestis (LINNAEUS, 1761)}

(Fig. 2: d-1)

\section{Material por niveles:}

A continuación se da la relación de material craneal. En primer lugar el material dentario que está en mandíbulas y en el cuadro final el número de $\mathrm{M}_{1}$ der. e izq. en el que se basa el NMI.

- Nivel 18b: 9 fr. man. der. y 6 fr. man izq. con dientes.

- Nivel 18c: 2 fr. man. der. y 4 fr. man. izq. con dientes.

- Nivel 20b: 49 fr. man. der. y 26 fr. man. izq. con dientes.

- Nivel 20c: 8 fr. man. der. y 4 fr. man. izq. con dientes.

- Nivel 20d: 22 fr. man. der. y 15 fr. man. izq. con dientes.
- Nivel 20e: 49 fr. man. der. y 33 fr. man. izq. con dientes.

- Nivel 21a: 189 fr. man. der. y 186 fr. man. izq. con dientes.

- Nivel 21b: 64 fr. man. der. y 59 fr. man. izq. con dientes.

Número de $M_{1} y$ NMI por niveles:

\begin{tabular}{lcccc}
\hline NIVEL & $\mathrm{N}^{\circ} \mathrm{M}_{1}$ der. & $\mathrm{N}^{\circ} \mathrm{M}_{1}$ izq. & $\mathrm{N}^{\circ} \mathrm{M}_{1}$ Totales & $\mathrm{NMI}$ \\
\hline $18 \mathrm{~b}$ & 143 & 147 & 290 & 147 \\
$18 \mathrm{c}$ & 24 & 17 & 41 & 24 \\
$20 \mathrm{~b}$ & 444 & 402 & 846 & 444 \\
$20 \mathrm{c}$ & 65 & 62 & 127 & 65 \\
$20 \mathrm{~d}$ & 83 & 52 & 135 & 83 \\
$20 \mathrm{e}$ & 56 & 69 & 125 & 69 \\
$21 \mathrm{a}$ & 1284 & 1256 & 2540 & 1284 \\
$21 \mathrm{~b}$ & 451 & 449 & 900 & 451 \\
TOTAL & 2550 & 2454 & 5004 & 2567 \\
\hline
\end{tabular}

\section{Comentarios:}

Los molares son arrizodontos y con cemento en los ángulos entrantes. La morfología del $\mathrm{M}_{1}$ en vista oclusal es la siguiente: está formado por un lóbulo posterior, cinco triángulos cerrados y el complejo anterior que, según los morfotipos descritos por Chaline (1972), varía entre una morfología de tipo "arvalis" (el más característico de la especie $M$. arvalis), con los triángulos T6 y T7 más o menos opuestos entre sí y confluyentes en la cúspide anterior que es de contorno ovoide o redondeado; la morfología de tipo "agrestis" (el más característico de la especie M. agrestis), con los triángulos T6 y T7 alternos y confluyentes en las cúspide anterior que es de contorno o bien ovoide, o alargado o anguloso, a veces con el T6 casi o totalmente cerrado y aislado del T7 que se abre a la cúspide anterior, tal como indican Chaline et al. (1974); y finalmente morfologías intermedias entre ambos morfotipos que no se pueden asignar con seguridad a uno u otro, por lo que optamos por la denominación taxonómica en conjunto de ambas especies tal como se encuentra en gran parte de la literatura científica (Sesé, 2005). Aunque, a parte de la morfología del complejo anterior que distingue los dos morfotipos extremos indicados, y por tanto las dos especies, se han aducido algunos caracteres de distinción entre ambas como la asimetría y alternancia 
de los triángulos en $M$. agrestis, frente a la simetría y paralelismo de los mismos en M. arvalis (Chaline et al., 1974), estos rasgos no siempre son claramente observables en la población de El Castillo; en algunos ejemplares se prestan a distintas interpretaciones, en los molares fragmentados de los que solo se conserva la parte anterior no se pueden apreciar, y en muchos casos quedan enmascarados por el estado de desgaste del diente que distorsiona su morfología. Por todo ello, dada la aparente continuidad morfológica que se observa en la población de El Castillo entre los morfotipos más característicos de $M$. agrestis y M. arvalis, con morfotipos intermedios o no asignables con certeza a uno u a otro, optamos por la denominación conjunta de ambas especies que, en todo caso, generalmente aparecen asociadas en muchos de los yacimientos en los que han sido determinadas por separado. En la población de El Castillo es mucho más abundante el morfotipo "arvalis" (entre un 60\% y algo más del $80 \%$ de las diferentes muestras) que el morfotipo "agrestis", como sucede en el yacimiento Cueva Cobrante (Sesé, 2009) y en el de Amutxate (Sesé, 2014).

En la península ibérica $M$. arvalis-M. agrestis se citan desde la última parte del Pleistoceno Medio en yacimientos como los niveles superiores de Gran Dolina y Complejo Tres Simas de Atapuerca (TN 4, 5 y 6, TG 9, 10 y 11, TD 10 y 11) (Gil, 1986; Sesé \& Gil, 1988; Gil \& Sesé, 1991). Ambas especies se registran en numerosos yacimientos del Pleistoceno Superior y Holoceno hasta la actualidad (Sesé, 1994 y 2005; Arribas, 2004; López García, 2008; García Ibaibarriaga, 2015).

M. arvalis es una especie endémica de Europa que actualmente se encuentra ampliamente distribuida por el continente hasta el centro de Rusia, excepto en Escandinavia, las islas y regiones mediterráneas, sur de Grecia, de Italia y de la península ibérica (Mitchell-Jones et al., 1999). Aunque hasta hace unos 35 años su distribución en la península ibérica se limitaba a los sistemas montañosos de la mitad norte peninsular (Cordillera Cantábrica, Pirineos, Sistema Central y Sistema Ibérico), desde entonces se ha expandido ocupando también en la actualidad casi totalmente la Meseta Norte (Palomo \& Gisbert, 2002). Habita en medios abiertos con una densa cobertura vegetal, herbácea o arbustiva, que se mantiene en el tiempo, desde los 500 a los 2.000 metros de altitud (Palomo \& Gisbert, 2002).
M. agrestis está muy extendida por casi toda Eurasia hasta Siberia y noroeste de China excepto Irlanda, islas mediterráneas, Italia, Grecia y sur de la península ibérica (Mitchell-Jones et al., 1999). En la península ibérica se distribuye solo en el tercio norte peninsular, en los Pirineos, Región Cantábrica, Galicia, Sierra de la demanda, norte de Castilla y León, y norte de Portugal hasta Lisboa (Palomo \& Gisbert, 2002). Es una especie de requerimientos ambientales centroeuropeos. Vive en hábitats húmedos preferentemente en praderas y herbazales espesos, aunque también se encuentra en bosques con suelo herbáceo desarrollado, en márgenes pedregosos de arroyos y en zonas húmedas de juncales, desde el nivel del mar hasta una altitud por encima de los $1.600 \mathrm{~m}$ (Palomo \& Gisbert, 2002).

$M$. arvalis- $M$. agrestis son los taxones más abundantes en todos los niveles de El Castillo (variando su abundancia desde el $22,12 \%$ hasta el $65,39 \%$, con un porcentaje total en el conjunto de niveles del $47,23 \%$ ). Aunque bajo una denominación común por lo dicho anteriormente, las dos especies están presentes en el yacimiento, siendo $M$. arvalis la más abundante con diferencia respecto a $M$. agrestis.

\section{Microtus lusitanicus (GERBE, 1879)}

(Fig. 2: m-o)

\section{Material por niveles:}

A continuación se da la relación de material craneal. En primer lugar el material dentario que está en mandíbulas y en el cuadro final el número de $\mathrm{M}_{1}$ der. e izq. en el que se basa el NMI.

- Nivel 18b: 4 fr. man. der. y 2 fr. man. izq. con dientes.

- Nivel 18c: 1 fr. man. der. con $\mathrm{M}_{1}$ y p.a.

- Nivel 20b: 5 fr. man. der. y 4 fr. man. izq. con dientes.

- Nivel 20c: 1 fr. man. izq. con I-M 1 , I.

- Nivel 20d: 4 fr. man. der. con dientes.

- Nivel 20e: 2 fr. man. der. y 2 fr. man. izq. con dientes.

- Nivel 21a: 23 fr. man. der. y 15 fr. man. izq. con dientes.

- Nivel 21b: 3 fr. man. der. y 4 fr. man. izq. con dientes. 
Número de $M_{1}$ y NMI por niveles:

\begin{tabular}{lcccc}
\hline NIVEL & $\mathrm{N}^{\circ} \mathrm{M}_{1}$ der. & $\mathrm{N}^{\circ} \mathrm{M}_{1}$ izq. & $\mathrm{N}^{\circ} \mathrm{M}_{1}$ Totales & $\mathrm{NMI}$ \\
\hline $18 \mathrm{~b}$ & 73 & 65 & 138 & 73 \\
$18 \mathrm{c}$ & 6 & 9 & 15 & 9 \\
$20 \mathrm{~b}$ & 77 & 56 & 133 & 77 \\
$20 \mathrm{c}$ & 12 & 13 & 25 & 13 \\
$20 \mathrm{~d}$ & 25 & 9 & 34 & 25 \\
$20 \mathrm{e}$ & 2 & 6 & 8 & 6 \\
$21 \mathrm{a}$ & 129 & 152 & 281 & 152 \\
$21 \mathrm{~b}$ & 36 & 43 & 79 & 43 \\
TOTAL & 360 & 353 & 713 & 398 \\
\hline
\end{tabular}

\section{Comentarios:}

Los molares son arrizodontos y con cemento en los ángulos entrantes. La morfología del $\mathrm{M}_{1}$ en vista oclusal es la siguiente: está formado por un lóbulo posterior; tres primeros triángulos cerrados; triángulos T4 y T5 confluyentes y enfrentados formando el 1lamado "rombo pitimiano"; triángulos T6 y T7 formando un segundo rombo pitimiano relativamente aislado de la cúspide anterior: ambos están bien desarrollados, prácticamente como los demás triángulos, enfrentados y confluyendo por un cuello relativamente estrecho en la cúspide anterior que es redondeada, ovalada o alargada en sentido oblicuo al eje longitudinal del diente. Esta morfología es la característica de Microtus lusitanicus y su talla también entra dentro de la variabilidad de las poblaciones de dicha especie de varios yacimientos como Combe-Grenal (Chaline, 1972), Cobrante (Sesé, 2009) y Amutxate (Sesé, 2014). Todo el material de El Castillo estudiado aquí presenta una morfología muy constante atribuible a Microtus lusitanicus, tal como se ha dicho; sin embargo Sánchez (1983) cita en el yacimiento dos especies: Microtus lusitanicus y Microtus pyrenaicus (= M. gerbei GERBE, 1879), una especie que no vive actualmente en Asturias sino en regiones más orientales del norte de la península ibérica.

Durante el Pleistoceno Superior se registra en numerosos yacimientos de la mitad norte peninsular especialmente en la Región Cantábrica, y también en yacimientos de los altos Pirineos franceses (Sesé, 2005; Arribas, 2004; López García, 2008).

$M$. lusitanicus es una especie endémica de la península ibérica, que actualmente solo se encuentra en el cuadrante noroccidental peninsular de
España y Portugal, y en el extremo suroccidental de Francia. Requiere suelos húmedos y blandos con una densa cobertura vegetal, generalmente en praderas y campos de cultivo, aunque también se encuentra en zonas boscosas y a orillas de los ríos, desde el nivel del mar hasta los 2.000 de altitud (Mitchell-Jones et al., 1999; Palomo \& Gisbert, 2002).

\section{Microtus oeconomus (PALLAS, 1776)}

(Fig. 2: p-q)

\section{Material por niveles:}

A continuación se da la relación de material craneal. En primer lugar el material dentario que está en mandíbulas y en el cuadro final el número de $\mathrm{M}_{1}$ der. e izq. en el que se basa el NMI.

- Nivel 21a: 3 fr. man. der. con dientes.

- Nivel 21b: 7 fr. man. der. y 6 fr. man. izq. con dientes.

Número de $M_{1} y$ NMI por niveles:

\begin{tabular}{lcccc}
\hline NIVEL & $\mathrm{N}^{\circ} \mathrm{M}_{1}$ der. & $\mathrm{N}^{\circ} \mathrm{M}_{1}$ izq. & $\mathrm{N}^{\circ} \mathrm{M}_{1}$ Totales & $\mathrm{NMI}$ \\
\hline 18b & --- & 1 & 1 & 1 \\
21a & 16 & 16 & 32 & 16 \\
21b & 44 & 46 & 90 & 46 \\
TOTAL & 60 & 63 & 123 & 63 \\
\hline
\end{tabular}

\section{Comentarios:}

Los molares son arrizodontos y con cemento en los ángulos entrantes. La morfología del $\mathrm{M}_{1}$ en vista oclusal es muy constante en todos los ejemplares: consta del lóbulo posterior, cuatro triángulos cerrados, T5 ampliamente confluyente por un amplio y alargado cuello con la cúspide anterior en la que también confluye el incipiente $\mathrm{T} 7$ que es mucho más pequeño que los demás triángulos linguales; no hay T6. Esta morfología corresponde al morfotipo "raticepoide" característico de Microtus oeconomus (= Microtus ratticeps (KEYSERLING \& BLASIUS, 1841) (Chaline, 1972).

Actualmente la especie vive en regiones septentrionales euroasiáticas: de forma casi continua desde el norte de Escandinavia, noreste de Alemania, 
Polonia, países bálticos, Bielorrusia, Ucrania, norte de Kazakastan, región del Transbaikal, por todo el centro y norte de Rusia, Siberia, noreste de China y norte de Mongolia, península de Kamchatka y borde del mar de Bering, y Alaska en norte América, y en algunas poblaciones europeas aisladas en el sur de Noruega, centro de Suecia, costa báltica de Finlandia, este de Austria, sudoeste de Eslovaquia, oeste de Hungría y Holanda (Mitchell-Jones et al., 1999; Shenbrot \& Krasnov, 2005; Wilson \& Reeder, 2005). M. oeconomus vive preferentemente en zonas con gran cobertura vegetal húmeda, en sustratos saturados como orillas de playas, lagos, ríos y arroyos, pantanos, turberas y prados húmedos, aunque en invierno emigran a zonas más secas de praderas herbáceas (Mitchell-Jones et al., 1999).

Durante el Pleistoceno Superior tuvo una distribución euroasiática muy amplia en la mayor parte de Europa, Rusia y Ucrania, en muchos países y zonas en los que no existe actualmente (como España, Francia, Italia, Alemania, Gran Bretaña) (Kowalski, 2001), por lo que su registro fósil documenta que la especie ha sufrido actualmente una reducción en su distribución geográfica respecto a dicho periodo.

M. oeconomus se registra durante el Pleistoceno Superior en numerosos yacimientos de la mitad norte de la península ibérica, la mayoría de ellos en la Región Cantábrica, (Sesé, 1994 y 2005; Sesé y Sevilla, 1996; Arribas, 2004; López García, 2008), unos pocos en los Pirineos orientales (López García, 2008), y algunos en el Sistema Central que constituye la zona más meridional de Europa en la que se registra la especie durante dicho periodo (Sevilla et al., 2011). Aunque generalmente esta especie está representada en la mayoría de los yacimientos por pocos restos, en algunos yacimientos del norte peninsular como Amalda, Erralla y Ekain es muy abundante (Sesé, 2005). Es muy posible, tal como sugieren Sevilla et al. (2011) que durante el último periodo glacial las montañas del norte y centro peninsular reunieran las condiciones óptimas para la expansión de dicha especie. En la península ibérica persistió en el Holoceno, aunque con escasos hallazgos, hasta su extinción en tiempos históricos. El último registro conocido de esta especie antes de su desaparición es en un nivel tardorromano del yacimiento de Amalda (Pemán 1990).

Dada la distribución periártica actual casi continua de la especie, a las fluctuaciones de sus poblaciones se les ha dado una interpretación paleoclimática, de forma que serían más abundantes en los periodos relativamente más fríos del Pleistoceno Superior (Chaline, 1972; Pemán, 1985), como ocurre en algunos yacimientos en los que constituye la mitad de los restos de micromamíferos (Pemán, 1985). No obstante, se encuentra también en niveles con asociaciones faunísticas de climas más templados y se registra en la Península hasta tiempos históricos, como se ha dicho, por lo que su significado paleoambiental no hay que considerarlo basándose solo en su presencia en un yacimiento sino, en todo caso, en su abundancia relativa con respecto al conjunto de micromamíferos (Sesé, 2005). Dados los hábitats actuales de la especie, lo que parece evidente es que está claramente asociada, al menos durante una buena parte del año, a medios generalmente bastante húmedos con desarrollo de una cobertura vegetal que también requiere humedad, como se ha indicado anteriormente; un tipo de medio que parece estar más generalizado en regiones septentrionales de Eurasia y Norteamérica en donde se distribuye actualmente la especie de forma más continua. Este tipo de medio podría haberlo encontrado durante el Pleistoceno Superior en la península ibérica en los sistemas montañosos de la región Cantábrica, Pirineos orientales y Sistema Central, quedando sus poblaciones aisladas. Estos hechos sugieren que, la tendencia a la aridificación del clima que se observa en la península ibérica desde el final del Pleistoceno Superior (Sesé, 1994), podría haber dado lugar, avanzado el Holoceno, a la retracción y desaparición de este tipo de medios favorables a su desarrollo, lo que junto al aislamiento poblacional de la especie se convirtió en un callejón sin salida para la misma dando lugar finalmente a su extinción en la península. Mitchell-Jones et al. (1999) por otra parte señalan que esta especie entra en competición actualmente con $M$. arvalis y $M$. agrestis, dos especies que son muy frecuentes y generalmente abundantes en la mayoría de los yacimientos del norte peninsular, tal como sucede en el yacimiento de El Castillo.

Chionomys nivalis (MARTINS, 1842)

(Fig. 2: $r-t$ )

\section{Material por niveles:}

Hay 1 fr. de mandíbula der. con $\mathrm{M}_{1}-\mathrm{M}_{2}$ en el nivel $21 \mathrm{~b}$. 


\begin{tabular}{lcccc}
\multicolumn{5}{l}{ Número de $M_{1} y$ NMI por niveles: } \\
\hline NIVEL & $\mathrm{N}^{\circ} \mathrm{M}_{1}$ der. & $\mathrm{N}^{\circ} \mathrm{M}_{1}$ izq. & $\mathrm{N}^{\circ} \mathrm{M}_{1}$ Totales & $\mathrm{NMI}$ \\
\hline $18 \mathrm{~b}$ & 1 & ---- & 1 & 1 \\
$20 \mathrm{~b}$ & 1 & 3 & 4 & 3 \\
$21 \mathrm{a}$ & 1 & 2 & 3 & 2 \\
$21 \mathrm{~b}$ & 2 & 1 & 3 & 2 \\
TOTAL & 5 & 6 & 11 & 8
\end{tabular}

\section{Comentarios:}

Los molares son arrizodontos y con cemento en los ángulos entrantes. El esmalte es más grueso que en el género Microtus. La morfología del $\mathrm{M}_{1}$ en vista oclusal es la siguiente: consta del lóbulo posterior, cuatro triángulos cerrados, el T5 confluye por un cuello más o menos estrecho en la cúspide anterior que es de forma lanceolada o subtriangular en donde la base son los triángulos T6 y T7, que están muchos menos desarrollados que los demás triángulos y en algunos ejemplares solo ligeramente esbozados; es el morfotipo "nivaloide" característico de Chionomys nivalis (Chaline, 1972).

En la península ibérica $C$. nivalis se registra durante el Pleistoceno Superior y Holoceno en numerosos yacimientos de la mitad norte y sureste situados generalmente en sistemas montañosos (Sesé 1994 y 2005; Sesé y Sevilla, 1996; Arribas, 2004; López García, 2008; García Ibaibarriaga, 2015). Actualmente en la península ibérica se encuentra restringida a los principales sistemas montañosos o regiones rocosas (excepto en Portugal), en los Pirineos, casi toda la Cornisa Cantábrica, montañas gallegas, Sierra Cebollera, sierras de los Ancares, de la Demanda, Gredos, Guadarrama y Sierra Nevada (Palomo \& Gisbert, 2002). En el Pleistoceno Superior y Holoceno se registra en numerosos yacimientos de toda Europa situados en zonas montañosas (Kowalski, 2001). Después de la gran expansión que tuvo durante el Pleistoceno Superior, sus poblaciones quedaron reducidas a núcleos aislados y discontinuos en regiones montañosas de Europa y Asia (Palomo \& Gisbert, 2002; Mitchell-Jones et al., 1999). Actualmente se encuentra en los principales sistemas montañosos euroasiáticos desde el suroeste de Europa hasta el sureste de Asia: principales sistemas montañosos de la península ibérica como se ha dicho, Alpes, Apeninos, Montes Tatra, Rumania, Polonia, Cárpatos, Balcanes, Rumanía, Grecia, Turquía, Israel, Líbano, Siria, Irán,
Ucrania, Rusia y Cáucaso (Mitchell-Jones et al., 1999; Palomo \& Gisbert, 2002; Shenbrot \& Krasnov, 2005; Wilson \& Reeder, 2005).

Es una especie rupícola y heliófila, muy bien adaptada a las condiciones de vida de alta montaña que vive en laderas generalmente orientadas al sur, en zonas rocosas con pedreras estables y escasa cobertura vegetal (Blanco, 1998). Habita fundamentalmente en zonas rocosas de pedrizas y canchales en regiones de alta montaña, por encima de la línea de árboles, generalmente entre los $1.000 \mathrm{y} \operatorname{los} 4.700 \mathrm{~m}$ de altitud, aunque en algunas áreas se encuentra en altitudes mucho menores, generalmente en medios rocosos y más raramente en zonas arbustivas, herbáceas o de claros de bosques (Mitchell-Jones et al., 1999; Blanco, 1998; Palomo \& Gisbert, 2002). Según Kowalski (1992) esta especie está más asociada a medios abiertos pedregosos que a la alta montaña ya que en algunas zonas montañosas desciende hasta casi la altura del nivel del mar.

\section{Arvicola terrestris (LINNAEUS, 1758)}

(Fig. 2: u)

\section{Material por niveles:}

A continuación se da la relación de material craneal. En primer lugar el material dentario que está en mandíbulas y en el cuadro final el número de $\mathrm{M}_{1}$ der. e izq. en el que se basa el NMI.

Nivel 18b: 9 fr. man. der. con molares; 5 fr. man. der. sin molares; 2 fr. man. izq. con molares; 3 fr. man. izq. sin molares; 11 fr. craneal con max. sup. der. e izq. con algunos molares y parte del arco zigomático; 1 fr. max. sup. con algunos molares der. e izq.; 7 fr. max. sup. con algunos molares. Otro rango de Ms aislados, no $\mathrm{M}_{1}$ : Ms: 182; fr. Ms: 23.

- Nivel 18c: 2 fr. man. der. con $\mathrm{M}_{1} ; 1$ fr. man. izq. con $\mathrm{M}_{1}-\mathrm{M}_{2}$ y p.a. Otro rango de Ms aislados, no $\mathrm{M}_{1}$ : Ms: 18 .

- Nivel 20b: 4 fr. man. der. con molares; 2 fr. man. der. sin molares; 4 fr. man. izq. con $\mathrm{M}_{1}-\mathrm{M}_{2} ; 2$ fr. man. izq. sin molares. Otro rango de $\mathrm{Ms}$ aislados, no $\mathrm{M}_{1}$ : Ms: 187; fr. Ms: 4.

- Nivel 20c: 1 fr. man. der. con $\mathrm{M}_{2} ; 1$ fr. man. der. sin molares; 3 fr. man. izq. con molares; 
2 fr. man. izq. sin molares. Otro rango de Ms aislados, no $\mathrm{M}_{1}$ : Ms: 59; fr. Ms: 2.

- Nivel 20d: 1 fr. man. der. con alv. primer M y p.a.; 1 fr. man. izq. con $\mathrm{I}_{-} \mathrm{M}_{2}$. Otro rango de $\mathrm{Ms}$ aislados, no $\mathrm{M}_{1:}$ Ms: 44; fr. Ms: 5.

- Nivel 20e: 10 fr. man. der. con molares; 5 fr. man. der. sin molares; 15 fr. man. izq. con molares; 3 fr. man. izq. sin molares; 6 fr. max. sup. sin molares. Otro rango de Ms aislados, no $\mathrm{M}_{1}$ : Ms: 71; fr. Ms: 2

- Nivel 21a: 56 fr. man. der. con molares; 21 fr. man. der. sin molares; 58 fr. man. izq. con molares; 14 fr. man. izq. sin molares; 6 fr. man. sin molares lado indet.; 10 fr. max. sup. con molares; 51 fr. max. sup. sin molares. Otro rango de Ms aislados, no $\mathrm{M}_{1}$ : Ms: 1861; fr. Ms: 136.

- Nivel 21b: 18 fr. man. der con molares; 5 fr. man. der. sin molares; 27 fr. man. izq. con molares; 4 fr. man. izq., sin molares; 1 fr. max. sup. con $\mathrm{M}^{1}$; 14 fr. max. sup. sin molares. Otro rango de Ms aislados, no $\mathrm{M}_{1}$ : Ms: 602; fr. Ms: 89.

Número de $M_{1}$ y NMI por niveles:

\begin{tabular}{lcccc}
\hline NIVEL & $\mathrm{N}^{\circ} \mathrm{M}_{1}$ der. & $\mathrm{N}^{\circ} \mathrm{M}_{1}$ izq. & $\mathrm{N}^{\circ} \mathrm{M}_{1}$ Totales & $\mathrm{NMI}$ \\
\hline $18 \mathrm{~b}$ & 40 & 45 & 85 & 45 \\
$18 \mathrm{c}$ & 4 & 3 & 7 & 4 \\
$20 \mathrm{~b}$ & 41 & 45 & 86 & 45 \\
$20 \mathrm{c}$ & 11 & 14 & 25 & 14 \\
$20 \mathrm{~d}$ & 17 & 9 & 26 & 17 \\
$20 \mathrm{e}$ & 30 & 35 & 65 & 35 \\
$21 \mathrm{a}$ & 405 & 382 & 787 & 405 \\
$21 \mathrm{~b}$ & 123 & 117 & 240 & 123 \\
TOTAL & 671 & 650 & 1321 & 688 \\
\hline
\end{tabular}

\section{Comentarios:}

Los $\mathrm{M}_{1}$ presentan la morfología característica del género Arvicola: está constituido por el lóbulo posterior, tres triángulos cerrados, y triángulos T4 y T5 más o menos opuestos, confluyentes y abiertos a la cúspide anterior. En todos los $\mathrm{M}_{1}$ se observa que, tal como sucede en Arvicola terrestris (denominada también por algunos autores Arvicola amphibius LINNAEUS, 1758), el esmalte es más grueso en la parte mesial de los triángulos que en la distal, a diferencia de lo que ocurre en Arvicola sapidus MILLER, 1908 en los que el esmalte es más grueso en la parte distal de los triángulos que en la mesial, lo que permite diferenciar ambas especies. Otro carácter de diferenciación de ambas especies que señalan Chaline et al. (1974) es que en el $\mathrm{M}_{1}$ de A. terrestris la cúspide anterior es redondeada, como ocurre en el material de El Castillo, mientras que en A. sapidus es asimétrica con un saliente agudo en el borde lingual.

A. terrestris se registra en Europa desde la última parte del Pleistoceno Medio según Kolfschoten (1992) y es uno de los roedores más comunes en numerosos yacimientos euroasiáticos durante el Pleistoceno Superior según Kowalski (2001). Es también muy común en los yacimientos del norte de la península ibérica durante el Pleistoceno Superior (Sesé, 1994 y 2005; Sesé \& Sevilla, 1996; Arribas, 2004; López-García, 2008). La cita de la especie en un yacimiento del Pleistoceno Superior excepcionalmente tan meridional como el de la Cueva de Ambrosio (Sesé \& Soto, 1988), fuera de su distribución usual en el norte peninsular durante dicho periodo, es sorprendente ya que no hay más datos que corroboren su distribución en el sur peninsular. Por esta razón hemos revisado el material depositado en el MNCN sobre el que dichos autores (o.c.) realizaron dicha atribución y a continuación exponemos las siguientes observaciones: de $\operatorname{los} 7 \mathrm{M}_{1}$ disponibles, 3 están muy desgastados y no se aprecia diferenciación en el esmalte, mientras que en los 4 restantes con poco o ningún desgaste, se observa que el esmalte es ligeramente más grueso en la parte distal de los triángulos que en la parte mesial; además, en todos ejemplares la cúspide anterior es asimétrica con un saliente agudo en el borde lingual, tal como se aprecia en el $\mathrm{M}_{1}$ figurado por Sesé \& Soto (1988: Figura 43: 23), caracteres que son propios de A. sapidus, por lo que consideramos que se trata de esta última especie.

En Eurasia se encuentra actualmente distribuida desde el norte de la península ibérica hasta el rio Lena en Siberia y el norte de China, desde el mar Ártico y lago Baikal por el norte, y por el sur hasta el norte de Irán, Irak, norte de Israel, Cáucaso y Turquía, y por casi toda en Europa excepto en el oeste y sur de Francia, centro y sur de Grecia, Irlanda, región septentrional de Escandinavia e islas mediterráneas excepto Sicilia. (Mitchell-Jones et al., 1999; Wilson \& Reeder, 2005; Shenbrot \& Krasnov, 2005). En la 
península ibérica se encuentra actualmente en el norte desde el Pirineo leridano hasta las sierras montañosas de Lugo, Zamora y norte de Portugal, aunque las poblaciones del Pirineo, norte de Guipúzcoa y Región Cantábrica están aisladas entre sí (Palomo \& Gisbert, 2002). Es una especie hipogea que dados sus hábitos cavadores necesita suelos húmedos, blandos y relativamente profundos que son los que delimitan su distribución. En la península ibérica generalmente ocupa prados naturales desde áreas costeras hasta altitudes elevadas en torno a los $2.000 \mathrm{~m}$, pero nunca se encuentra en bosques densos. Sin embargo, A. terrestris en el resto de Eurasia, es una especie semiacuática que ocupa los mismos tipos de hábitats que $A$. sapidus en la península ibérica (Blanco, 1998; Mitchell-Jones et al., 1999; Palomo \& Gisbert, 2002).

Familia Muridae ILLIGER, 1811 Apodemus sylvaticus (LINNAEUS, 1758)Apodemus flavicollis (MELCHIOR, 1834) (Fig. 2: v-w)

Material por niveles:

\begin{tabular}{|c|c|c|}
\hline NIVEL & MATERIAL & NMI \\
\hline $18 \mathrm{~b}$ & $\begin{array}{l}2 \text { fr. man. der. con } I-M_{1}-M_{2} ; 1 \text { fr. man. izq. } \\
\text { con I y alvs. de } M s ; 3 \text { fr. man. izq. sin } \\
\text { dientes con alvs. de } M s ; 1 \text { fr. max. sup. } \\
\text { der. con } \mathrm{M}^{1}-\mathrm{M}^{2} ; 2 \text { fr. max. sup. izq. sin } \\
\text { dientes con alvs. de } M s \text { ( } 1 \text { con arranque } \\
\text { del arco zigomático) } ; 1 M_{1} \text { der.; } 2 \mathrm{M}_{1} \text { izq. }\end{array}$ & 4 \\
\hline $18 \mathrm{c}$ & $1 \mathrm{M}_{1}$ izq. & 1 \\
\hline $20 \mathrm{~b}$ & $2 \mathrm{M}_{1}$ der. & 2 \\
\hline $20 c$ & $\begin{array}{l}1 \text { fr. man. der. con } M_{1} ; 1 \text { fr. man. izq. con I, } \\
M_{1}-M_{2} ; 2 \text { fr. man. izq. con I y alvs. Ms; } 1 \\
\text { fr. max. sup. der. con } M^{1}-M^{2}-M^{3} \text {. }\end{array}$ & 3 \\
\hline $20 d$ & $2 \mathrm{M}_{1}$ der. & 2 \\
\hline $21 a$ & $\begin{array}{l}1 \text { fr. man der. con } M_{1}-M_{2} ; 1 \text { fr. man. der. con } \\
\text { I y alvs. de } M s ; 1 \text { fr. man. izq. con I y alv. } \\
\text { primer } M . ; 1 \text { fr. max. sup. con alvs. de } \\
\text { Ms; } 2 M_{1} \text { izq. }\end{array}$ & 2 \\
\hline $21 b$ & $\begin{array}{l}1 \text { fr. mand der. con alvs. de Ms; } 1 \text { fr. man. } \\
\text { izq. con } M_{1}-M_{2} ; 1 \text { fr. man. izq. con I y } \\
\text { alvs. de } M s ; 1 M_{1} \text { izq.; } 1 \mathrm{M}^{2} \text { der.; }\end{array}$ & 2 \\
\hline TOTAL & & 16 \\
\hline
\end{tabular}

\section{Comentarios:}

La especies de talla media del género Apodemus, Apodemus sylvaticus y Apodemus flavicollis, son difíciles de distinguir por la dentición, especialmente cuando se dispone de pocos ejemplares, por lo que en la literatura científica la identificación de estos múridos en muchos yacimientos se cita como Apodemus sylvaticus -Apodemus flavicollis, Apodemus sp., o como una u otra de las dos especies, muchas veces con "cf." o "aff." indicando el grado de seguridad de la determinación. Aunque A. flavicollis es de mayor tamaño que $A$. sylvaticus, la talla no es determinante para su distinción ya que se solapa la de ambas especies. Pasquier (1974) y Michaux \& Pasquier (1974), en poblaciones actuales numerosas, distinguen A. sylvaticus de A. flavicollis por tener la primera especie una relación $\mathrm{L} / \mathrm{A}$ de $\operatorname{los} \mathrm{M}_{2} \mathrm{y} \mathrm{M}^{2}$ con valores inferiores a los de las segunda; T9 en el $\mathrm{M}^{2}$ generalmente bien desarrollado mientras que en la segunda especie suele estar reducido, poco desarrollado o ausente (carácter también señalado por Nores, 1988); y en el $\mathrm{M}^{1}$ los tubérculos T4 y T7 generalmente unidos, mientas que en la segunda especie suelen estar separados. Pasquier (1974) y Michaux \& Pasquier (1974) reúnen los primeros caracteres de los índices L/A de los $\mathrm{M}_{2}$ y $\mathrm{M}^{2}$ y los porcentajes de reducción del T9 en $\mathrm{M}^{2}$ en sendos diagramas de dispersión en los que se observa la separación de ambas especies. En el material de El Castillo los valores de la relación L/A de los $3 \mathrm{M}_{2}$ que hay sin desgastar son respectivamente $1,06 \mathrm{~mm} ; 1,07 \mathrm{~mm}$ y $1,08 \mathrm{~mm}$ (valores que le aproximan a A. flavicollis); y en los $2 \mathrm{M}^{2}$ no desgastados son respectivamente $1,02 \mathrm{~mm}$ y $1,07 \mathrm{~mm}$ (el primer valor le aproxima a $A$. sylvaticus y el segundo a $A$. flavicollis respectivamente), según los datos para dichas especies de Pasquier (1974), Michaux \& Pasquier (1974) y López Martínez (1980). Los dos $\mathrm{M}^{2}$ de El Castillo que no han sufrido desgaste muestran un T9 desarrollado aunque es de menor tamaño que el T6, lo que le aproxima a A. sylvaticus. En los dos $\mathrm{M}^{1}$ de $\mathrm{El}$ Castillo, T4 y T7 están separados, como ocurre en A. flavicollis. Puesto que el material de El Castillo es muy escaso y parece presentar caracteres de una $\mathrm{y}$ otra especie, y puesto que los caracteres indicados para el $\mathrm{M}^{1}$ y $\mathrm{M}^{2}$ se miden en función de su representación porcentual en poblaciones numerosas en relación con los valores de los índices $\mathrm{L} / \mathrm{A}$ de $\operatorname{los} \mathrm{M}_{2} \mathrm{y}$ $\mathrm{M}^{2}$, no se puede determinar con seguridad la especie o incluso si están las dos especies en el yacimiento de El Castillo. 
El registro fósil de ambas especies en Europa comienza en el Villafranquiense (Kowalski, 2001). En la península ibérica ambas están en numerosos yacimientos del Pleistoceno y Holoceno (Sesé, 1994 y 2005; Sesé \& Sevilla, 1996; Arribas, 2004; López-García, 2008).

A. sylvaticus actualmente tiene una amplia distribución por Europa desde la península ibérica hasta el oeste de Rusia, sur de Escandinavia, Asia Menor, norte de África, islas mediterráneas, Irlanda, Gran Bretaña e Islandia (Mitchell-Jones et al., 1999; Palomo \& Gisbert, 2002). En la península ibérica es uno de los micromamíferos más ampliamente extendidos y abundantes (Palomo \& Gisbert, 2002). Aunque esta especie se encuentra actualmente en una gran variedad de hábitats, incluso en las condiciones de clima mediterráneo más áridas, vive preferentemente en áreas con una buena cobertura vegetal arbustiva o arbórea, en este último caso con preferencia por zonas marginales de bosque (Mitchell-Jones et al., 1999; Palomo \& Gisbert, 2002).

A. flavicollis tiene actualmente una distribución fundamentalmente centroeuropea desde el norte de la península ibérica, por Europa, sur de Noruega, Suecia, Finlandia y Gran Bretaña, hasta los Urales, Cáucaso, los Balcanes y Palestina. En la península ibérica solo se encuentra en tercio norte peninsular por toda la Cornisa Cantábrica hasta el norte de la Meseta (León, Burgos, la Rioja y Soria) y algunas poblaciones aisladas en los Pirineos centrales cuyo límite sur son el Montseny y sierras costeras catalanas (Palomo \& Gisbert, 2002). Es una especie típicamente forestal asociada a bosques húmedos de caducifolios o de galería de ríos y arroyos, aunque también se encuentra en zonas con una densa cobertura arbustiva o herbácea pero casi siempre arboladas (Blanco, 1998; Palomo \& Gisbert, 2002).

Orden Lagomorpha BRANDT, 1855

Leporidae FISCHER, 1817

Lepus sp. LINNAEUS, 1758

Fig. (3: a)

Material por niveles:

\begin{tabular}{llc}
\hline NIVEL & MATERIAL & NMI \\
\hline 20e & 1 P/M sup. & 1 \\
21a & 1 I $^{1}$ der.; 1 I $^{1}$ izq.; 1 P/M sup.; & 1 \\
21b & 1 P der.; 1 P/M inf.; 1 P/M sup.; $_{\text {TOTAL }}$ & 1 \\
\hline
\end{tabular}

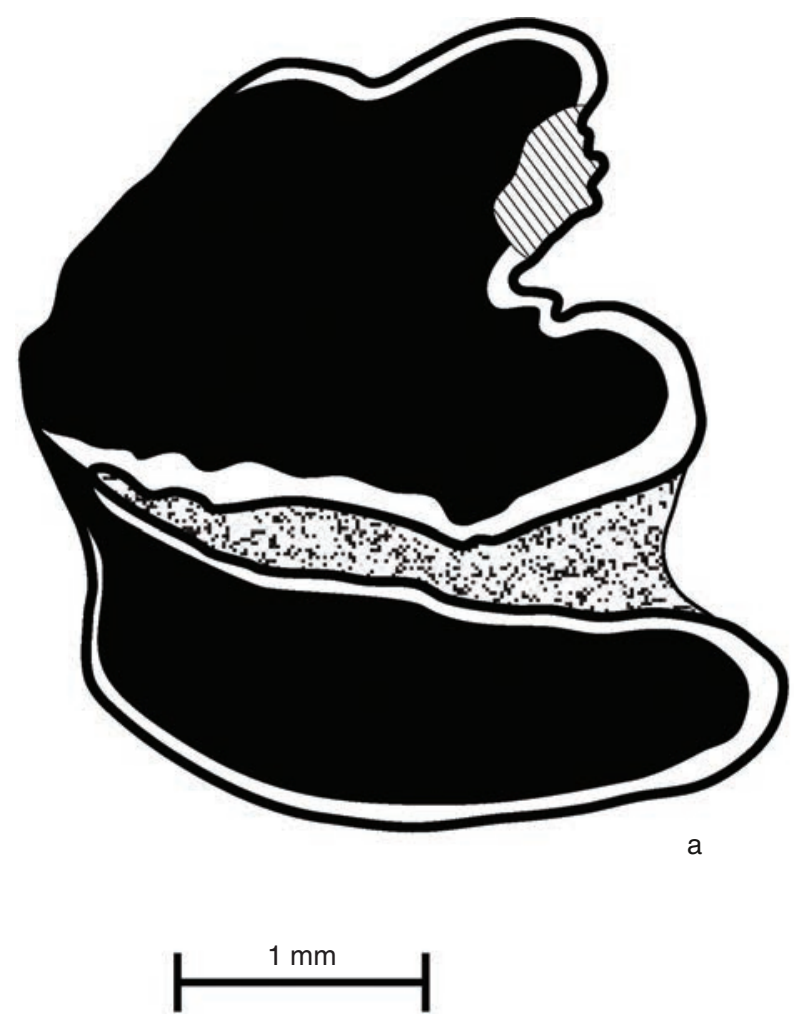

Fig. 3.-Dibujo de diente de lagomorfo del yacimiento de la cueva de El Castillo: Lepus sp: a) $\mathrm{P}_{3}$ der. (CST03; Nivel 21b; N 17.3; Caja 361).

\section{Comentarios:}

El $\mathrm{P}_{3}$, que es la pieza dentaria que presenta caracteres con valor diagnóstico que permiten distinguir taxones, en El Castillo presenta la morfología característica del género Lepus según López Martínez (1989): anterocónidos reducidos (en El Castillo, muy reducidos y desiguales); anterocónido lingual muy reducido y de borde lingual redondeado (en El Castillo apenas está esbozado); anterofléxido muy estrecho y poco profundo (en El Castillo es una ligera inflexión del esmalte entre ambos anterocónidos); sin fléxidos linguales, siendo la cara lingual redondeada (en El Castillo el perfil lingual no llega a ser del todo redondeado porque el diente ha sufrido desgaste en la parte lingual del trigónido); protofléxido con algunas irregulares en el esmalte; hipofléxido grueso y con paredes irregulares. Aunque los demás dientes no presentan rasgos característicos importantes, se pueden atribuir también a este taxón. Dada la escasez de material no se puede determinar 
la especie y por tanto tampoco el tipo de hábitat que podría frecuentar.

Como puede observarse, el material de lagomorfos es muy escaso en El Castillo (solo está representado en tres niveles, en los que el NMI es de uno y en total en el yacimiento el NMI es de 3, representando tan solo el $0,06 \%$ del total de micromamíferos), máxime si se tiene en cuenta la abundancia del resto de los micromamíferos, exceptuando los quirópteros y algunos insectívoros, en prácticamente todos los niveles. Esto no es excepcional ya que Altuna (1972) y Sesé (2005) señalan la escasez en general del registro de Lagomorfos (género Lepus y Oryctolagus cuniculus) en la Región Cantábrica con respecto al resto de la península ibérica durante el Pleistoceno Superior, especialmente de esta última especie. Aunque excepcionalmente hay yacimientos de cronologías más recientes que las de El Castillo, como es el yacimiento de Coímbre (Asturias), del final del Pleistoceno Superior, en el que esta última especie es muy abundante debido muy posiblemente a la acción cinegética humana (Yravedra et al., 2016; 2017 a y b; Sesé, 2017).

\section{Consideraciones tafonómicas}

En este apartado, para el recuento del material, en los arvicolinos se han tenido en cuenta los primeros molares inferiores, en múridos todos los molares que permiten su clasificación, en sorícidos y tálpidos las mandíbulas y maxilares superiores con molares, y en este último grupo también los molares aislados ya que son muchos los que durante los procesos de extracción del material se han podido desprender de sus respectivas mandíbulas y maxilares, muchas de las cuales aparecen sin dientes. No se han tenido en cuenta los quirópteros al no haber dientes, ni los lagomorfos al ser tan escaso el material.

Para las consideraciones tafonómicas se han tenido en cuenta los trabajos de Andrews (1990), Demirel et al. (2011) y Fernández-Jalvo et al. (2016). En este último se tiene en consideración no solo la vista lateral de los molares de arvicolinos y otros grupos, sino la vista oclusal de los mismos que es la que se utiliza en taxonomía para clasificarlos.

Según la clasificación de los distintos grados de digestión de Andrews (1990), Demirel et al. (2011) y Fernández-Jalvo et al. (2016) (sin digestión y digestión débil, moderada, fuerte y extrema), la gran mayoría de los molares de El Castillo (más de tres cuartas partes) no presentan ninguna señal de digestión, (entre el 77,11\% y el 95,07\% según los distintos niveles), aunque algunos dientes presentan señales de digestión, generalmente débil (entre el 3,2\% y el $15,15 \%)$, en mucha menor medida por orden decreciente una digestión moderada (entre el $0,72 \%$ y el $8,52 \%$ ) y fuerte (entre el $0,59 \%$ y el $3,46 \%$ ) respectivamente, y en la mayoría de los grupos la digestión en grado extremo se produce muy raramente (del $0,26 \%$ al $1,41 \%$ ) o está ausente, sobre todo en los arvicólidos (ver tabla 1 en la que se presentan el número y porcentaje de dientes por niveles del yacimiento según estos grados). En este sentido, entre los insectívoros (excepto el erizo en el que no hay señales de digestión en ninguno de los dientes) en los sorícidos y sobre todo en los tálpidos (generalmente Talpa europaea ya que Galemys pyrenaicus es muy escaso), sí que hay cierto porcentaje de dientes que muestran los tres últimos grados de digestión, ya que el primero (débil) no se puede reconocer (Fernández-Jalvo et al. (2016). En estos grupos cabe señalar que en algunos casos en una misma mandíbula o maxilar, puede presentar señales de digestión un solo diente y el resto no. En los dientes de arvicolinos hay también diferencias de grados de digestión y porcentaje según los grupos taxonómicos; la digestión es más frecuente en el género Microtus (aunque en su mayoría es débil) que en los demás géneros de este grupo. Así, en el género Arvicola la digestión es menos frecuente y de menor grado: de un total en el yacimiento de 1252 molares hay 1214 (97\%) que no han sufrido digestión, 29 (2,3\%) que presentan digestión débil, $8(0,63 \%)$ con digestión moderada, $1(0,07 \%)$ con digestión fuerte y ninguno con digestión extrema; y en los géneros Pliomys y Chionomys no se ha encontrado ningún molar con huellas de digestión. Esto evidentemente debe estar relacionado con el grosor del esmalte de los molares, mucho mayor en estos tres últimos géneros con respecto al género Microtus, que por tanto les proporciona una mayor resistencia frente a la acción digestiva de los predadores.

Según nuestras propias observaciones en arvicolinos, el grado de digestión moderada que se observa en dientes aislados, según la definición de la misma: esmalte removido a lo largo de la mitad 
Sesé, C.

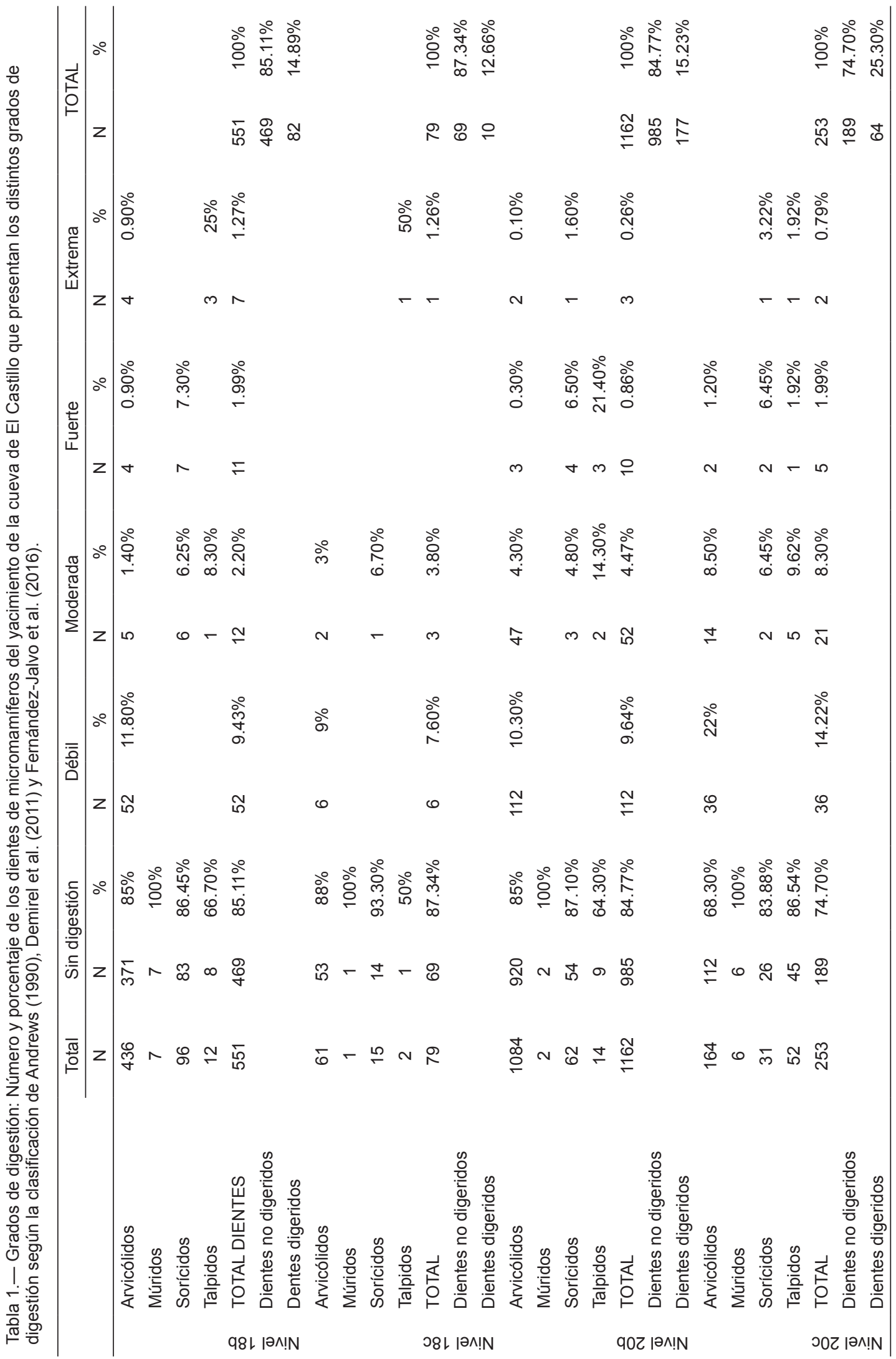




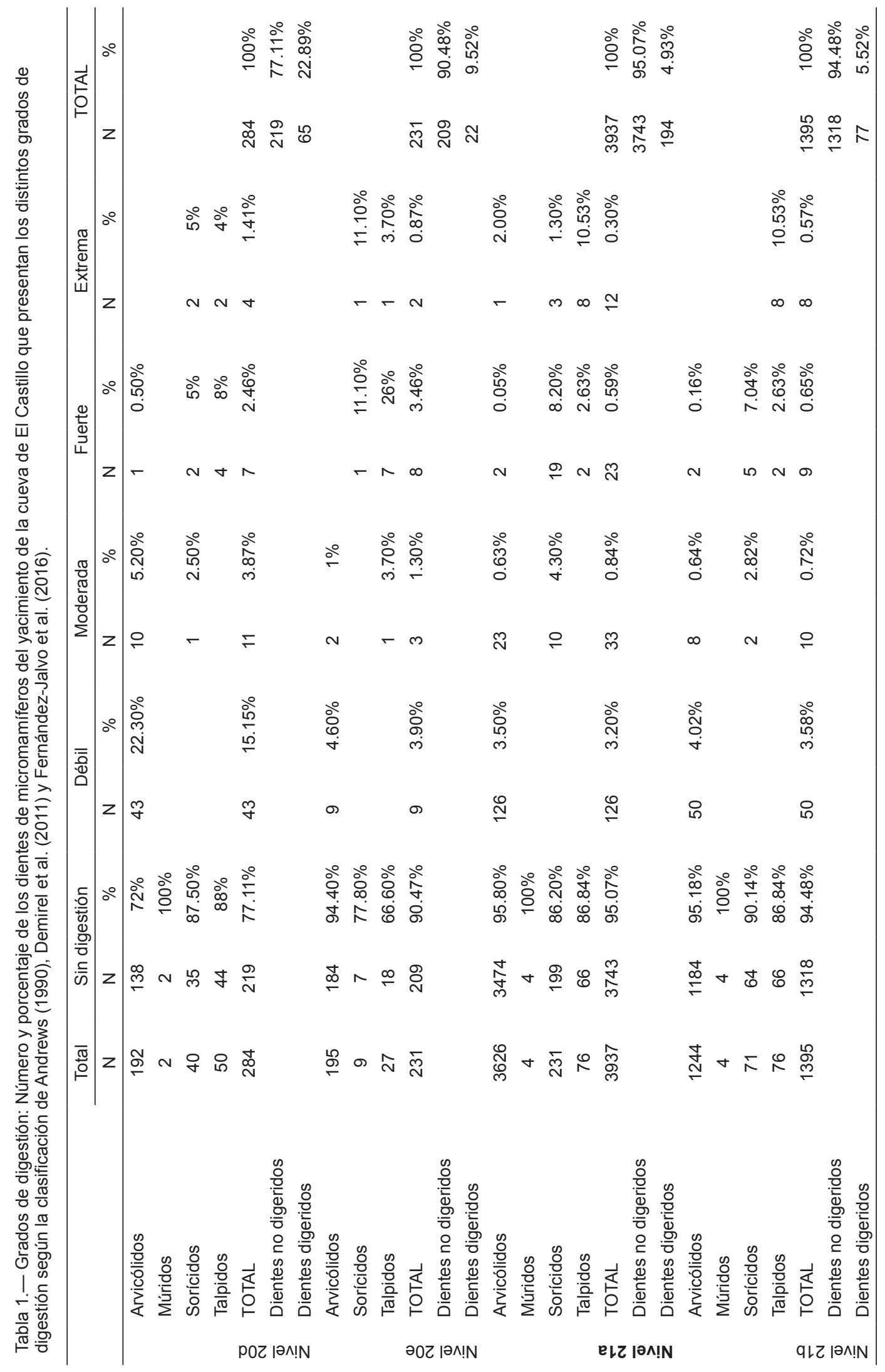


de la altura del diente en vista lateral (Andrews, 1990; Fernández-Jalvo et al. 2016), en algunos casos podría corresponder en nuestra opinión a un grado superior (fuerte, en el que la digestión afecta a lo largo de toda la altura de los ángulos salientes del diente) ya que, la línea virtual casi horizontal y paralela a la superficie oclusal del diente en la que parece detenerse bruscamente el desgaste hacia la tercera parte o la mitad del diente, podría corresponder a la protección que le brinda al resto del molar el hueso mandibular o maxilar antes de desprenderse el molar de la mandíbula o maxilar correspondiente por la manipulación del material en su fase de extracción, ya que en muchas muestras se han encontrado muchas mandíbulas sin dientes y molares aislados que podrían corresponderse originalmente. Esto es algo que se aprecia también en los primeros molares que están en sus respectivas mandíbulas y que presentan desgate moderado (o de un grado superior: fuerte): el desgaste solo afecta a la parte expuesta del diente (sea la tercera parte o la mitad del diente) y se observa que no afecta al resto del diente que está en el interior de la mandíbula. Es por ello también que Andrews (1990) distingue entre porcentaje de digestión de molares in situ en mandíbulas y maxilares, y molares aislados, que pueden presentar un grado de digestión diferente y en algunos casos mayor por lo dicho anteriormente. Solo que habría que tener en cuenta que entre los molares que se encuentran aislados, hay algunos que podrían haber estado originalmente en su mandíbula y/o maxilar y haberse desprendido posteriormente de forma accidental por la manipulación del material, y cuyo grado de desgaste podría no ser siempre moderado sino de un grado mayor, fuerte o incluso extremo. En los molares de los múridos (muy escasos por otra parte) no se han observado señales de digestión. En todos los niveles, el mayor porcentaje de digestión en general en todos los grupos taxonómicos corresponde al grado débil, siguiendo por orden decreciente la moderada y fuerte, y por último la extrema es escasa o ausente según grupos taxonómicos y niveles.

Respecto a las categorías establecidas por Andrews (1990), Demirel et al. (2011) y Fernández-Jalvo et al. (2016), según los porcentajes de digestión de los molares en los diferentes niveles, los molares de El Castillo se podrían clasificar de forma tentativa de la siguiente manera: los niveles 18b (14,89\%),
$18 \mathrm{c}(12,66 \%), 20 \mathrm{~b}(15,23 \%), 20 \mathrm{c}(25,3 \%)$ y $20 \mathrm{~d}$ $(22,89 \%)$ podrían corresponder a la categoría 3 (fuerte de bajo nivel); mientras que los niveles 20e $(9,52 \%), 21 \mathrm{a}(4,93 \%)$ y $21 \mathrm{~b}(5,52 \%)$ podrían corresponder a las categorías 1 ó 2 (digestión ausente o mínima y débil o moderada, respectivamente).

En los incisivos de arvicolinos que se conservan en sus respectivas mandíbulas ( 15 en el nivel $18 b$, 4 en el 18c, 28 en el 20b, 5 en el 20c, 13 en el 20d, 32 en el 20e, 154 en el 21a y 44 en el 21b) no se han observado señales claras de digestión, lo que les asimilarían también a las categorías más bajas de las 5 mencionadas anteriormente. Tampoco se ha observado ninguna señal de digestión en los incisivos conservados en las mandíbulas de los sorícidos o aislados. No obstante, de los numerosos incisivos de roedores aislados, aunque la mayoría de ellos no muestran signos de digestión, en algunos se ha observado el esmalte removido de la punta, es decir, que corresponderían a la categoría de digestión débil.

En cuanto al estado del material ya se ha dicho en los correspondientes apartados que hay numerosas mandíbulas de todos los grupos que conservan parte o incluso todos los dientes y muchos fragmentos de maxilares con dientes y sin dientes e incluso de cráneos, y que por tanto el estado de conservación del material es bastante bueno. Esto es especialmente frecuente en los sorícidos, muchas de cuyas mandíbulas conservan algunos o todos los dientes, y la rama ascendente y cóndilo articular completos. Es de hacer notar también la gran abundancia de mandíbulas y maxilares de arvicolinos; además de los referenciados en sus respectivos taxones, hay muchos más que no se han podido asignar a ninguna especie del género Microtus por no conservar el $\mathrm{M}_{1}$, en un número muy elevado en el conjunto total de niveles: 61 fragmentos de mandíbulas con dientes, 778 fragmentos de mandíbulas sin dientes, 110 fragmentos de maxilares con molares y 598 fragmentos de maxilares sin molares, así como un número muy elevado de molares aislados de rango distinto al $\mathrm{M}_{1}$, (la mayoría de los cuales podrían pertenecer originalmente a estos restos mandibulares y maxilares, y haberse desprendido posteriormente en los procesos de recuperación del material): 13.517 molares enteros y 804 fragmentos de molares. Con respecto al grado de rotura de mandíbulas y maxilares propuesto por Andrews (1990) de menos rotura 
(A y B) a extrema (E), la mayoría de las mandíbulas de sorícidos que han podido ser clasificados taxonómicamente (exceptuando por tanto los determinados como Soricidae indet.) corresponde a las categorías A, B y C, y en mucha menor medida a las D y E. Hay también muchas mandíbulas de arvicolinos que conservan los dientes, generalmente el primero o los dos primeros molares, y más raramente los tres ya que la parte posterior de la mandíbula parece romperse fácilmente durante los procesos de extracción del material. En este sentido cabe señalar que generalmente en las mandíbulas de arvicolinos que conservan los tres molares, estos suelen estar recubiertos por sedimento muy compactado. También hay algunos maxilares y partes de cráneos bastante bien conservados, al menos dos de arvicolinos y sobre todo cuatro de sorícidos bastante completos. Las mandíbulas de arvicolinos y tálpidos corresponden generalmente a las categorías de rotura $\mathrm{C}$ y $\mathrm{D}, \mathrm{y}$ en menor medida a la $\mathrm{E}$, pero en la mayoría de estos restos es evidente la rotura reciente por la manipulación del material en los procesos de su extracción. Cabe señalar también el buen estado de los dientes aislados, que en su gran mayoría aparecen enteros, y los fragmentados parecen serlo por los propios procesos de manipulación del material.

De los predadores propuestos por Andrews (1990), Demirel et al. (2011) y Fernández-Jalvo et al. (2016) para las distintas categorías de digestión, en los niveles de El Castillo tentativamente podrían ser las siguientes aves: posiblemente Bubo bubo (búho real) en los niveles $18 \mathrm{~b}, 18 \mathrm{c}$ y $20 \mathrm{~b}$ (con porcentajes de digestión entre 12,66 y 15,23\%), Strix aluco (cárabo común) en los niveles 20c y 20d (con porcentajes de digestión respectivamente de $25,3 \%$ y $22,89 \%$ ), y Asio otus (búho chico) en los niveles 20e, 21a y 21b (con porcentajes de digestión entre 4,93\% y 9,52\%). El búho real es un ave de tamaño grande y oportunista, que caza en una extensa área tanto en zonas boscosas como abiertas próximas al agua, que suele proporcionar una diversidad de especies entre $13 \mathrm{y}$ 20, aunque cuando abundan los arvicolinos llegan a constituir entre el $30 \%$ y el $80 \%$ de sus presas. El cárabo común es una especie de tamaño medio y oportunista que caza en zonas boscosas y herbáceas, que proporciona una variedad de especies entre $8 \mathrm{y}$ 16 , aunque el roedor dominante en su territorio de caza suele ser su presa más común. El búho chico es una ave de tamaño medio que suele cazar en una extensa área generalmente en medios abiertos, que proporciona entre 10 y 12 especies, y que tiene preferencia por arvicolinos como Microtus arvalis, Microtus agrestis y Terricola (Andrews, 1990; Fernández-Jalvo et al., 2016).

En cuanto al tipo de predadores propuestos por Andrews (1990), Demirel et al. (2011) y Fernández-Jalvo et al. (2016) para la categoría 2, tanto la de digestión débil, Nyctea scandica o búho nival, una especie de las regiones frías de Eurasia (Escandinavia, Asia) y Norte América, como las de digestión moderada, Bubo africanus o búho manchado, de Oriente Medio y África, y Strix nebulosa o cárabo lapón, de Asia y Norte América, cabe decir que ninguna de estas aves se distribuyen en el sur de Europa y que por lo tanto no hay actualmente aves propuestas para las faunas actuales y pleistocenas de España y en general del sur de Europa que presenten este tipo de digestión, lo que imposibilita la identificación del tipo de predador de esta categoría en esta región.

Según todas estas indicaciones, la fauna de micromamíferos recuperada en los distintos niveles y cronologías del yacimiento de El Castillo podría ser bastante representativa tanto en composición como en abundancia de una extensa área del entorno del yacimiento en los momentos de formación de los mismos.

En el estudio realizado por Sanchiz \& Lobo (2006) sobre la herpetofauna de los niveles superiores auriñacienses de El Castillo (16 a 19 sup.), de los que en el presente trabajo solo tenemos material de micromamíferos de los niveles $18 \mathrm{~b}$ y $18 \mathrm{c}$, deducen tafonómicamente que los restos proceden también de egagrópilas de aves rapaces nocturnas, posiblemente de Tyto alba (lechuza), un ave que está dentro de la categoría 1 anteriormente mencionada (Andrews, 1990; Demirel et al.. 2011; Fernández-Jalvo et al., 2016) con digestión ausente o mínima.

\section{Interpretación paleoambiental}

Con respecto a las inferencias paleoambientales, por sus preferencias ecológicas, los micromamíferos identificados en El Castillo se pueden distribuir en los siguientes biotopos: 
- Bosque y termófilo: Apodemus.

- Bosque, bordes de bosques y/o zonas abiertas arbustivas: Erinaceus europaeus

- Bosque y/o pradera húmeda: Sorex coronatus, Sorex minutus y Talpa europaea (hipogea).

- Alpino ripícola: Galemys pyrenaicus.

- Ripícola: Neomys fodiens.

- Pradera húmeda y/o zonas encharcadas o pantanosas: Microtus oeconomus.

- Pradera húmeda: Arvicola terrestris (hipogea) y Microtus lusitanicus

- Pradera húmeda y/o seca: Microtus agrestis y Microtus arvalis

- Pradera seca: Crocidura russula.

- Alpino rupícola heliófila: Chionomys nivalis.

Se han dejado fuera de este estudio Pliomys lenki, un taxón extinguido sin representantes actuales, y los quirópteros y Lepus sp. por su indeterminación taxonómica y su escasez. En cuanto a los sorícidos, como ya se ha dicho anteriormente son más abundantes que lo indicado por los taxones identificados: Crocidura russula, Sorex coronatus (la especie más abundante en todos los niveles del yacimiento), Sorex minutus y Neomys fodiens, ya que hay muchos restos atribuidos a Soricidae indet. (1,77\% en el conjunto de niveles del yacimiento). Estos restos, son de una talla que podría ser similar a Crocidura russula o a Sorex coronatus que como se ha indicado es el sorícido más abundante.

A la vista de los hábitats de los diferentes taxones indicados anteriormente y de su abundancia relativa (tabla 2 y figura 4) se pueden realizar las siguientes observaciones: Solo hay un taxón que se puede considerar en general forestal y termófilo: Apodemus; a pesar de que se registra en prácticamente todos los niveles, excepto el 20e, es muy escaso en todos ellos, variando su abundancia entre $0,23 \%$ y el $1,75 \%$. A pesar de la riqueza en restos de micromamíferos y la diversidad de especies en el yacimiento de El Castillo, faltan otras especies termófilas y/o indicadoras de bosque como Glis glis, Clethrionomys glareolus y Sciurus vulgaris (taxones ausentes también en el estudio realizado anteriormente en el yacimiento por Sánchez, 1983). Erinaceus europaeus que puede habitar en bosques, borde de bosques y zonas abiertas arbustivas es también muy escaso (entre el $0,04 \%$ y el $0,32 \%$ ) y se encuentra solo en los tres niveles más inferiores. Otras especies que pueden habitar en bosques y praderas húmedas son Sorex coronatus y Talpa europaea (hipogea) presentes en todos los niveles (con una representación total en el yacimiento de $6,88 \%$ y $20,17 \%$ ) y Sorex minutus en algunos niveles y muy escasa, con un porcentaje total del $0,17 \%$. El resto de los taxones son indicadores claramente de espacios abiertos: ripícolas, muy escasas y no en todos los niveles: Galemys pyrenaicus $(0,07 \%)$ y Neomys fodiens $(0,4 \%)$; praderas muy húmedas o zonas pantanosas: Microtus oeconomus, no en todos los niveles y con un porcentaje total del 1,16\%; praderas húmedas: Arvicola terrestris (hipogea), en todos los niveles y con un porcentaje del $12,66 \%$ y Microtus lusitanicus, en todos los niveles y con un porcentaje del 7,32\%; praderas húmedas o secas: Microtus agrestis y Microtus arvalis en todos los niveles: son las especies generalmente más abundantes en casi todos los niveles con un porcentaje total del 47,23\%; praderas secas solo representadas por Crocidura russula en algunos niveles en los que es muy escasa, con un porcentaje total del $0,15 \%$; y finalmente Chionomys nivalis, una especie rupícola y heliófila que está en algunos niveles escasamente representada con un porcentaje total del $0,15 \%$. Esta última especie y Galemys pyrenaicus son dos especies alpinas. Todas las especies mencionadas, excepto Chionomys nivalis, requieren por lo general una buena cobertura vegetal a nivel del suelo. Es decir que la fauna en su conjunto parece indicar un medio predominantemente abierto, por lo general de praderas húmedas (y en mucha menor medida praderas secas) con una buena cobertura vegetal, en el que habría también algunas zonas arboladas o boscosas, y algún curso de agua. Las asociaciones del conjunto de niveles 20 y 21 parecen indicar medios más húmedos que el conjunto de niveles superiores (18b y 18c), por la mayor abundancia relativa de Talpa europaea y de arvicolinos en general (en este sentido Microtus oeconomus está algo mejor representada en el conjunto de niveles 21 que en el 18). En cuanto a la temperatura, el único indicador termófilo (el género Apodemus) es muy escaso como ya se ha dicho $(0,29 \%$ en el conjunto de niveles del yacimiento), y el género Crocidura que habita generalmente en climas templados, es también muy escaso $(0,15 \%$ en el conjunto de niveles del yacimiento). En este sentido, el clima podría ser algo menos templado que en otros 


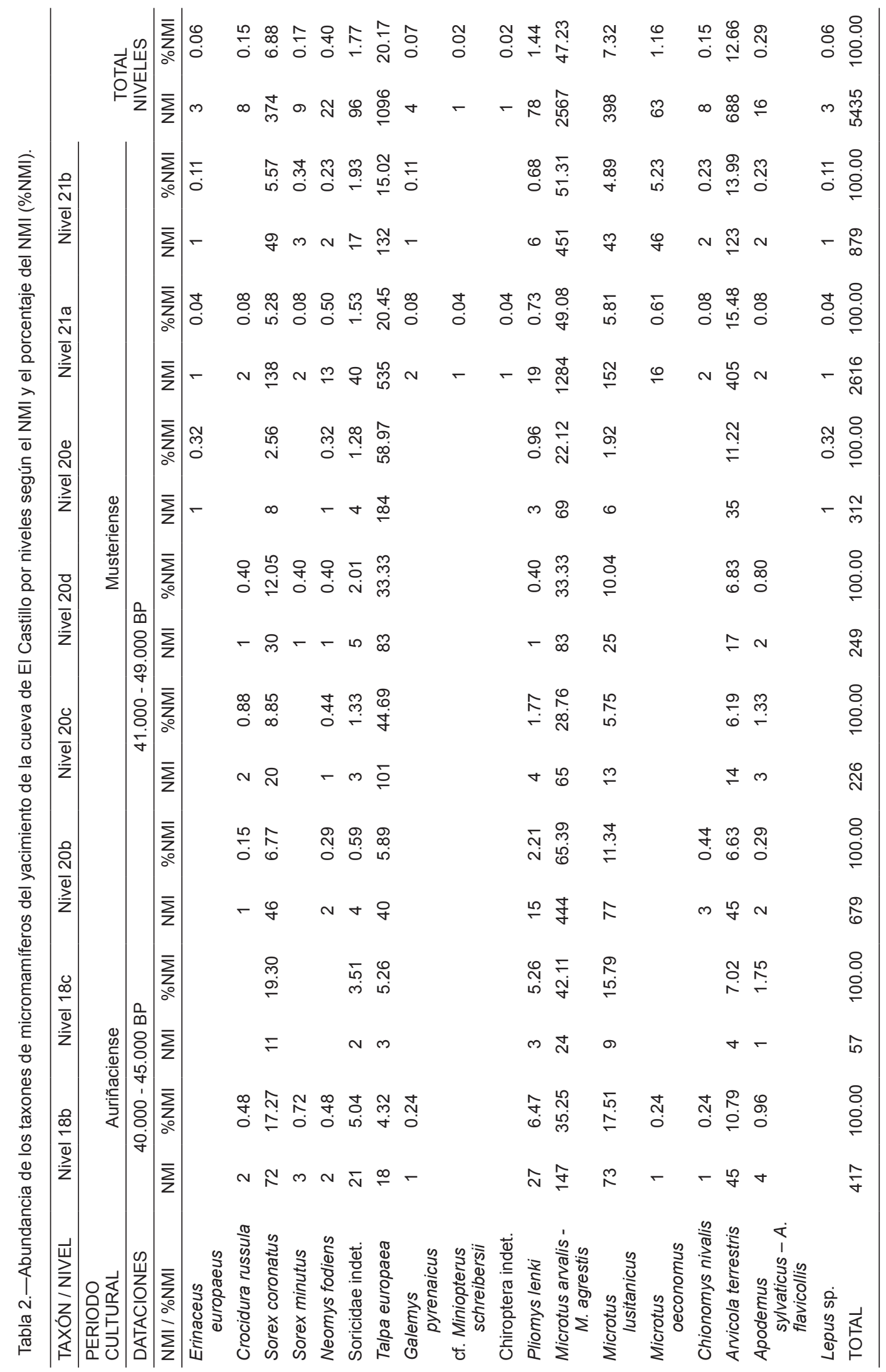




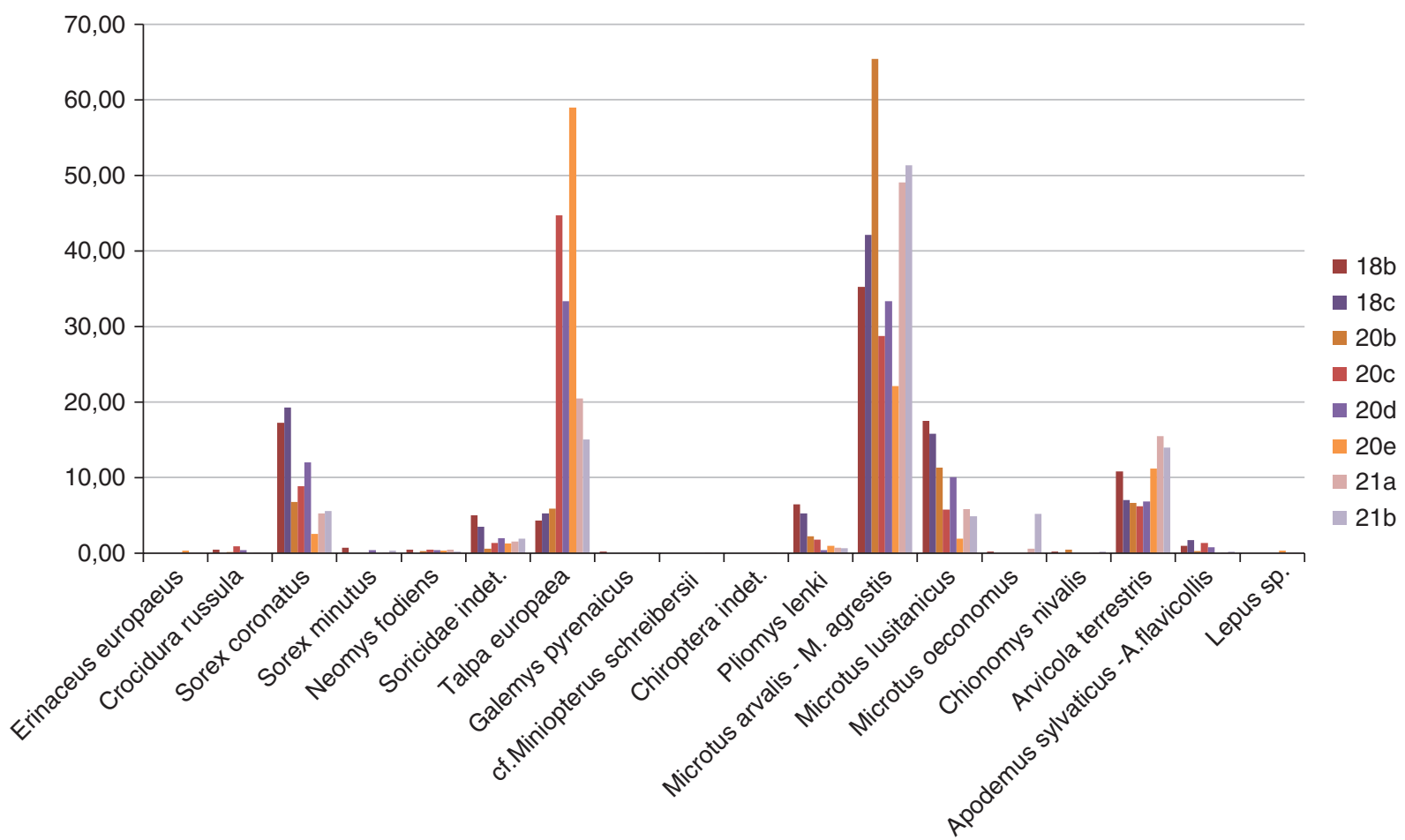

Fig. 4.-Representación gráfica de la abundancia de los taxones de micromamíferos del yacimiento de la cueva de El Castillo por niveles según el NMI y el porcentaje del NMI (\%NMI).

periodos del Pleistoceno superior y que actualmente en la zona, pero hay que señalar que no hay ningún indicador de clima frío o riguroso en ningún nivel.

\section{Conclusiones}

Se realiza en este trabajo el estudio detallado de los micromamíferos del yacimiento de la cueva de El Castillo, que es uno de los más importantes registros del Paleolítico medio y superior de la península ibérica y de Europa en general (Bernaldo de Quirós et al., 2014). La asociación de micromamíferos identificada es la siguiente: Erinaceus europaeus, Crocidura russula, Sorex coronatus, Sorex minutus, Neomys fodiens, Talpa europaea, Galemys pyrenaicus, cf. Miniopterus schreibersii, Chiroptera indet., Pliomys lenki, Microtus arvalis - Microtus agrestis, Microtus lusitanicus, Microtus oeconomus, Chionomys nivalis, Arvicola terrestris, Apodemus sylvaticus - Apodemus flavicollis y Lepus sp. (ver tablas 2 y 3). Esta fauna se ha encontrado en los niveles $18 \mathrm{~b}$ y $18 \mathrm{c}$ (de la unidad 18), $20 \mathrm{~b}, 20 \mathrm{c}, 20 \mathrm{~d}$ y $20 \mathrm{e}$ (de la unidad 20 ) y 21 a y $21 \mathrm{~b}$ (de la unidad 21). Teniendo en cuenta que, aunque no se han podido separar las especies Microtus arvalis y Microtus agrestis y se denominan en conjunto, están presentes ambas en el yacimiento, y que sin embargo Apodemus sylvaticus - Apodemus flavicollis no es posible diferenciarlas y saber si está presente una sola o dos especies en el yacimiento, hay un total de al menos 18 especies: 7 del orden Eulipotyphla, 2 Chiroptera, 8 Rodentia y 1 Lagomorpha, con un total de 5435 de NMI. Con respecto a los micromamíferos del nivel 19, no incluidos en el estudio sistemático, ni en las tablas, ni en las conclusiones de este manuscrito, remitimos a la Adenda al final del mismo. En cuanto a los micromamíferos identificados en El Castillo anteriormente por Sánchez (1983), en el presente trabajo se mantienen las determinaciones de Arvicola terrestris, Microtus agrestis, Microtus arvalis, Microtus oeconomus, Microtus lusitanicus, Chionomys nivalis, Pliomys lenki, Apodemus sp., Talpa europaea, Galemys pyrenaicus, Sorex coronatus, Sorex minutus y Neomys fodiens, y se amplía la lista en cinco taxones más: Lepus sp., Erinaceus europaeus, Crocidura russula, cf. Miniopterus schreibersii y Chiroptera indet. 
Tabla 3.-Abundancia de los taxones de micromamíferos del yacimiento de la cueva de El Castillo por unidades según el NMI y el porcentaje del NMI (\%NMI)

\begin{tabular}{|c|c|c|c|c|c|c|c|c|}
\hline TAXÓN / UNIDAD & \multirow{2}{*}{\multicolumn{2}{|c|}{$\begin{array}{c}\text { Unidad } 18 \\
\text { Auriñaciense }\end{array}$}} & \multicolumn{2}{|c|}{ Unidad 20} & \multicolumn{2}{|c|}{ Unidad 21} & \multirow{3}{*}{\multicolumn{2}{|c|}{ TOTAL UNIDADES }} \\
\hline PERIODO CULTURAL & & & & Mus & ense & & & \\
\hline DATACIONES & \multicolumn{2}{|c|}{$40000-45000$} & \multicolumn{2}{|c|}{$41000-49000$} & \multirow[b]{2}{*}{ NMI } & \multirow[b]{2}{*}{$\% \mathrm{NMI}$} & & \\
\hline $\mathrm{NMI} / \% \mathrm{NMI}$ & NMI & $\% \mathrm{NMI}$ & NMI & $\% \mathrm{NMI}$ & & & NMI & $\% \mathrm{NMI}$ \\
\hline Erinaceus europaeus & & & 1 & 0.07 & 2 & 0.06 & 3 & 0.06 \\
\hline Crocidura russula & 2 & 0.42 & 4 & 0.27 & 2 & 0.06 & 8 & 0.15 \\
\hline Sorex coronatus & 83 & 17.51 & 104 & 7.09 & 187 & 5.35 & 374 & 6.88 \\
\hline Sorex minutus & 3 & 0.63 & 1 & 0.07 & 5 & 0.14 & 9 & 0.17 \\
\hline Neomys fodiens & 2 & 0.42 & 5 & 0.34 & 15 & 0.43 & 22 & 0.40 \\
\hline Soricidae indet. & 23 & 4.85 & 16 & 1.09 & 57 & 1.63 & 96 & 1.77 \\
\hline Talpa europaea & 21 & 4.43 & 408 & 27.83 & 667 & 19.08 & 1096 & 20.17 \\
\hline Galemys pyrenaicus & 1 & 0.21 & & & 3 & 0.09 & 4 & 0.07 \\
\hline cf. Miniopterus schreibersii & & & & & 1 & 0.03 & 1 & 0.02 \\
\hline Chiroptera indet. & & & & & 1 & 0.03 & 1 & 0.02 \\
\hline Pliomys lenki & 30 & 6.33 & 23 & 1.57 & 25 & 0.72 & 78 & 1.44 \\
\hline Microtus arvalis - $M$. agrestis & 171 & 36.08 & 661 & 45.09 & 1735 & 49.64 & 2567 & 47.23 \\
\hline Microtus lusitanicus & 82 & 17.30 & 121 & 8.25 & 195 & 5.58 & 398 & 7.32 \\
\hline Microtus oeconomus & 1 & 0.21 & & & 62 & 1.77 & 63 & 1.16 \\
\hline Chionomys nivalis & 1 & 0.21 & 3 & 0.20 & 4 & 0.11 & 8 & 0.15 \\
\hline Arvicola terrestris & 49 & 10.34 & 111 & 7.57 & 528 & 15.11 & 688 & 12.66 \\
\hline Apodemus sylvaticus - A. flavicollis & 5 & 1.05 & 7 & 0.48 & 4 & 0.11 & 16 & 0.29 \\
\hline Lepus sp. & & & 1 & 0.07 & 2 & 0.06 & 3 & 0.06 \\
\hline TOTAL & 474 & 100.00 & 1466 & 100.00 & 3495 & 100.00 & 5435 & 100.00 \\
\hline
\end{tabular}

No todos los niveles considerados en este trabajo están igualmente bien representados en cuanto a restos faunísticos dependiendo de la potencia estratigráfica de los diferentes niveles, y por tanto de las distintas cantidades de sedimento cribados, así como de la riqueza de cada uno de ellos. En este sentido, el menos representativo es el nivel $18 \mathrm{c}$ con un NMI de 57 , mientras que todos los demás se pueden considerar con una buena representación faunística ya que tienen desde un NMI de 226 para el nivel 20c hasta un NMI de 2616 para el nivel 21a.

La gran mayoría de estas especies están presentes en la fauna actual de Cantabria, excepto Pliomys lenki que se extinguió en el último tercio del Pleistoceno Superior, y Microtus oeconomus, que persistió en la península ibérica durante el Holoceno bien avanzado hasta su desaparición en tiempos históricos que es cuando tiene su último registro en niveles tardo romanos, y que actualmente está en regiones euroasiáticas más septentrionales. Erinaceus europaeus, Crocidura russula, Miniopterus schreibersii, Apodemus sylvaticus y el género Lepus se distribuyen por toda la península ibérica; Chionomys nivalis en los principales sistemas montañosos del sur, centro y norte peninsular; Sorex minutus, Galemys pyrenaicus y Microtus arvalis en la mitad norte peninsular; Microtus lusitanicus en el cuadrante noroccidental peninsular; y finalmente Sorex coronatus, Neomys fodiens, Talpa europaea, Microtus agrestis, Arvicola terrestris y Apodemus flavicollis en el tercio norte peninsular.

Se observa en las tablas 2 y 3 una gran continuidad de la gran mayoría de los taxones, especialmente los que son más abundantes, en todos los niveles desde el más antiguo $21 \mathrm{~b}$ al más reciente $18 \mathrm{~b}$. Tan solo cabe señalar las siguientes excepciones: Erinaceus europaeus, que es muy escaso, como suele ocurrir en los yacimientos en los que se registra, está representado solo por un NMI de 1 en los niveles más inferiores 20c, 21a y 21b; lo mismo sucede con Lepus sp. representado por un NMI de 1 en dichos niveles inferiores; los dos quirópteros, también con un NMI de 1 respectivamente, solo se encuentran en el nivel 21a. Otros taxones que son muy escasos como 
Galemys pyrenaicus, se registran tanto en niveles inferiores (21a y 21b) como superiores (nivel 18b); lo mismo puede decirse de Chionomys nivalis, presente en los niveles 21a, 21b, 20b y 18b. La mayor diversidad, con el total de 18 taxones diferentes, se encuentra en el nivel 21a que es también el más rico en restos de micromamíferos con un NMI de 2616.

Hay sin embargo algunas diferencias entre niveles en cuanto a la abundancia de los diferentes taxones, lo que puede estar relacionado con el tipo de predadores que podrían estar en el origen de las diferentes acumulaciones, tal como se ha dicho en el apartado anterior, y también con su abundancia relativa en el medio. Sin olvidar que no todos los niveles están igualmente bien representados ya que hay una gran diferencia entre por ejemplo el nivel 21a con un NMI de 2616 y el nivel 28c con un NMI de 57, aunque la mayoría de los demás niveles varían entre un NMI de algo más de 200 y 879 , lo que supone en general una buena representación faunística si se exceptúa el mencionado nivel $28 \mathrm{c}$ que a efectos de consideraciones faunísticas es el menos representativo.

Con respecto a la abundancia relativa de los diferentes taxones se pueden hacer las siguientes observaciones (tabla 2): Microtus arvalis - M. agrestis es el taxón más abundante en los niveles $18 \mathrm{~b}(35,5 \%)$, $18 \mathrm{c}(42,11 \%), 20 \mathrm{~b}(65,39 \%), 21 \mathrm{a}(49,08 \%)$ y $21 \mathrm{~b}$ $(51,31 \%)$; mientras que en el nivel $20 \mathrm{~d}(33,33)$ es igualmente abundante que Talpa europaea $(33,33 \%)$. Talpa europaea es el taxón más abundante en los niveles 20c (44,69\%) y 20e (58,97\%), siguiéndole en abundancia Microtus arvalis - M. agrestis $(28,76 \%$ en el 20c y $22,12 \%$ en el 20e). Aunque con gran diferencia con respecto a estos altos porcentajes, están por lo general bastante bien representados en todos los niveles Arvicola terrestris (variando entre un 6,19\% y un $15,48 \%$ ) y Sorex coronatus (variando entre un 2,56\% y un 19,30\%). Microtus lusitanicus, también presente en todos los niveles, en general parece ser relativamente más abundante en los niveles superiores: $18 \mathrm{~b}(17,51 \%), 18 \mathrm{c}(15,79 \%), 20 \mathrm{c}(5,75 \%), 20 \mathrm{~d}$ $(10,04 \%)$, que en los niveles inferiores $20 \mathrm{e}(1,92 \%)$, $21 \mathrm{a}(5,81 \%), 21 \mathrm{~b}(4,89 \%)$. Pliomys lenki se registra también en todos los niveles con porcentajes que varían entre el $0,40 \%$ y el $6,47 \%$; en general es relativamente más abundante en los niveles superiores que en los inferiores. Apodemus sylvaticus A. flavicollis se registra en todos los niveles pero en porcentajes muy bajos, entre el 0,23\% y el 1,75\%. Microtus oeconomus no es abundante en ningún nivel y no aparece en todos los niveles; parece ir por orden de abundancia decreciente desde los niveles más inferiores a los más superiores: $5,23 \%$ en el nivel $21 \mathrm{~b}, 0,61 \%$ en el nivel 21 a y $0,24 \%$ en el nivel 18b. Los demás taxones, que no están presentes en todos los niveles: Erinaceus europaeus, Crocidura russula, Sorex minutus, Neomys fodiens, Galemys pyrenaicus, cf. Miniopterus schreibersii, Chiroptera indet., Chionomys nivalis y Lepus sp., cuando aparecen es en porcentajes inferiores al 1\%. En general, en casi todos los niveles los arvicolinos, sumando la representación de todos ellos, Pliomys lenki, Microtus arvalis - M. agrestis, Microtus lusitanicus, Microtus oeconomus, Chionomys nivalis, Arvicola terrestris, son el grupo más abundante, excepto en los mencionados niveles 20c y $20 \mathrm{e}$ en los que Talpa europaea seguiría siendo el taxón más abundante. En cuanto a los sorícidos, si tenemos en cuenta que además de las especies identificadas taxonómicamente: Crocidura russula, Sorex coronatus, Sorex minutus y Neomys fodiens, hay en todos los niveles un cierto porcentaje (entre el $0,59 \%$ y el $5,04 \%$ ) de sorícidos indeterminados (Soricidae indet.), sería un grupo bastante bien representado en general, tanto a nivel de diversidad como a nivel de abundancia relativa, con respecto a otros grupos.

Ya se ha dicho en las consideraciones tafonómicas que el origen de las acumulaciones de restos en los diferentes niveles de El Castillo pueden ser egagrópilas de aves rapaces nocturnas que podrían ser diferentes en los distintos niveles: en los niveles $18 \mathrm{~b}, 18 \mathrm{c}$ y $20 \mathrm{~b}$ posiblemente el búho real, un ave que caza en medios boscosos y abiertos y que, aunque es oportunista, cuando abundan los arvicolinos llegan a constituir gran parte de sus presas; en los niveles 20 c y $20 \mathrm{~d}$ el cárabo común un ave que caza en zonas boscosas y abiertas de tipo herbáceo, también oportunista, aunque el roedor dominante suele ser su presa más común; y en los niveles 20e, 21a y $21 \mathrm{~b}$ el búho chico que suele cazar en medios abiertos y tiene preferencia por los pequeños arvicolinos del género Microtus. Por la composición de la fauna de los distintos niveles y el tipo de predador que podría estar en el origen, se puede deducir que en general las asociaciones faunísticas registradas pueden ser bastante representativas de las que podría haber 
habido en los momentos de depósito de los sedimentos de los distintos niveles, composición faunística que muestra en general una gran continuidad en el tiempo aunque con algunas variaciones en los porcentajes de los distintos taxones.

La relación de taxones de micromamíferos de la cueva de El Castillo se ha comparado con las de otros yacimientos de la Región Cantábrica de edades más o menos similares, como la cueva del Mirón (Cantabria) (Cuenca-Bescós et al. (2008), la cueva de Cobrante (Cantabria) (Sesé, 2009), la cueva de Covalejos (Cantabria) (Sesé, 2005, 2009 y en prensa) y la cueva de Amutxate (Navarra) (Sesé, 2014), aunque este último es más del interior que de la Región Cantábrica propiamente dicha (ver tabla 4). El Castillo es un yacimiento con una gran diversidad taxonómica, con hasta 18 taxones diferentes (contabilizando Microtus arvalis y Microtus agrestis como dos especies diferentes como sucede en casi todos los yacimientos en los que se describen en conjunto), frente a estos yacimientos de edades más o menos similares. Así, en orden decreciente de diversidad en la cueva de Covalejos hay 16 taxones, en Amutxate 15, en la cueva de Cobrante 12 y en la cueva de El Mirón 8. Prácticamente todos los taxones que se registran en El Castillo son comunes con los demás yacimientos excepto la presencia de Sorex minutus que sólo se cita en El Castillo, y la ausencia en este yacimiento de Glis glis y Oryctolagus cuniculus, presentes ambos sin embargo en la cueva de Amutxate (Sesé, 2014), un yacimiento situado no propiamente en la Región Cantábrica sino más al sur hacia el interior. Con esta excepción, destaca la ausencia de glíridos en los yacimientos mencionados de estas edades de la región Cantábrica, incluido El Castillo. Otros yacimientos de Cantabria en los que se registran micromamíferos, pero en niveles de edades del final del Pleistoceno Superior, más recientes por tanto que las de El Castillo, son El Juyo (Pokines, 1998), la Cueva de Cualventi (Sesé, 2016a), la Cueva del Linar (Sesé, 2016c) y la Cueva de las Aguas (Sesé, 2016d).

Con respecto a las inferencias paleoambientales y como se ha dicho anteriormente, la asociación de micromamíferos de El Castillo en conjunto parece que indica un medio predominantemente abierto, de praderas húmedas por lo general $\mathrm{y}$ en mucha menor medida de praderas secas, con buena cobertura vegetal, en el que también habría algunas áreas arboladas o boscosas, y algún curso de agua. Las asociaciones de micromamíferos del conjunto de niveles inferiores 20 y 21 parecen indicar medios más húmedos que el conjunto de niveles superiores, $18 \mathrm{~b}$ y $18 \mathrm{c}$. Esto estaría en consonancia con las deducciones de Sanchiz \& Lobo (2006) sobre la herpetofauna de los niveles auriñacienses superiores $(16,17,18$ y 19) acerca de un clima más seco que el actual. Por lo que respecta a la temperatura, los indicadores termófilos o de climas templados son escasos, por lo que el clima podría ser algo menos templado que en otros periodos del Pleistoceno superior y que actualmente en la zona, aunque hay que señalar que no hay ningún indicador de clima frío o riguroso en ningún nivel. Apoyaría esta última hipótesis el trabajo realizado por Sanchiz \& Lobo (2006) que por la herpetofauna del yacimiento deducen para los mencionados niveles superiores un clima más frío que el actual.

\section{Adenda}

Recientemente la autora de este trabajo ha tenido acceso a un material desconocido para ella procedente del nivel 19 de El Castillo de la campaña de excavación de 1994, que le fue entregado cuando este manuscrito ya estaba en prensa y que por lo tanto no está incluido en el texto. A continuación se da sucintamente la identificación de los micromamíferos de dicho nivel y también, entre paréntesis, el NMI y porcentaje del NMI respectivamente de cada taxón (teniendo en cuenta que el NMI total de micromamíferos resultante del nivel 19 es de 512): Sorex coronatus (28; 5,47\%), Sorex minutus (1; $0,20 \%)$, Neomys fodiens $(1 ; 0,20 \%)$, Soricidae indet. (4; 0,78\%), Talpa europaea (18; 3,52\%), Pliomys lenki $(8 ; 1,56 \%)$, Microtus arvalis - M. agrestis (345; 67,38\%), Microtus lusitanicus (46; 8,98\%), Microtus oeconomus (1; 0,20\%), Chionomys nivalis (4; 0,78\%), Arvicola terrestris (55;10,74\%), y Apodemus sylvaticus - A. flavicollis (1; 0,20\%). Destaca la abundancia de Microtus arvalis M. agrestis con las dos terceras partes del porcentaje del NMI total. La composición faunística es similar a la de los demás niveles de El Castillo. La abundancia porcentual relativa de los diferentes taxones se asemeja mucho a la del nivel 20b. 
Tabla 4.-Comparación de la asociación de micromamíferos del yacimiento de la cueva de El Castillo con las de otros yacimientos de edades similares de la región cantábrica: El Mirón (Cuenca et al., 2008), Cobrante (Sesé, 2009), Covalejos (Sesé 2005 y en prensa), Amutxate (Sesé, 2014).

\begin{tabular}{|c|c|c|c|c|c|c|}
\hline YACIMIENTO & \multicolumn{2}{|c|}{ Castillo } & El Mirón & Cobrante & Covalejos & Amutxate \\
\hline REGION & \multicolumn{2}{|c|}{ Cantabria } & Cantabria & Cantabria & Cantabria & Navarra \\
\hline PERIODO CULTURAL & Auriñaciense & Musteriense & Musteriense & Auriñaciense & & \\
\hline UNIDADES / NIVELES & U. 18 & Us. 20 y 21 & N. 130 & Nvs. 5 y 6 & N. J & N. 1 \\
\hline DATACIONES & $40000-45000$ & $>41000-49000$ & 41280 & $30480-33320$ & $38344 \pm 3560$ & $45000-65000$ \\
\hline \multicolumn{7}{|c|}{ TAXONES DE MICROMAMIFEROS } \\
\hline Erinaceus europaeus & $x$ & $x$ & & & $x$ & $x$ \\
\hline Crocidura russula & $x$ & $x$ & & & $x$ & \\
\hline $\begin{array}{l}\text { Sorex coronatus (X)/S. } \\
\quad \text { araneus }(+) / S \text {.gr. } \\
\quad \text { coronatus -araneus (gr.) }\end{array}$ & $x$ & $\mathrm{x}$ & gr. & + & + & + \\
\hline Sorex minutus & $x$ & $x$ & & & & \\
\hline Neomys fodiens & $x$ & $\mathrm{x}$ & $\mathrm{x}$ & $x$ & & \\
\hline Talpa europaea & $x$ & $x$ & $\mathrm{X}$ & $x$ & $x$ & $\mathrm{X}$ \\
\hline Galemys pyrenaicus & $x$ & $x$ & $x$ & & $x$ & $x$ \\
\hline Miniopterus schreibersii & & cf. & & & & $x$ \\
\hline Chiroptera indet. & & $x$ & & & $x$ & \\
\hline Glis glis & & & & & & $x$ \\
\hline Pliomys lenki & $x$ & $x$ & $x$ & $x$ & $x$ & $x$ \\
\hline $\begin{array}{l}\text { Microtus arvalis }-M \text {. agrestis } \\
\quad(\mathrm{X}) / M \text {. agrestis }(+)\end{array}$ & $x$ & $x$ & + & $x$ & $x$ & $x$ \\
\hline Microtus lusitanicus & $x$ & $x$ & $x$ & $x$ & $x$ & $x$ \\
\hline Microtus oeconomus & $x$ & $x$ & & $x$ & $x$ & \\
\hline Chionomys nivalis & $x$ & $x$ & & $X$ & $x$ & $x$ \\
\hline Arvicola terrestris & $x$ & $\mathrm{X}$ & $x$ & $x$ & $x$ & $X$ \\
\hline Cletrionomys glareolus & & & & & $x$ & $X$ \\
\hline $\begin{array}{l}\text { Apodemus sylvaticus - } A \text {. } \\
\text { flavicollis }\end{array}$ & $x$ & $x$ & & $x$ & $x$ & $x$ \\
\hline Lepus sp. & $x$ & $x$ & & $x$ & $x$ & \\
\hline Oryctolagus cuniculus & & & & & & $X$ \\
\hline
\end{tabular}

\section{AGRADECIMIENTOS}

Mi más sincero agradecimiento a Victoria Cabrera Valdés, cuya muerte a temprana edad en 2004 fue una gran pérdida para el mundo científico y personalmente para sus colegas y amigos por su gran calidad humana, y a Federico Bernaldo de Quirós, quienes me confiaron el material de micromamíferos de sus excavaciones en la cueva de El Castillo para su estudio, y a José Manuel Maíllo, que junto con ellos pertenece al equipo de investigación del yacimiento; ellos me han dado toda clase de facilidades para su estudio y toda la información necesaria. Mi agradecimiento también a Enrique Soto que amablemente ha puesto a punto los dibujos del material fósil y las láminas, a Yolanda Fernández-Jalvo por sus valiosas sugerencias en las consideraciones tafonómicas, al editor de la revista, José María Cebriá, por su amabilidad, y a los revisores, César Laplana y Javier Murelaga, por su valiosas sugerencias al manuscrito.

\section{Referencias}

Agustí, J.; Blain, H.-A.; Furió, M.; Marfà, R. De \& Santos-Cubedo, A. (2010). The early Pleistocene small vertebrate succession from the Orce region (Guadix-Baza Basin, SE Spain) and its bearing on the first human occupation of Europe. Quaternary International, 223-224: 162-169. https://doi. org/10.1016/j.quaint.2009.12.011

Agusti, J.; Santos-Cubedo, A.; Furió, M.; Marfà, R. De \& Blain, H. A. (2011). The late Neogene-early Quaternary small vertebrate succession from the Almenara-Casablanca karst complex (Castellón, Eastern Spain): Chronologic and paleoclimatic context. Quaternary International, 243: 183-191. https://doi. org/10.1016/j.quaint.2010.11.016

Altuna, J. (1972). Fauna de mamíferos de los yacimientos prehistóricos de Guipúzcoa. Con catálogo de los 
Mamíferos Cuaternarios del Cantábrico y del Pirineo Occidental. Munibe, 1-4: 464 pp.

Andrews, P. (1990). Owls, Caves and Fossils. The University of Chicago Press, $231 \mathrm{pp}$.

Arribas, O. (2004): Fauna y paisaje de los Pirineos en la Era Glaciar. Lynx. ed.: 540 pp.

Arsuaga, J. L.; Baquedano, B.; Pérez-González, A.; Sala, Ma T. N.; García, N.; Álvarez Lao, D.; Laplana, C.; Huguet, R.; Sevilla, P.; Maldonado, E.; Blain, H.-A.; Quam, R.; Ruiz Zapata, M ${ }^{\text {a }}$

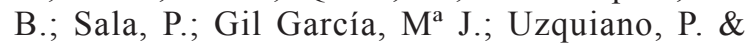
Pantoja, A. (2010). El yacimiento arqueopaleontológico del Pleistoceno Superior de la Cueva del Camino en el Calvero de la Higuera (Pinilla del Valle, Madrid). In: Actas de la $1^{\text {a }}$ Reunión de científicos sobre cubiles de hiena (y otros grandes carnívoros) en los yacimientos arqueológicos de la Península ibérica (Baquedano, E. \& Rosell, J., Dirs.). Zona Arqueológica, 13: 422-442.

Bartolomei. G.; Chaline, J.; Fejfar, O.; Jánossy, D.; Jeannet, M.; Koenigswald, W. v. \& Kowalski, K. (1975). Pliomys lenki (HELLER 1930) (Rodentia, Mammalia) en Europe. Acta Zoologica Cracoviensia, 10, 20: 393-467.

Bennàsar, M. L.; Cáceres, I.; Cuenca-Bescós, G. \& Rofes, J. (2009). Toothmarks on Micromammal Remains from Level TE9 of Sima del Elefante (Sierra de Atapuerca, Burgos, Spain). Journal of Taphonomy, 7 (2-3): 109-120.

Bernaldo de Quirós, F.; Castaños, P.; Maíllo-Fernández, J. M. \& Neira, A. (2012). El Gravetiense de la cueva de El Castillo. Nuevos datos. In: Pensando el Gravetiense: nuevos datos para la región cantábrica en su contexto peninsular y pirenaico. Ministerio de Educación, Cultura y Deporte: 264-275

Bernaldo de Quirós, F.; Neira Campos, A. \& Maíllo Fernández, J. M. (2014). La Cueva de "El Castillo". In: Los cazadores recolectores del Pleistoceno y del Holoceno en Iberia y el estrecho de Gibraltar. Estado actual del conocimiento del registro arqueológico (Sala Ramos, R., Ed.). Universidad de Burgos Fundación Atapuerca, Burgos: 55-60.

Bernaldo de Quirós, F.; Castaños, P.; Maíllo-Fernández, J. M.; \& Neira, A. (2015) The Solutrean unit of El Castillo cave, Spain. In: Forgotten times and spaces: New perspectives in paleoanthropological, paleontological and archeological studies (Sazelova, S.; Novak, M. \& Mizerova, A., Eds.). 1st Edition. Brno: Institute of Archeology of the Czech Academy of Sciences; Masaryk University, 410-417.

Blanco, J. C. (1998). Mamíferos de España: I: Insectívoros, Quirópteros, Primates y Carnívoros de la península Ibérica, Baleares y Canarias; II: Cetáceos, Artiodáctilos, Roedores y Lagomorfos de las península Ibérica, Baleares y Canarias. Geoplaneta: 457 pp. y 383 pp.
Castells, Á. \& Mayo, M. (1993). Guía de los Mamíferos en libertad de España y Portugal. Ed. Pirámide, Madrid: 470 pp.

Chaline, J. (1970). Pliomys lenki, forme relique dans la Microfaune du Würm ancien de la Grotte de Lezetxiki (Guipúzcoa-Espagene). Munibe, 22 (1/2): 43-49.

Chaline, J. (1972). Les Rongeurs du Pléistocène Moyen et Supérieur de France. (Systématique, Biostratigraphie, Paléoclimatologie). Cahiers de Paleontologie, C.N.R.S.: 410 pp.

Chaline, J.; Baudvin, H.; Jammot, D. \& Saint Girons, M. C. (1974). Les proies des rapaces. Petits Mammifères et leur environnement. Doin Ed., Paris: 141 pp.

Cleef-Roders, J. T. van \& L. W. van den Hoek Ostende (2001). Dental morphology of Talpa europaea and Talpa occidentalis (Mammalia: Insectivora) with a discussion of fossil Talpa in the Pleistocene of Europe. Zoologische Mededelingen. Leiden, 75 (2): 51-68.

Cuenca-Bescós, G. \& García, N. (2007). Biostratigraphic succession of the Early and Middle Pleistocene mammal faunas of the Atapuerca cave sites (Burgos, Spain). In: Late Neogene and Quaternary biodiversity and evolution: Regional developments and interregional correlations (Kahlke, R. D.; Maul, L. C. \& Mazza, P. P. A., Eds.). II. Courier Forschunsginstitut Senckenberg, 259: 99-110.

Cuenca-Bescós, G.; Strauss, L. G.; González Morales, M. R. \& García Pimienta, J. C. (2008). Paleoclima y paisaje del final del cuaternario en Cantabria: Los Pequeños mamíferos de la cueva del Mirón (Ramales de la Victoria). Revista Española de Paleontología, 23 (1), 91-126.

Cuenca-Bescós, G.; Rofes, J.; López-García, J. M.; Blain, H. A.; De Marfà, R. J.; Galindo-Pellicena, M. A.; Bennàsar-Serra, M. L.; Melero-Rubio, M.; Arsuaga, J. K.; Bermúdez de Castro, J. M. \& Carbonell, E. (2010a). Biochronology of Spanish Quaternary small vertebrate faunas. Quaternary International, 212: 109-119. https://doi.org/10.1016/j. quaint.2009.06.007

Cuenca-Bescós, G.; Straus, L. G.; García-Pimienta, J. C.; González Morales, M. R. \& López-García, J. M. (2010b). Late Quaternary small mammal turnover in the Cantabrian Region: The extintion of Pliomys lenki (Rodentia, Mammalia). Quaternary International, 212: 129-136. https://doi.org/10.1016/j. quaint.2009.06.006

Demirel, A.; Andrews, P.; Yalçinkaya, I. \& Ersoy, A. (2011). The Taphonomy and paleoenvironmental implications of the small mammals from Karain Cave, Turkey. Journal of Archaoelogical Science, 38: 3048-3059. https://doi.org/10.1016/j. jas.2011.07.003

Fernández-Jalvo, Y.; Andrews, P.; Denys, C.; Sesé, C.; Stoetzel, E.; Marin-Monfort, D. \& Pesquero, D. 
(2016). Taphonomy for taxonomists: Implications of predation in small mammal studies. Quaternary Science Reviews, 139: 138-157. https://doi. org/10.1016/j.quascirev.2016.03.016

Garcia-Ibaibarriaga, N. (2015). Los microvertebrados en el registro arqueopaleontológico del País Vasco: cambios climáticos y evolución paleoambiental durante el Pleistoceno Superior. Tesis Doctoral. Universidad del País Vasco. 340 pp.

Garcia-Ibaibarriaga, N.; Murelaga Bereikua, X.; Bailon, S.; Rofes Chávez, J. \& Ordiales Castrillo, A. (2013a). Estudio de los microvertebrados de la cueva de Arlanpe (Lemoa, Bizkaia). Kobie Serie Bizkaiko Arkeologi Indusketak. Excavaciones Arqueológicas en Bizkaia, 3: 81-110.

Garcia-Ibaibarriaga, N.; Iriarte-Chiapuso, M.-J. \& Murelaga, X. (2013b). Primeros datos sobre los micromamíferos (roedores e insectívoros) coetáneos al Solutrense en la cueva de Kiputz IX (Mutriku, Guipuzkoa, España). Espacio Tiempo y Forma. Serie I, Nueva Prehistoria y Arqueología, t. 5, 212: 285-295.

Garcia-Ibaibarriaga, N.; Rofes, J.; Bailon, S.; Garate, D.; Ríos-Garaizar, J.; Martínez-García, B. \& Murelaga, X. (2015a). A palaeoenvironmental estimate in Askondo (Bizkaia, Spain) using small vertebrates. Quaternary International, 364: 244-254. https://doi. org/10.1016/j.quaint.2014.09.069

Garcia-Ibaibarriaga, N.; Arrizabalaga, A.; IriarteChiapusso, M.-J.; Rofes, J. \& Murelaga, X. (2015b). The return to the Iberian Peninsula: first Quaternary record of Muscardinus and a palaeogeographical overview of the genus in Europe. Quaternary Science Reviews, 119:106-115. https://doi.org/10.1016/j. quascirev.2015.04.017

Gil, E. (1986).Taxonomía y bioestratigrafía de micromamíferos del Pleistoceno Medio, especialmente roedores, de los rellenos kársticos de la Trinchera del Ferrocarril de la Sierra de Atapuerca (Burgos). Tesis Doctoral, Universidad de Zaragoza: $229 \mathrm{pp}$.

Gil, E. \& Sesé, C. (1991). Middle Pleistocene small mammals from Atapuerca (Burgos, Spain). Cahiers du Quaternaire, 16: 337-347.

Gosálbez, J.; López-Fuster, Mª J.; Fons, R. \& Sans-Coma, V. (1980). Sobre la musaraña enana, Sorex minutus LINNAEUS, 1766 (Insectivora, Soricinae) en el nordeste de la península ibérica. Miscel-lània Zoològica, VI: 109-134.

Guillem Calatayud, P. (2000). Secuencia climática del Pleistoceno medio final y del Pleistoceno superior inicial en la fachada central mediterránea a partir de micromamíferos (Rodentia e Insectivora). SAGVNTVM (Papeles del Laboratorio de Arqueología de Valencia), 32: 9-30.

Hernández, A. (2005). Topos en la dieta de zorros rojos en el noroeste de España. Galemys, 17 (1-2): 87-90.

Hillson, S. (2005). Teeth. Cambridge university press: 373 pp. https://doi.org/10.1017/CBO9780511614477
Hoek Ostende, L. W. van den \& Furió, M. (2005). The fossil record of the Eurasian Neogene insectivores Erinaceomorpha, Soricomorpha, Mammalia): Spain. In: The fossil record of the Eurasian Neogene insectivores (Erinaceomorpha, Soricomorpha, Mammalia) (Hoek Ostende, L. W. van den; Doukas, C. S. \& Reumer, J. W. F., Eds.). Part 1. Scripta Geologica, Special Issue, 5: 149-284.

Kolfschoten, T. van (1992). Aspects of the migration of mammals to Northwestern Europe during the Pleistocene, in particular the reimmigration of Arvicola terrestris. Courier Forschungsinstitut Senckenberg, 153, 213-220.

Kowalski, K. (1992). Remarks on the zoogeography of Quaternary Rodents in Europe. Courier Forschungsinstitut Senckenberg, 153: 197-203.

Kowalski, K. (2001). Pleistocene Rodents of Europe. Folia Quaternaria, 72: 389 pp.

Krystufek, B.; Davison, A. \& Griffiths, H. I. (2000). Evolutionary biogeography of water shrews (Neomys spp.) in the western Palaeartic Region. Canandian Journal of Zoology, 78: 1616-1625. https://doi. org/10.1139/z00-105

Liberda, J. J.; Thompson,, J. W.; Rink, W. J.; Bernaldo de Quirós, F.; Jayaraman, R.; Selvaretinam, K.; Chancellor-Maddison, K. \& Volterra, V. (2010). ESR Dating of Tooth Enamel in Mousterian Layer 20, El Castillo, Spain. Geoarchaeology, 25 4: 467-474. https://doi.org/10.1002/gea.20320

López-García, J. M. (2008). Evolución de la diversidad taxonómica de los micromamíferos en la Península Ibérica y cambios Paleoambientales durante el Pleistoceno Superior. Tesis Doctoral. Universitat Rovira I Virgili: 368 pp., 13 Láms.

López-García, J. M.; Cuenca-Bescós, G. \& RosellArdevol, J. (2007). Resultados del estudio de microvertebrados del Neolítico de la cueva de el Mirador (Ibeas de Juarros, Sierra de Atapuerca, Burgos). In: Actas del IV Congreso de Neolítico en la Península ibérica (Manresa, O., Ed.). Museo Arqueológico de Alicante, Alicante: 1-7.

López-García, J. M. \& Cuenca-Bescós, G. (2010). Évolution climatique durant le Pléistocène Supérieur en Catalogne (Nord-Est de l'Espagne) d'Après l'étude des micromammifères. Quaternaire, 21 (3): 249-257. https://doi.org/10.4000/quaternaire.5597

López-García, J. M.; Blain, H. A.; Cuenca-Bescós, G.; Ruiz Zapata, Mª B.; Dorado Valiño, M.; Gil García, M ${ }^{\mathrm{a}}$ J.; Valdeolmillos, A.; Ortega, A. I.; Carretero, J. M.; Arsuaga, J. L.; Bermúdez de Castro, J. $\mathrm{M}^{\mathrm{a}}$ \& Carbonell, E. (2010). Palaeoenvironmental and palaeoclimatic reconstruction of the Latest Pleistocene of El Portalón Site, Sierra de Atapuerca, northwestern Spain. Palaeogeography, Palaeoclimatology, Palaeoecology, 292, 3-4: 453-464.

López-García, J. M.; Cuenca-Bescós, G.; Blain, H.-A.; Álvarez-Lao, D.; Uzquiano, P.; Adán, G.; Arbizu. 
M. \& Arsuaga, J. L. (2011a). Palaeoenvironment and palaeoclimate of the Mousteriane-Aurignacian transition in northern Iberia: The small-vertebrate assemblage from Cueva del Conde (Santo Adriano, Asturias). Journal of Human Evolution, 61: 108-116. https://doi.org/10.1016/j.jhevol.2011.01.010

López-García, J. M.; Cuenca-Bescós, G.; Finlayson, C.; Brown, K. \& Giles Pacheco, F. (2011b). Palaeoenvironmental and palaeoclimatic proxies of the Gorham's cave small mammal sequence, Gibraltar, southern Iberia. Quaternary International, 243: 137-142. https://doi.org/10.1016/j.quaint.2010.12.032

López-García, J. M.; Blain, H.-A.; Burjachs, F.; Ballesteros, A.; Allué, E.; Cuevas-Ruiz, G. E.; Rivals, F.; Blasco, R.; Morales, J. I.; Rodríguez Hidalgo, A.; Carbonell, E.; Serrat, D. \& Rosell, J. (2012). A multidisciplinary approach to reconstructing the chronology and environment of southwestern European Neanderthals: the contribution of Teixoneres cave (Moią, Barcelona, Spain). Quaternary Science Reviews, 43: 33-44. https://doi.org/10.1016/j. quascirev.2012.04.008

López-García; J. M.; Soler, N.; Maroto, J.; Soler, J.; Alcalde, G.; Galobart, A.; Bennàsar, M. \& Burjachs, F. (2015). Palaeoenvironmental and palaeoclimatic reconstruction of the Latest Pleistocene of L'Arbreda Cave (Serinyà, Girona, northeastern Iberia) inferred from the small-mammal (insectivore and rodent) assemblages. Palaeogeography, Palaeoclimatology, Palaeoecology,435:244-253.https://doi.org/10.1016/ j.palaeo.2015.06.022

López Martínez, N. (1980). Los micromamíferos (Rodentia, Insectivora, Lagomorpha y Chiroptera), del sitio de ocupación Achelense de Áridos-1 (Arganda, Madrid). In: Ocupaciones Achelenses en el Valle del Jarama (Arganda, Madrid) (Santonja, M.; López Martínez, N. \& Pérez-González, A., Eds.). Arqueología y Paleoecología, 1. Diputación Provincial de Madrid, 161-202.

López Martínez, N. (1989). Revisión sistemática y biostratigráfica de los lagomorfos (Mammalia) del Terciario y Cuaternario de España. Memorias del Museo Paleontológico de la Universidad de Zaragoza, 3 (3): 343 pp.

López Martínez, N. \& Ruiz Bustos, A. (1977). Descubrimiento de dos yacimientos del Pleistoceno medio en el karst de la Sierra de Alfaguara (Granada). Síntesis estratigráfica de este periodo en la región Bética. Estudios Geológicos, 33: 255-265.

Michaux, J. \& Pasquier, L. (1974). Dynamique des populations de Mulots (Rodentia, Apodemus) en Europe durant le Quaternaire. Premières données. Bulletin de la Société Géologique de France, 16 (4): 431-439.

Mitchell-Jones, A. J.; Amori, G.; Bogdanowicz, W.; Krystufek, B.; Reijnders, P. J. H.; Spitzenberger, F.; Stubbe, M.; Thissen, J. B. M.; Vohralík, V. \& Zima, J.
(1999). The Atlas of European Mammals. Academic Press. T \& AD Poyser Ltd. UK, London: 484 pp.

Murelaga, X.; Mujika Alustiza, J. A.; Bailon, S.; Castaños, P. \& Sáez de Lafuente, X. (2008). La fauna de vertebrados del yacimiento Holoceno (Aziliense) de Aizkoltxo (Mendaro, Gipuzkoa). Geogaceta, 45: 71-74.

Niethammer, J. (1990). Talpa. In: Niethammer, J. \& F. Krapp (eds.) Handbuch der Säugetiere Europas. Bd. 3. Insektenfresser-Insectivora, Herrentiere-Primates. Wiesbaden: 93-161.

Nores, C. (1988). Diferenciación biométrica de Apodemus sylvaticus y Apodemus flavicollis en la Cordillera Cantábrica. Primeros resultados. Revista de Biología de la Universidad de Oviedo, 6, 109-116.

Ordiales, A.; Suárez-Bilbao, A.; Garcia-Ibaibarriaga, N.; Ibarra, J. L. \& Murelaga, X. (2015). Estudio de los micromamíferos de los lechos de la Edad del Bronce de la Cueva de Arenaza I (Galdames, Bizkaia). Geogaceta, 58: 55-58.

Palomo, L. J. \& Gisbert, J. (Eds.) (2002). Atlas de los Mamíferos terrestres de España. Dirección General de Conservación de la Naturaleza - SECEM SECEMU, Madrid, 564 pp.

Pasquier, L. (1974). Dynamique évolutive d'un sousgenre de Muridae, Apodemus (Sylvaemus). Etude biometrique des caractères dentaires des populations fossiles et actuelles d'Europe Occidentale. Thèse, Université des Sciences et Techniques du Lanquedoc, Montpellier, $184 \mathrm{pp}$.

Pemán, E. (1983). Biometría y sistemática del género Neomys Kamp 1771 (Mammalia, Insectivora) en el País Vasco. Munibe, 35, 1-2: 115-148.

Pemán, E. (1985). Aspectos climáticos y ecológicos de los Micromamíferos del yacimiento de Erralla. Munibe, 37: 49-57.

Pemán, E. (1990). Los micromamíferos de la cueva de Amalda y su significación. Comentarios sobre Pliomys lenki. In: La cueva de Amalda (Zestoa, País Vasco). Ocupaciones paleolíticas y postpaleolíticas (Altuna, J., Baldeón, A. \& Mariezkurrena, K., Eds.). San Sebastián, Fundación Eusko Ikastunza: 225-238.

Pemán, E. (1994). Los micromamíferos de Laminak II (Berriatua, Bizkaia). KOBIE (Serie Paleoantropología), 21: 225-233.

Pike, A. W. G.; Hoffmann, D. L.; García-Díez, M.; Pettitt, P. B.; Alcolea, J.; Balbín R. de; GonzálezSainz, C.; Heras, C. de las; Lasheras, J. A.; Montes, R. \& Zilhao, J. (2012). En los orígenes del arte rupestre Paleolítico: dataciones por la serie de Uranio en las cuevas de Altamira, El Castillo y Tito Bustillo. In: Pensando el Gravetiense: nuevos datos para la región cantábrica en su contexto peninsular y pirenaico. (Heras, C. de las; Lasheras, J. A.; Arrizabalaga, A. \& Rasilla, M. de la, Coords.). Monografías del Museo Nacional y Centro de Investigación de Altamira, 23: $461-475$. 
Poitevin, F.; Catalan, J.; Fons, R. \& Croset, H. (1986). Biologie evolutive des populations ouest-europeennes des Crocidures. I.- Criteres d'identification et repartition biogeographique de Crocidura russula (HERMMANN, 1780) et Crocidura suaveolens (PALLAS, 1811). Revue d'Ecologie (Terre Vie), 41: 299-314.

Pokines, J. T. (1998). The Paleoecology of Lower Magdalenian Cantabrian Spain. BAR International Series, 713: 189 pp.

Reumer, J. W. F. (1984). Ruscinian and early Pleistocenen Soricidae (Insectivora, Mammalia) from Tegelen (The Netherlands) and Hungary. Scripta Geologica, 73: $173 \mathrm{pp}$.

Reumer, J. W. F. (1996). Quaternary Insectivora (Mammalia) from southwestern France. Acta Zoologica Cracoviensia, 39 (1): 413-426.

Reumer, J. W. F. \& Hordijk, L. W. (1999). Pleistocene Insectivora (Mammalia) from the Zuurland boreholes near Rotterdam, The Netherlands. In: Elephants have a snorkel! Paper in honor of Paul Y. Sondaar (Reumer, J. W. F. \& de Vos, J., Eds.). DEINSEA, 7: 253-281.

Rink, W. J.; Schwarcz, H. P.; Lee, H. K., Cabrera Valdés, V.; Bernaldo de Quirós, F. \& Hoyos, M. (1996). ESR dating of tooth enamel: comparison with 14C dates at El Castillo Cave, Spain. Journal of Archaeological Science 23, 945-951. https://doi.org/10.1006/ jasc. 1996.0088

Rink, W. J.; Schwarcz, H. P.; Lee, H. K.; Cabrera Valdés, V. Bernaldo de Quirós, F. \& Hoyos, M. (1997). ESR dating of Mousterian levels at El Castillo Cave, Cantabria, Spain. Journal of Archaeological Science, 24: 593-600. https://doi.org/10.1006/jasc.1996.0143

Rofes, J. \& Cuenca-Bescós, G. (2010). Evolutionary history and biogeography of the genus Crocidura (Mammalia, Soricidae) in Europe, with emphasis on Crocidura kornfeldi. Mammalian Biology, 76: 64-78. https://doi.org/10.1016/j.mambio.2009.12.001

Rofes, J.; Zuluaga, M. C.; Murelaga, X.; FernándezEraso, J.; Bailon, S.; Iriarte, M. J.; Ortega, L. A. \& Alonso-Olazabal, A. (2013). Paleoenvironmental reconstruction of the early Neolithic to middle Bronze Age Peña Larga rock shelter (Alava, Spain) from the small mammal record. Quaternary Research, 79: 158-167 https://doi.org/10.1016/j. yqres.2012.11.002

Rofes, J.; Garcia-Ibaibarriaga, N.; Aguirre, M.; MartínezGarcía, B.; Ortega, L.; Cruz Zuluaga, M.; Bailon, S.; Alonso-Olazábal, A; Castaños, J. \& Murelaga, X. (2015) Combining Small-Vertebrate, Marine and Stable-Isotope Data to Reconstruct Past Environments. Scientific Reports, 5:14219: 1-12. https://doi. org/10.1038/srep14219

Rzebik-Kowalska, B. (1995). Climate and history of European shrews (family Soricidae). Acta Zoologica Cracoviensia, 38 (1): 95-107.
Rzebik-Kowalska, B. (2007). New data on Soricomopha (Lipotypphla, Mammalia) from the Pliocene and Pleistocene of Transbailkalia and Irkutsk Region (Russia). Acta Zoologica Cracoviensia, 50 A, 1-2: $15-48$.

Rzebik-Kowalska, B. (2009). Biodiversity of Polish fossil insectivores (Erinaceomorpha, Soricomorpha, Insectivora, Mammalia) compared to the European and global faunas. Institute of Systematics and Evolution of Animals Polish Academy of Sciences, Krakow: $123 \mathrm{pp}$.

Rümke, C. G. (1985). A review of fossil and recent Desmaninae (Talpidae, Insectivora). Utrecht Micropaleontological Bulletins, 4, Special Publication: 241 pp.

Saint-Girons, M. C. (1972). La reconnaissance des proies contenues dans les pelotes de réjection des rapaces en France, Belgique, Pays-Bas et Luxembourg. Overdruk publicaties van het natuurhistorisch Genootschap in Limburg, Reeks XXII, afflevering, 1(2): 3.

Saint Girons, M. C.; Fons, R. \& Nicolau-Guillaumet, P. (1979). Caractères distintifs de Crocidura russula, Crocidura leucodon et Crocidura suaveolens en France continentale. Mammalia, 43, 4: 511-518. https://doi.org/10.1515/mamm.1979.43.4.511

Sánchez, A. (1983). Estudio comparativo de las faunas pleistocénicas y actuales de micromamíferos (Insectívoros y Roedores) en Puenteviesgo (Santander). Tesis de Licenciatura, Facultad de Biología, UCM, 208 pp.

Sanchiz, B \& Lobo, J. M. (2006). Restos herpetológicos de niveles auriñacienses de la Cueva de El Castillo (Puente Viesgo, Cantabria). In: En el centenario de la Cueva de El Castillo: El ocaso de los Neandertales (Cabrera Valdés, V.; Bernaldo de Quirós Guidotti \& Maíllo Fernández, J. M., Eds.). Centro Asociado a la Universidad Nacional de Educación a Distancia en Cantabria, Santander: 403-416.

Sesé, C. (1994): Paleoclimatical interpretation of the Quaternary small mammals of Spain. Geobios, 27, 6: 753-767. https://doi.org/10.1016/S0016-6995(94) $80060-\mathrm{X}$

Sesé, C. (2005). Aportación de los micromamíferos al conocimiento paleoambiental del Pleistoceno Superior de la Región Cantábrica: Nuevos datos y síntesis. In: Neandertales Cantábricos, estado de la cuestión (Montes Barquín, R. \& Lasheras Corruchaga, J. A., Eds.). Monografías del Museo Nacional y Centro de Investigación de Altamira, 20: 167-200.

Sesé, C. (2009). Los micromamíferos (Rodentia, Insectivora y Lagomorpha) del yacimiento del Pleistoceno Superior de la cueva de Cobrante. Sautuola, XV: $85-100$.

Sesé, C. (2014). Micromamíferos (Insectívoros, Quirópteros, Roedores y Lagomorfos) del yacimiento del Pleistoceno Superior de la Cueva de Amutxate (Aralar, Navarra, Norte de España): sistemática y paleoclimatología. In: La historia del oso de las Cavernas: vida y muerte de un animal desaparecido. 
Nuevas aportaciones de la excavación de la cueva de Amutxate (Aralar, Navarra) (Torres, T., Ed.). Madrid, 172-201.

Sesé, C. (2016a). Los Micromamíferos (Rodentia, Insectivora y Lagomorpha) del yacimiento del final del Pleistoceno Superior de la cueva de Cualventi (Cantabria, Norte de España). In: Proyecto de investigación "Los tiempos de Altamira". Actuaciones arqueológicas en las cuevas de Cualventi, El Linar y Las Aguas (Alfoz de Lloredo. Cantabria) (Lasheras Corruchaga, J. A., Dir.). Monografías del Museo Nacional y Centro de Investigación de Altamira, 26: 219-241.

Sesé, C. (2016b). Interpretación paleoambiental de los micromamíferos de los yacimientos del final del Pleistoceno superior de la cueva de Cualventi, cueva de El Linar y cueva de Las Aguas (Cantabria, norte de España). In: Proyecto de investigación "Los tiempos de Altamira". Actuaciones arqueológicas en las cuevas de Cualventi, El Linar y Las Aguas (Alfoz de Lloredo. Cantabria) (Lasheras Corruchaga, J. A., Dir.). Monografías del Museo Nacional y Centro de Investigación de Altamira, 26: 287-319.

Sesé, C. (2016c). Los micromamíferos (Rodentia, Insectivora y Lagomorpha) del yacimiento del final del Pleistoceno superior de la Cueva del Linar (Cantabria, Norte de España). In: Proyecto de investigación "Los tiempos de Altamira". Actuaciones arqueológicas en las cuevas de Cualventi, El Linar y Las Aguas (Alfoz de Lloredo. Cantabria) (Lasheras Corruchaga, J. A., Dir.). Monografías del Museo Nacional y Centro de Investigación de Altamira, 26: pp. 242-263.

Sesé, C. (2016d). Los micromamíferos (Rodentia, Insectivora y Lagomorpha) del yacimiento del final del Pleistoceno superior de la Cueva de Las Aguas (Cantabria, Norte de España). In: Proyecto de investigación "Los tiempos de Altamira". Actuaciones arqueológicas en las cuevas de Cualventi, El Linar y Las Aguas (Alfoz de Lloredo. Cantabria) (Lasheras Corruchaga, J. A., Dir.). Monografías del Museo Nacional y Centro de Investigación de Altamira, 26: pp. 264-286.

Sesé, C. (2017). Los micromamíferos (Erinaceomorpha, Soricomorpha, Rodentia y Lagomorpha) del yacimiento del final del Pleistoceno superior de la cueva de Coímbre (Asturias, España). In: La Cueva de Coímbre (Peñamellera Alta, Asturias): Ocupaciones humanas en el valle del Cares durante el Paleolítico superior (Álvarez-Alonso, D. \& Yravedra, J., Dirs.). Ed. Fundación $\mathrm{M}^{\mathrm{a}}$ Cristina Masaveu Peterson. In press

Sesé, C. (en prensa). Los micromamíferos (Rodentia, Insectivora, Lagomorpha y Chiroptera) del yacimiento del Pleistoceno Superior de la Cueva de Covalejos (Cantabria): Paleontología e interpretación paleoambiental. In: La cueva de Covalejos (Velo de Piélagos, Cantabria). Actuaciones Arqueológicas,
1997-2002 (Sanguino, J. \& Montes, R., Eds.). Ayuntamiento de Piélagos - Parlamento de Cantabria.

Sesé, C. \& Gil, E. (1988). Los micromamíferos del Pleistoceno medio del complejo cárstico de Atapuerca (Burgos). In: El hombre fósil de Ibeas y el Pleistoceno de la Sierra de Atapuerca (Aguirre, E.; Carbonell, E. \& Bermúdez de Castro, J. M., Eds.). Junta de Castilla y León: 75-88.

Sesé, C. \& Soto, E. (1988): Los micromamíferos (Rodentia, Insectivora y Lagomorpha). In: La Cueva de Ambrosio (Almería, Spain) y su posición cronoestratigráfica en el Mediterráneo Occidental (Ripoll López, S., Ed.). BAR, International Series, 462 (I): $157-168$.

Sesé, C. \& Sevilla, P. (1996). Los micromamíferos del Cuaternario peninsular español: cronoestratigrafía e implicaciones bioestratigráficas. Revista Española de Paleontología, No Extraordinario: 278-287.

Sevilla, P. (1988). Estudio paleontológico de los Quirópteros del Cuaternario español. Paleontologia i Evolució. 22: 113-233.

Sevilla, P.; Laplana, C.; Sesé, C.; Arsuaga, J. L.; Baquedano, E.; Cacho Quesada, C. \& Vega-Toscano, L. G. (2011). Evidence of the presence of the Root Vole (Microtus oeconomus) in Central Spain during the Late Pleistocene. XVIII INQUA Congress, Berna.

Shenbrot, G. I. \& Krasnov, B. R. (2005). An Atlas of the Geographic Distribution of the Arvicoline Rodents of the World (Rodentia, Muridae: Arvicolinae). PENSOFT, Sofia-Moscow.

Suárez-Bilbao, A.; Garcia-Ibaibarriaga, N.; Castaños, J.; Castaños, P.; Iriarte-Chiapusso, M.-J.; Arrizabalaga, A.; Torres, T.; Ortiz, J. E. \& Murelaga, X. (2016). A new Late Pleistocene non-anthropogenic vertebrate assemblage from the northern Iberian Peninsula: Artazu VII (Arrasate, Basque Country). Comptes Rendus Palevol, 15: 950-957. https://doi. org/10.1016/j.crpv.2016.05.002

Wilson, D. E. \& Reeder, D. M. (2005). Mammal Species of the World. A Taxonomic and Geographic Reference. The Johns Hopkins University Press, Baltimore.

Wood, R.; Bernaldo de Quirós, F.; Maíllo-Fernández, J. M.; Tejero, J. M.; Neira, A. \& Higham, T. (2016). El Castillo (Cantabria, northern Iberia) and the Transitional Aurignacian: Using radiocarbon dating to assess site taphonomy. Quaternary International. In press. https://doi.org/10.1016/j. quaint.2016.03.005

Yravedra, J.; Álvarez-Alonso, D.; Estaca-Gómez, V.; López-Cisneros, P.; Arrizabalaga, A.; Elorza, M.; Iriarte, M.J.; Jordá Pardo, J.F.; Sesé, C.\&Uzquiano,P. (2016). New evidence of bones used as fuel in the Gravettian level at Coímbre cave, northern Iberian Peninsula. Archaeological and Anthropological Sciences. https://doi.org/10.1007/s12520-016-0317-0 
Yravedra Sainz de los Terreros, J.; Herranz, D.; ÁlvarezAlonso, D. \& Sesé, C. (2017a). El aprovechamiento de lagomorfos en el Paleolítico superior cantábrico. Nuevas perspectivas desde la cueva de Coímbre (Asturias). Arqueobiología durante el Greenland Stadial 2 en la Región Cantábrica (CA. 22000-15000 CAL BP). Salamanca, Universidad de Salamanca, 5. http://hdl.handle.net/10261/148780

Yravedra, J., López-Cisneros, P., Andrés-Chain, M., Estaca, V., Moreno, A. y Rodrigo, D. (2017b). Estrategias de subsistencia sobre macrovertebrados y lagomorfos en la cueva de Coímbre, zona B (Peñamellera Alta, Asturias): Los patrones de ocupación en el valle del Cares durante el Paleolítico superior. In: La Cueva de Coímbre (Peñamellera Alta, Asturias): Ocupaciones humanas en el valle del Cares durante el Paleolítico superior (Álvarez-Alonso, D. \& Yravedra, J., Eds.). Fundación $\mathrm{M}^{\mathrm{a}}$ Cristina Masaveu Peterson. In press. 